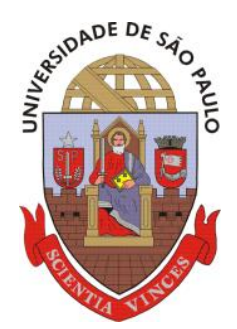

UNIVERSITY OF SÃO PAULO

SCHOOL OF ENGINEERING OF SÃO CARLOS

DEPARTMENT OF MECHANICAL ENGINEERING

GRADUATE PROGRAM IN MECHANICAL ENGINEERING

ASHRAF EL DROUBI

\title{
Investigation of the Efficiency of a Novel Three Electrode Configuration for The Dielectric Barrier Discharge
}

São Carlos - SP 



\title{
Investigation of the Efficiency of a Novel Three Electrode Configuration for The Dielectric Barrier Discharge
}

\begin{abstract}
Thesis submitted to the School of Engineering in São Carlos of the University of São Paulo, in partial fulfillment of the requirements for the degree of Doctor of Philosophy in Mechanical Engineering.
\end{abstract}

Area of concentration: Aeronautics

Advisor: Prof. Dr. Paulo Celso Greco

THIS IS A REVISED VERSION
OF THE THESIS. THE
ORIGINAL VERSION CAN BE
FOUND AT THE
MECHANICAL ENGINEERING
DEPARTMENT AT EESC-USP.

São Carlos - SP 



\section{Investigação da Eficiência de Uma Nova Configuração de Eletrodos para a Descarga de Barreira Dielétrica}

Tese apresentada à Escola de Engenharia de São Carlos da Universidade de São Paulo, como parte dos requisitos para obtenção do título de Doutor em Ciências.

Área de concentração: Aeronaves

Orientador: Prof. Dr. Paulo Celso Greco

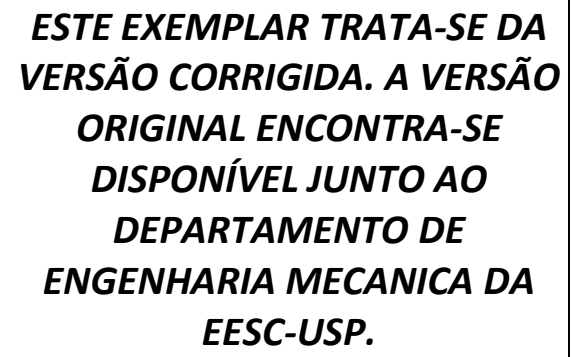

São Carlos - SP 
AUTORIZO A REPRODUÇÃO TOTAL OU PARCIAL DESTE TRABALHO, POR QUALQUER MEIO CONVENCIONAL OU ELETRÔNICO, PARA FINS DE ESTUDO E PESQUISA, DESDE QUE CITADA A FONTE.

Ficha catalográfica elaborada pela Biblioteca Prof. Dr. Sérgio Rodrigues Fontes da EESC/USP com os dados inseridos pelo(a) autor(a).

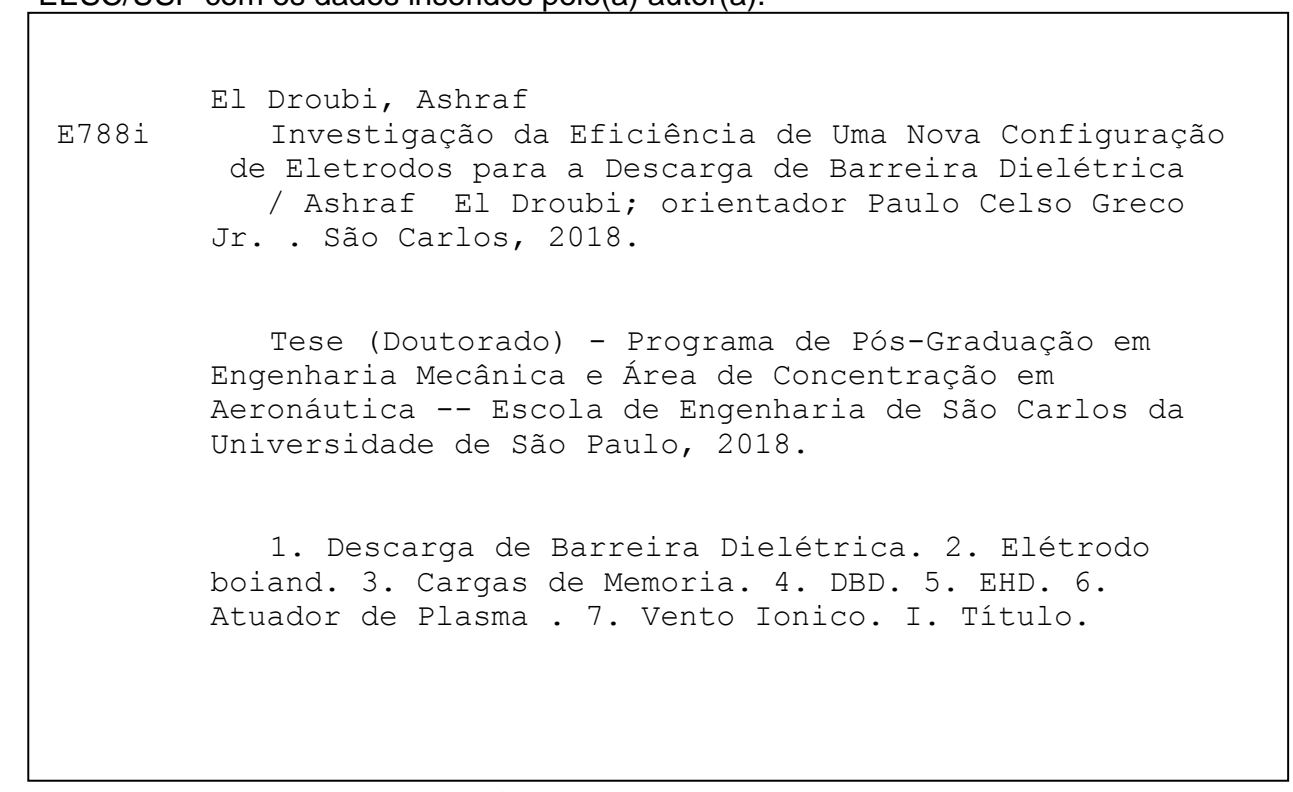

Eduardo Graziosi Silva - CRB - 8/8907 


\section{FOLHA DE JULGAMENTO}

Candidato: Bacharel ASHRAF EL DROUBI.

Título da tese: "Investigação da eficiência de uma nova configuração de eletrodos para a descarga de barreira dielétrica".

Data da defesa: 17/08/2018.

Comissão Julgadora:

Resultado:

Prof. Associado Paulo Celso Greco Junior (Orientador)

APROVIDO

(Escola de Engenharia de São Carlos/EESC)

Prof. Dr. Hernan Dario Céron Muñoz

Aprouad

(Escola de Engenharia de São Carlos/EESC)

Prof. Dr. Paolo Gessini

APnoVAOO

(Universidade de Brasília/UnB)

Prof. Dr. José Antônio Garcia Croce.

APROVADO

(Instituto Federal São Paulo/IFSP)

Prof. Dr. Dawson Tadeu Izola

APROUADO

(Centro Universitário Hermínio Ometto)

Coordenador do Programa de Pós-Graduação em Engenharia Mecânica:

Prof. Associado Gherhardt Ribatski

Presidente da Comissão de Pós-Graduação:

Prof. Associado Luís Fernando Costa Alberto 

To Possibilities 

“...don't do it. unless it comes out of your soul like a rocket, unless being still would drive you to madness or suicide or murder, don't do it. unless the sun inside you is burning your gut, don't do it."

Charles Bukowsky 



\section{ACKNOWLEDGEMENTS}

A research project is never accomplished alone. I would like extend my gratitude to prof. Paulo Greco, who was kind enough to offer me the liberty of research, for his confidence, orientation, and support. I would also like to thank Prof. Dawson Izola for his inspiration throughout these 4 years. A very special thanks to the Aeronautics Department technician Eng. Mario Sbampato, who was as much part of the experimental phase of this project as I was and whose genius electronic skills worked a miracle in the most urgent times of this project. I would also like to thank dearly my colleague Bernardo Martinez Rocamora Jr. for his generosity and help. And finally I'd like to express my gratitude for the openness of. Prof. Rodrigo Intini, Prof. Paolo Gessini, and Prof. José Croce. My thanks to all technicians and secretaries of the aeronautics department.

In a four years period, the doctorate research becomes a part of your life that is shared, perhaps not on the technical level, with some people who play an essential part in it as well. My dearest and deepest regards to my parents, siblings, and friends. 



\section{AbSTRACT}

DROUBI, EL A. Investigation of the Efficiency of a Novel Three Electrode Configuration for The Dielectric Barrier Discharge. 2018. Thesis (Doctorate) - School of Engineering in São Carlos, University of São Paulo, São Carlos, Brazil, 2018.

Having gained popularity in the last decade, the dielectric barrier discharge (DBD) has been studied in numerous ways as a device for air acceleration. A major interest of all these works has been concentrated on achieving higher efficiency and producing higher jet velocities. These studies considered alternative geometries, different voltage waveforms etc., yet none of these studies tackle the inherently inefficient process of force creation and actuation in a DBD. Air acceleration has been attributed to the electric force that switches direction on each voltage half cycle (that is due to the nature of the discharge mechanism) yet has a forward resulting force. The present thesis considers the phenomenon of memory charge accumulation on the dielectric surface and reasons that the backward force in the second half cycle can be reversed by further migration of the memory charges to an added exposed anode. Hence a novel 3-electrode configuration is presented. Flow velocity investigations showed a $27 \%$ improvement in efficiency in comparison with the traditional 2-electrode actuator. This meant a $0.4 \mathrm{~m} / \mathrm{s}$ gain along the velocity profile. During the investigation process, a new discharge mechanism was encountered. This was characterized by the double discharge lines along the exposed electrode edges while in the presence of a "floating" encapsulated electrode.

Keywords: Dielectric Barrier Discharge; Floating electrode; memory charge; DBD, EHD. 


\section{RESUMO}

\section{DROUBI, EL A. Investigação da Eficiência de Uma Nova Configuração de} Eletrodos para a Descarga de Barreira Dielétrica. 2018. Tese (Doutorado) - Escola de Engenharia de São Carlos, Universidade de São Paulo, São Carlos, Brasil, 2018.

Tendo ganho popularidade na última década, a descarga de barreira dielétrica (DBD) foi estudada de várias maneiras como um dispositivo para aceleração do ar e controle aerodinâmico. Um grande interesse de todos esses trabalhos foi concentrado em alcançar maior eficiência e produzir maiores velocidades de jato. Alguns desses estudos consideraram geometrias alternativas, diferentes formas de onda de tensão, etc., mas nenhum desses estudos aborda o processo inerentemente ineficiente de criação e atuação da força em um DBD. A Aceleração do ar tem sido atribuída à força elétrica que muda de direção em cada meio ciclo (que é devido à natureza do mecanismo de descarga), mas que tem uma força resultante para a frente. A presente tese considera o fenômeno de acumulação de carga de memória na superfície dielétrica e raciocina que a força contraria no segundo meio ciclo da descarga pode ser revertida por migração dessas cargas de memória para um ânodo adicional exposto. Assim, uma nova configuração de 3 eletrodos é apresentada. Investigações de velocidade do fluxo mostraram uma melhoria de $27 \%$ na eficiência em comparação com o tradicional atuador de 2 eletrodos. Isso significou um ganho de $0,3 \mathrm{~m} / \mathrm{s}$ ao longo do perfil de velocidade. Durante o processo de investigação, foi encontrado um novo mecanismo de descarga. Isso foi caracterizado por uma dupla descarga ao longo das bordas do eletrodos expostos, enquanto na presença de um eletrodo encapsulado "pendurado".

Palavras-chave: Descarga de Barreira Dielétrica; Elétrodo boiando; Cargas de Memoria; DBD, EHD. 


\section{TABLE OF CONTENTS}

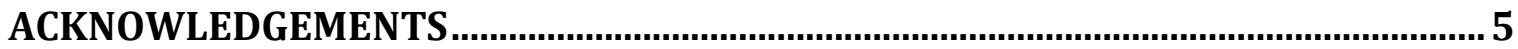

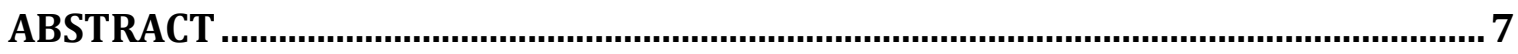

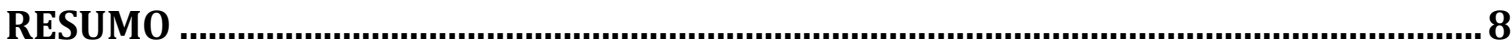

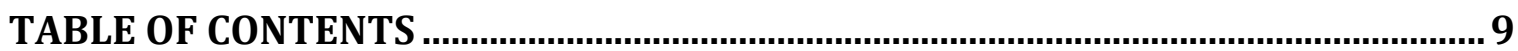

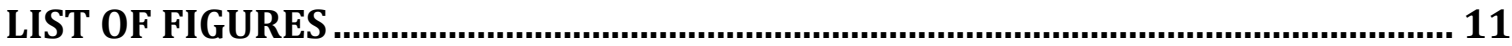

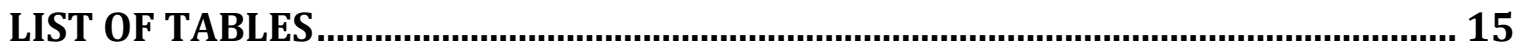

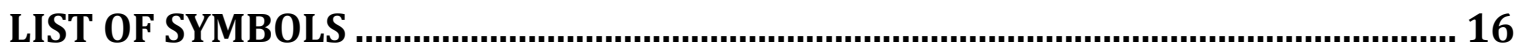

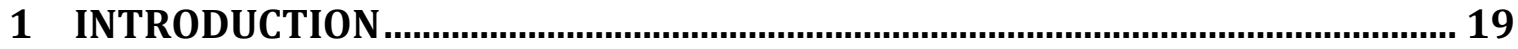

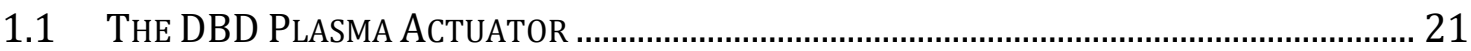

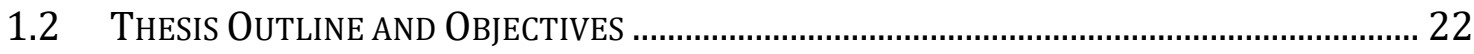

2 ELECTRICAL DISCHARGES

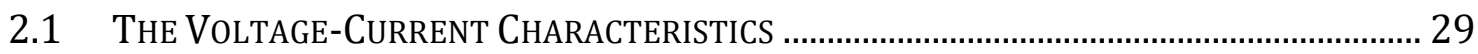

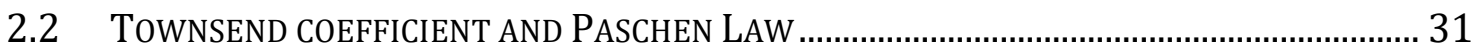

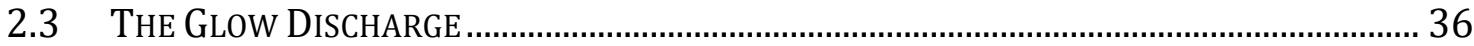

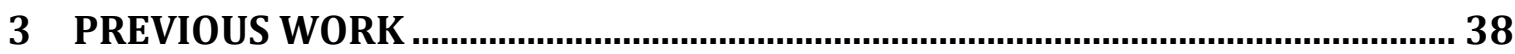

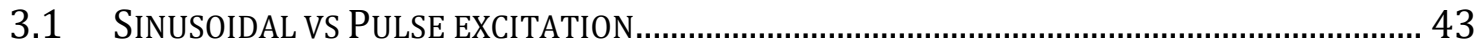

3.2 ForCE GENERATION DIFFERENCE BETWEEN DBD AND CORONA DISCHARGE ................... 46

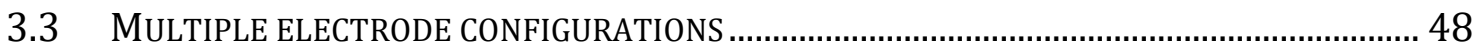

3.3.1 Statement Of Research Objective ........................................................................... 50

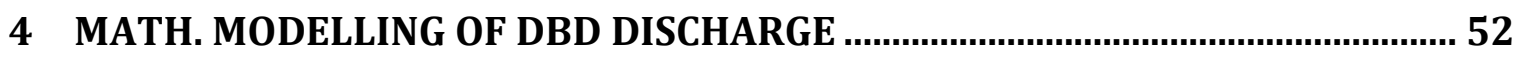

4.1 A Complete Mathematical Plasma DesCription ....................................................... 52

4.2 NUMERICAL APPROACHES FOR PLASMA SIMULATION ...................................................... 54

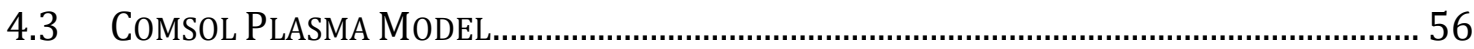

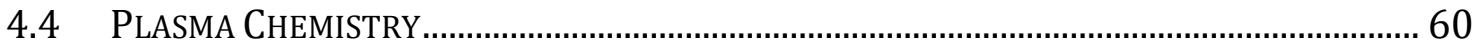

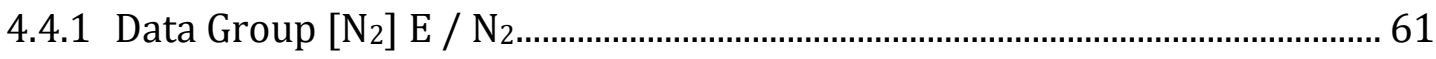

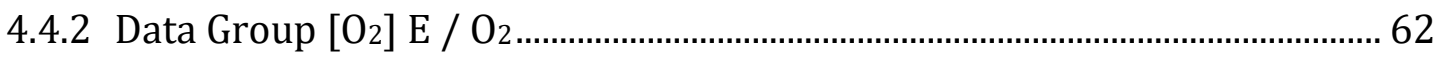




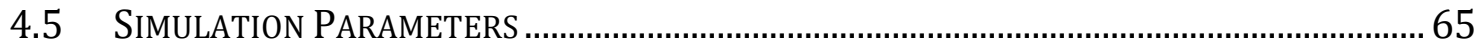

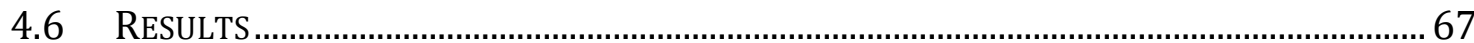

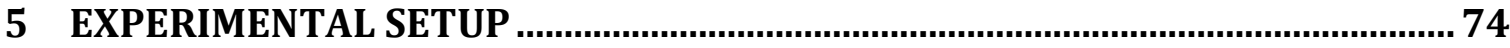

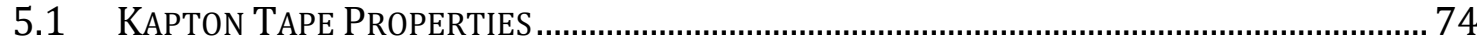

5.1.1 Electrical Properties Of Kapton.......................................................................... 75

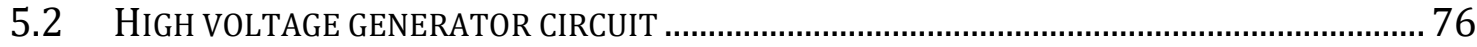

5.2.1 High Voltage Circuit Behavior And Calibration.................................................. 81

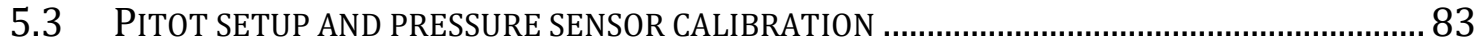

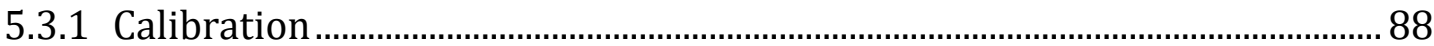

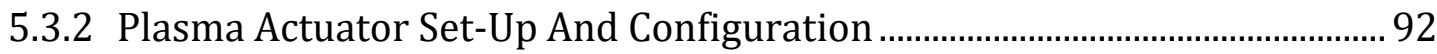

6 EXPERIMENTAL CONDITIONS AND RESULTS ...................................................... 97

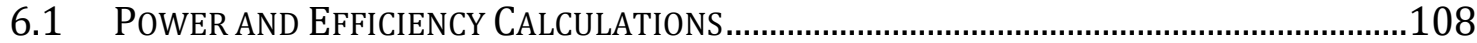

6.2 FURTHER EXPERIMENTS AND OBSERVATIONS .............................................................111

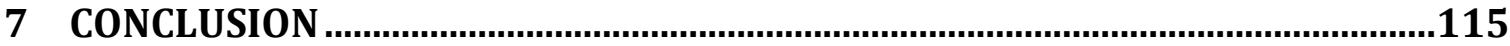

APPENDIX A STATISTICAL DATA ANALYSIS .......................................................117

APPENDIX B EXPERIMENTAL DATA AND CALCULATIONS ..................................121

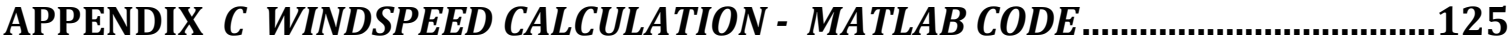

APPENDIX D PRESSURE TRANSDUCER ACQUISITION- MATLAB CODE ...............126

APPENDIX E ELECTROMECHANICAL POSITIONER - ARDUINO CODE .................127

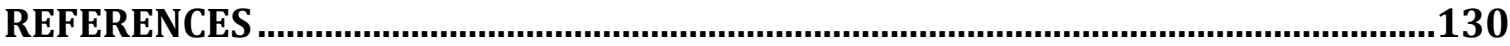




\section{LIST OF FIGURES}

Figure 1 - LEADING EDGE SEPARATION CONTROL, NACA0015, ANGLE OF ATTACK = 12॰. (A) FLOW WITH ACTUATOR OFF AND (B) ON. [8].

FIGURE 2 - CP CURVE WITH THE ACTUATOR BOTH ON AND OFF. ACTUATOR POSITIONED AT 90 ON A CYLINDER. [9] 20

FIGURE 3 - ILLUSTRATION OF THE PLASMA ACTUATOR WITH INDUCED FLOW............................................. 21

FIGURE 4 - SHOWING A PLASMA DISCHARGE ALONG THE ELECTRODE. [9] ...................................................... 22

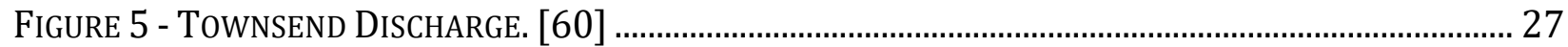

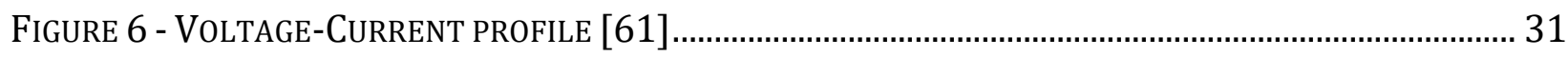

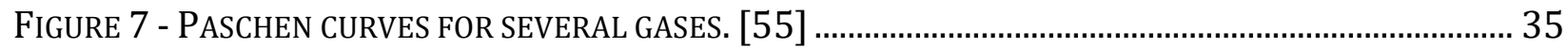

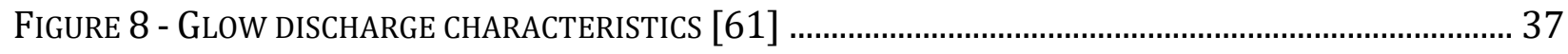

FIGURE 9 - CHARGE DiSTRIBUTION FOR (A) POSITIVE CURRENT AND (B) NEGATIVE CURRENT IN AN ASYMMETRIC DBD IN AIR WITH A GAP WIDTH OF 0.6 MM AND THE SECONDARY ELECTRODE COVERED BY 0.6 TO 2.0 MM ALUMINA. THE APPLIED VOLTAGE AMPLITUDE IS 8.0 KVPP [15] ............................ 41

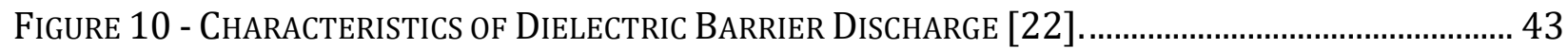

FIGURE 11 - TYPICAL DISCHARGE SIGNAL SHOWING BOTH POSITIVE AND NEGATIVE DISCHARGE. ................. 44

FIgURE 12 - PULSE EXCITATION SHOWING 2 DISCHARGES PER CYCLE.......................................................... 45

FIGURE 13 - VELOCITY PROFILE COMPARING DBD AND CORONA DISCHARGES. [27] ................................. 47

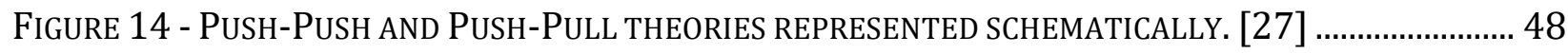

FIGURE 15 - FOUR PERMUTATIONS FOR A MULTI ELECTRODE SYSTEM WITH VARIOUS ENCAPSULATED

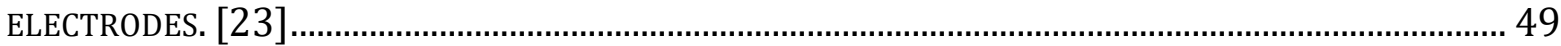

Figure 16 - Subrata Roy, Patent Application Publication Number: US 2010/0102174 A1. APRIL 29, 2010 [24] 50

FIGURE 17 - PLASMA TIMESCALES (IN SECONDS) DELIVER AN EXTREMELY CHALLENGING NUMERICAL COMPLEXITY. 
FigURE 18 - SCHEMATIC OF THE IMPACT AND RADIATIVE IONIZATION AND RECOMBINATION REACTIONS IN A PLASMA

FIGURE 19 - CROSS SECTION VALUES RELATIVE TO PLASMA ENERGY. [37] ................................................... 63

FigURE 20 - THE SPECIES REACTION RATES RELATIVE TO THE PLASMA ELECTRON ENERGY. [37] ................ 63

Figure 21 - The Plasma mobility*Density RELATIVE to the PlaSma ELECTRON ENERGy. [38] .......... 64

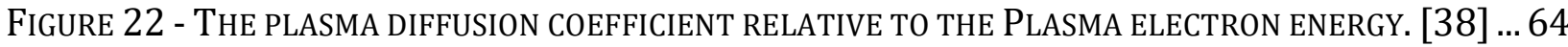
FiguRE 23 - The REDUCED TOWNSEND COEFFICIENT RELATIVE TO THE PLASMA ELECTRON ENERgy.[38] 65

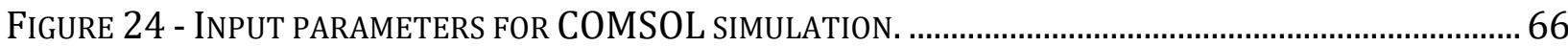

FigURE 25 - COMPUTATIONAL GEOMETRY DISPLAYING BOTH LINE ELECTRODES ENCAPSULATING THE

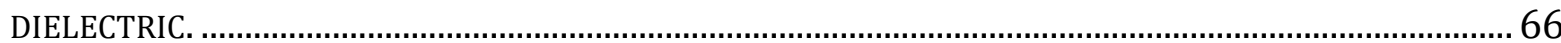

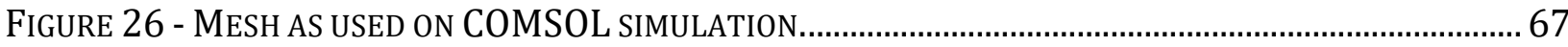

FigURE 27 - ELECTRON NUMBER DENSITY AS CALCULATED IN COMSOL......................................................... 68

FigURE 28 - ELECTRON TEMPERATURE IN EV AS CALCULATED BY COMSOL................................................. 69

FIGURE 29 - ELECTRIC POTENTIAL FOLLOWS THE ELECTRODE GEOMETRY.................................................. 70

FIGURE 30 - ELECTRON FLUX IN THE NEGATIVE CYCLE LEAVING THE EXPOSED ELECTRODE BEFORE

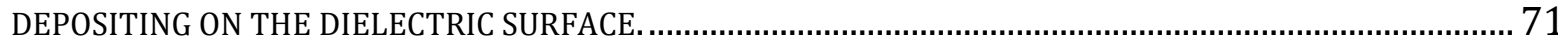

FIGURE 31 - ION FLUX IN THE NEGATIVE CYCLE MIGRATING TOWARDS THE EXPOSED ELECTRODE............... 71

FigURE 32 - ELECTRON FLUX DURING THE POSITIVE HALF CYCLE. ......................................................... 72

FIGURE 33 - ION FLUX DURING THE POSITIVE HALF CYCLE .......................................................................... 72

FIGURE 34 - ELECTRIC FIELD LINES CONCENTRATED BETWEEN THE ELECTRODE GAP................................. 73

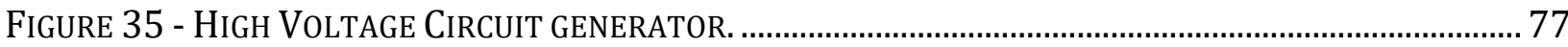

FIGURE 36 - CIRCUIT DIAGRAM SHOWING THE TWO CIRCUITS WITH THE SAME INPUT GOING INTO TWO

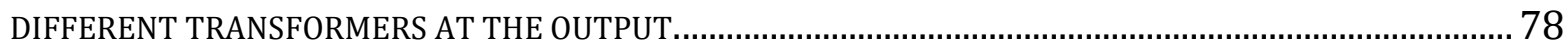

FIGURE 37 - THE ACTUAL CIRCUIT OF THE HIGH VOLTAGE SIGNAL, WITHOUT THE MOSFET AND TRANSFORMER 79

FIGURE 38 - HIGH VOLTAGE CIRCUIT CONNECTOR CASE ............................................................................... 79

FIGURE 39 - CAR IGNITION COIL USED AS A HIGH VOLTAGE TRANSFORMER. .................................................... 80

FIGURE 40 - OSCILLOSCOPE USED FOR SIGNAL GENERATOR AS INPUT INTO THE HIGH VOLTAGE CIRCUIT, .... 81 
FIGURE 41 - INPUT AND OUTPUT SIGNAL WITHOUT TRANSFORMER. 82

FIGURE 42 - INPUT AND OUTPUT SIGNAL WITH TRANSFORMER. 82

FIGURE 43 - INPUT AND OUTPUT SIGNAL WITH TRANSFORMER AND WITH FILTER APPLIED. 83

FIGURE 44 - PITOT MOUNTED ON THE STEP POSITIONER WITH THE CONTROL INTERFACE. 84

FIGURE 45 - THE PITOT TUBE MOUNTED ONTO THE SHAFT CONTROLLED BY STEP MOTOR ON THE RIGHT. .. 85

FIgURE 46 - TRANSDUCER READING THE PITOT TOTAL AND STATIC PRESSURE. 87

FIgURE 47 - TRANSDUCER WITH DAQ PORT 87

FIGURE 48 - DAQ NI9214 USED FOR DATA ACQUISITION. 88

FIGURE 49 - DigitAL MANOMETER USED FOR CALIBRATION. 89

FIGURE 50 - CURVE FITTING RELATING PRESSURE SENSOR VOLTAGE TO THE DYNAMIC PRESSURE................90

FIGURE 51 - CALIBRATION PLOT RELATING THE WIND SPEED TO THE PRESSURE SENSOR VOLTAGE. ............. 91

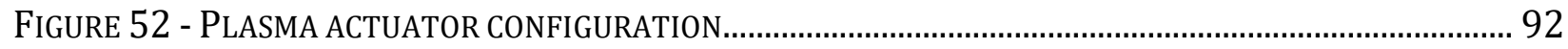

FIgURE 53 - PlASMA FILAMENTARY FORMATION AT THE CATHODE EDGE. THE AIRFLOW IS IN THE DIRECTION OF THE COVERED ELECTRODE. 93

FIGURE 54 - SCHEMATIC SHOWING THE ACTUATOR CONFIGURATION. 94

FIGURE 55 - PLASMA ACTUATOR ELECTRIC CONSUMPTION. THE DISPLAY SHOWS THE VOLTAGE AND CURRENT DELIVERED INTO THE PRIMARY COIL OF THE TRANSFORMER. 94

FigURE 56 - SPATIAL DISCRETIZATION IN THE X DIRECTION. 95

FIGURE 57 - SHOWING THE PITOT PLACEMENT FOR PRESSURE MEASUREMENTS FOR A TWO ELECTRODE DBD DISCHARGE. 96

FiguRE 58 - SAMPLE MEASUREMENT DISPLAYING ACQUISITION OVER 5 SECONDS OF 200,000 SAMPLES... 98

FIGURE 59 - SAMPLE DISTRIBUTION SHOWING A NORMAL CURVE DISTRIBUTION.. 99

FigURE 60 - BULGING AIR BUBBLE AT THE PLASMA DISCHARGE REGIME. .100

FIGURE 61 - VOLTAGE MEASUREMENT OSCILLATION DUE TO BUBBLE FORMATION AT THE PLASMA SHEATH. .101

FIGURE 62 - THE ELECTRIC ARC FORMATION AT HIGH THERMO-IONIC EMISSION POINTS. ...........................102

FiguRE 63 - PRESSURE MEASUREMENT SHOWING A TOTAL CESSATION OF AIR FLOW DUE TO ARCING........103 
FIGURE 64 - VELOCITY PLOT COMPARISON FOR 2 AND 3-ELECTRODE CONFIGURATIONS FOR SEVERAL FREQUENCIES, ALONG WITH THE INPUT POWER. …..............................................................................104

FIGURE 65 - X-VELOCITY PROFILE IN M/S ALONG THE Y DIRECTION IN MM FOR BOTH CONFIGURATIONS AT X= $5 \mathrm{MM}$ 105

FIGURE 66 - X-VELOCITY PROFILE IN M/S ALONG THE Y DIRECTION IN MM FOR BOTH CONFIGURATIONS AT X= 10MM. 106

FIGURE 67 - X-VELOCITY PROFILE IN M/S ALONG THE Y DIRECTION IN MM FOR BOTH CONFIGURATIONS AT X=

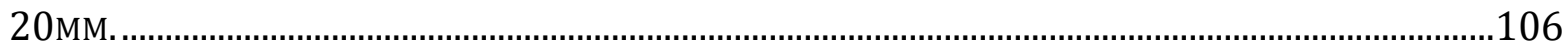

FIGURE 68 - VELOCITY PROFILE EVOLUTION IN X-DIRECTION. ..................................................................107

FIGURE 69: A GRAPHICAL COMPARISON BETWEEN THE POWER OF THE INDUCED JET WITH BOTH CONFIGURATIONS. 110

FigURE 70 - DoUBLE DISCHARGE DUE TO "FLOATING" ELECTRODE..........................................................112

FIGURE 71 - A SCHEMATIC OF THE FLOATING ELECTRODE CONFIGURATION................................................112

FIGURE 72 - SURFACE VELOCITY AT DIFFERENT FREQUENCIES OF THE FLOATING ELECTRODE CONFIGURATION

FIGURE 73 - VELOCITY PROFILE FOR FLOATING ELECTRODE AT X=10MM AND FREQUENCY OF 11KHZ. ....114

FIGURE 74 - PROBABILITY DENSITY FUNCTION OF A NORMAL DISTRIBUTION N $(0, \Sigma 2)$. .118 


\section{LIST OF TABLES}

TABle 1 - Electrical Properties of KaPton TAPE (Fonte:2017 DuPonT ${ }^{\text {TM }}$. KAPTON.Com) .............. 76

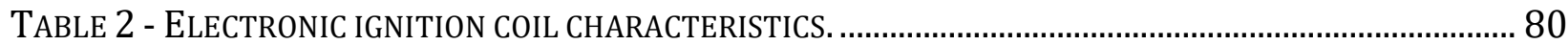

TABLE 3 - HDI PRESSURE SENSOR SPECIFICATIONS................................................................................. 86

TABLE 4 - INTERVAL OF CONFIDENCE OF 95\% FOR JET SPEED MEASUREMENTS ON THE Y AXIS..................105

TABLE 5 - OUTPUT POWER VALUES FOR THE DIFFERENT CONFIGURATIONS …..........................................109

TABLE 6 - OUTPUT EFFICIENCY VALUES FOR THE DIFFERENT CONFIGURATIONS ..........................................110 


\section{LiST OF SYMBOLS}

$\boldsymbol{\rho} \quad$ Gas Density

$\boldsymbol{P} \quad$ Pressure

$\boldsymbol{T}$ Temperature

$\boldsymbol{V} \quad$ Electric potential

$\boldsymbol{E} \quad$ Electric Field

$\boldsymbol{R} \quad$ Universal Gas Const.

$\boldsymbol{n}_{\boldsymbol{k}} \quad$ Number density, species k

$q$ Unit charge

$\boldsymbol{K}_{\boldsymbol{B}} \quad$ Boltzmann Constant

$\boldsymbol{j}_{\boldsymbol{k}} \quad$ Diffusive flux vector, species $\mathrm{k}$

$\gamma_{\boldsymbol{i}} \quad$ Secondary emission coefficient

$\boldsymbol{w}_{\boldsymbol{k}} \quad$ Mass fraction of species

$\boldsymbol{D}_{\boldsymbol{k}} \quad$ Diffusion coefficient, species k $\frac{\mathrm{m}^{2}}{\mathrm{~s}}$

$\boldsymbol{\mu}_{\boldsymbol{k}} \quad$ Mobility, species k

$\boldsymbol{M}_{\boldsymbol{k}}$ Molecular weight, species k

$x_{\boldsymbol{k}} \quad$ Mole fraction, species k

$\boldsymbol{Z}_{\boldsymbol{k}} \quad$ Charge ratio, species k

$\boldsymbol{r}_{\boldsymbol{j}} \quad$ Reaction rate, reaction $\mathrm{j}$

$\boldsymbol{k}_{\boldsymbol{j}} \quad$ Rate coefficient, reaction j

$\Gamma_{\boldsymbol{e}} \quad$ Electron flux

$\boldsymbol{\varepsilon} \quad$ Electron energy

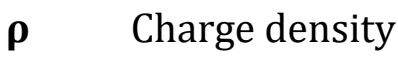

$\boldsymbol{v}_{\boldsymbol{d}} \quad$ Drift velocity
$\frac{K g}{m^{3}}$

$P a$

K

V

$V / m$

$J /(\operatorname{mol} . K)$

$\frac{1}{m^{3}}$

C

$J / K$

$\frac{K g}{m^{2} \cdot s}$

1

$\mathrm{k}$

$\frac{m^{2}}{V . s}$

$\mathrm{Kg} / \mathrm{mol}$

1

1

$\frac{m o l}{m^{3} \cdot s}$

$\frac{m^{3}}{\text { mol.s }}$

$\frac{1}{m^{2} . s}$

V

$\frac{C}{m^{3}}$

$\mathrm{m} / \mathrm{s}$ 


$\begin{array}{llc}\boldsymbol{L}_{\boldsymbol{e}} & \text { Free mean path } & m \\ \boldsymbol{N}_{\boldsymbol{n}} & \text { Neutral number density } & \frac{1}{m^{2}}\end{array}$




\section{1 mrreouctrox}

When studying flow control, one is essentially studying possibilities and techniques of modification of fluid motion. Those can be generated mechanically, thermally, and electrically. For about a century, researchers have pushed the envelope in the field of flow control and many different techniques were developed with results in transition delay [1], separation prevention [2,3], lift production enhancement [4,45], noise reduction or suppression [5,46], drag reduction [6] and more [7].

Of the recent popular trends in research in this area, one particular technique has gained much interest around the scientific community in the past decade or so. It is the boundary layer flow control using a Dielectric barrier discharge (DBD) Plasma actuator.

An example of this technique is found in Figure 1 [8] where the flow streamlines are visualized around an airfoil. The flow naturally separates above the airfoil (left) and a formation of a large wake is visible. When the flow is controlled, it reattaches on the suction side of the airfoil, thus reducing the wake, hence also the drag, generated by the airfoil. 

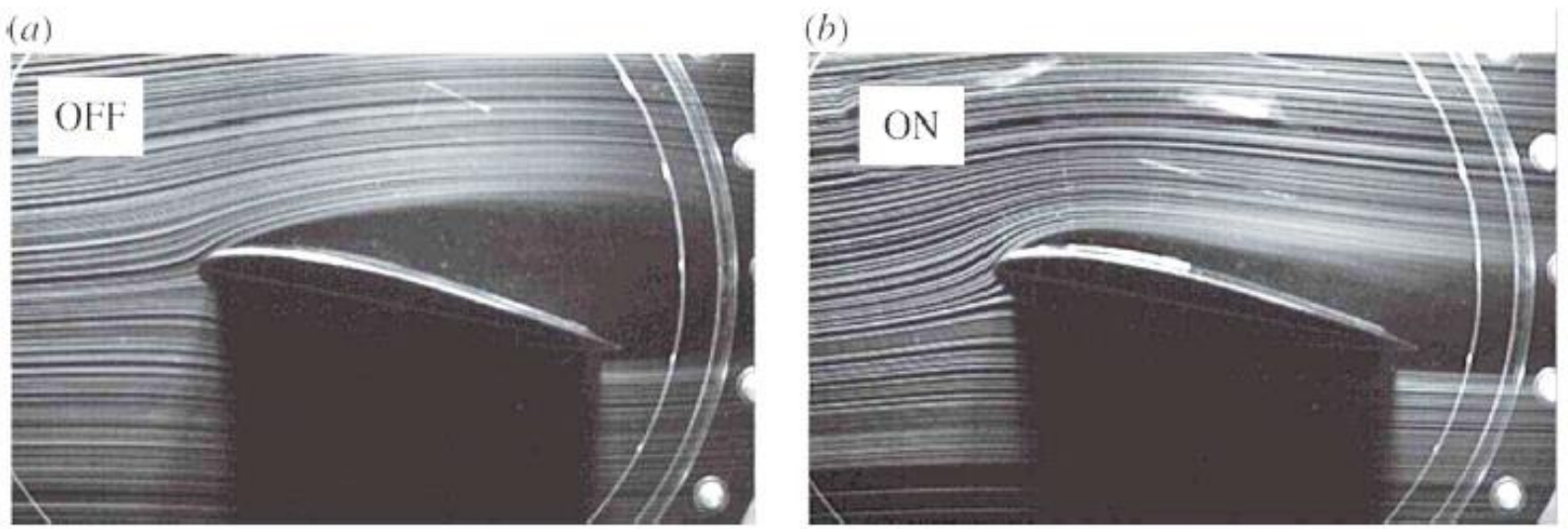

Figure 1 - Leading edge separation control, NACA0015, angle of attack $=12 \circ$. (a) Flow with actuator OFF and (b) ON. [8]

Other works showed the quantitative effect of this actuation. For example, Figure 2 shows how the Cp curve of the flow around a cylinder is modified by DBD actuation[9].

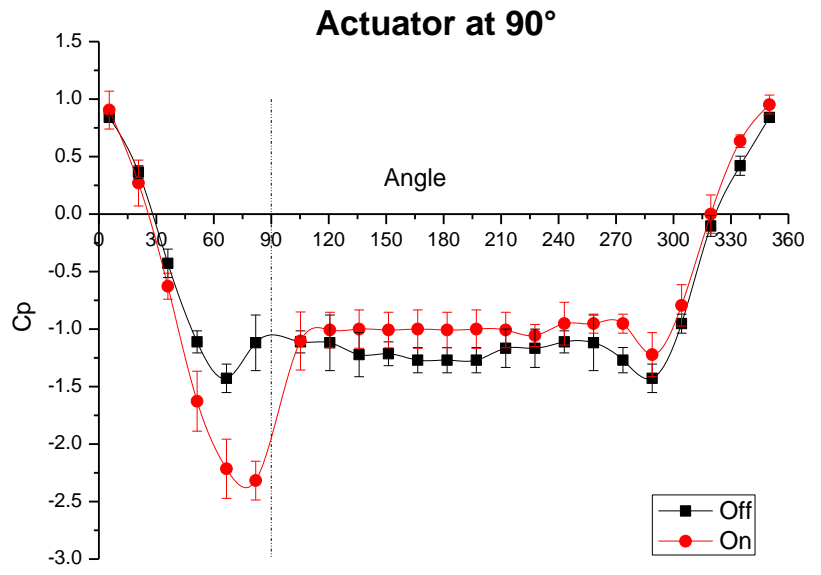

Figure 2 - Cp curve with the actuator both on and off. Actuator positioned at $90^{\circ}$ on a cylinder. [9] 
Clearly, this kind of interference in the boundary layer is of quite an interest to researchers in this area as it presents promising results.

\subsection{The DBD Plasma Actuator}

The aerodynamic plasma actuator is a particular configuration of the dielectric glow discharge. The actuator consists of two thin electrodes asymmetrically installed having a superior electrode exposed to the fluid flow and another inferior one. The two electrodes are separated by a thin sheet of insulating material, the dielectric, as shown in

Figure 3.

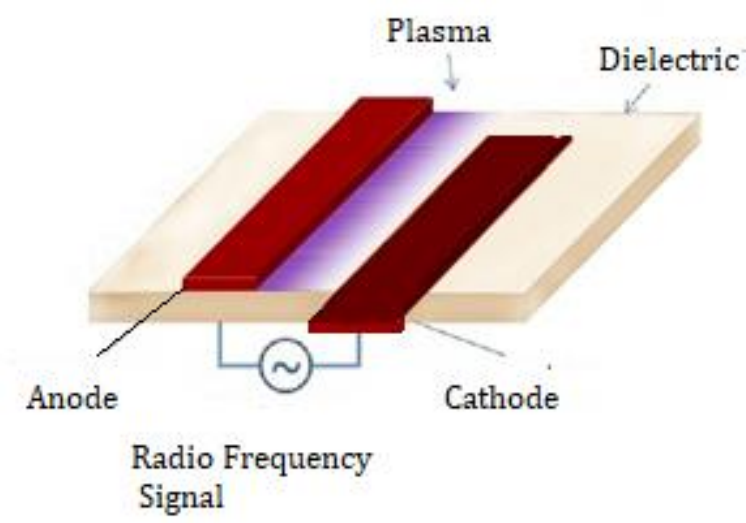

Figure 3 - Illustration of the plasma actuator with induced flow. 
The electrodes of the plasma actuator are long and thin, installed along the span of the aerodynamic body. When applying across the electrodes a voltage difference of 5-30 kV with a frequency of 3-15 kHz the actuator ionizes the air molecules around it and produces a glow discharge plasma that appear along the electrode gap with a bluish color, a result of oxygen ionizations (Figure 4). The charged particles are accelerated by the electric field and collide with the neutral air particles around it. The result is an exchange of momentum which can alter the flow around the body. The effect is perceived as a small jet along the body.

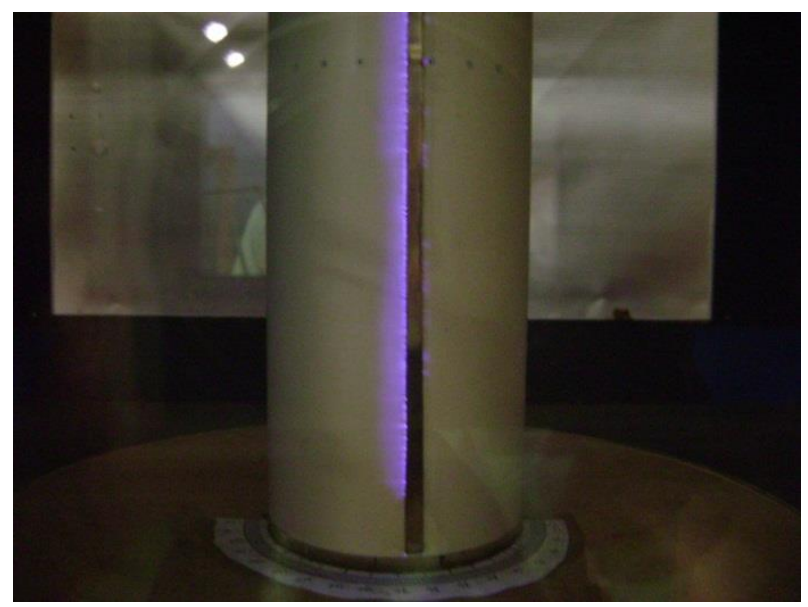

Figure 4 - Showing a plasma discharge along the electrode. [9]

\subsection{THESIS OUTLINE AND OBJECTIVES}

In this thesis, we will discuss the mechanisms of a plasma discharge, from ionization to force creation and actuation. With reference to published work we shed light on the phenomenon of memory charge accumulation and then present a 3-electrode configuration, 
that is argued to make use of that phenomenon, in order to achieve higher induced flow velocities along the actuator. In this thesis, we present the experimental data of such a configuration. In comparison with the traditional 2-electrode actuator, the data shows a high consistency in the results of the new configuration with higher flow velocity values. As we proceed in our investigations, a new interesting phenomenon is observed were a double discharge is obtained in the presence of a disconnected middle electrode. It shall be referred to it as a "floating" electrode. 


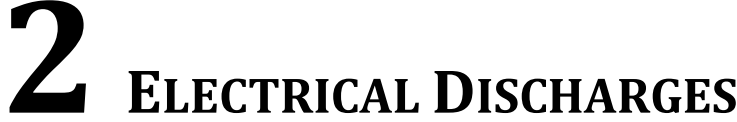

An electrical discharge results from the creation of a conducting path between two points of different electrical potential in the medium in which the points are immersed. Usually, the medium is a gas, often the atmosphere, and the potential difference is a large one, from a few hundred volts to millions of volts. If the two points are separated by a vacuum, there can be no discharge because the transfer of matter between the two points is necessary and since only matter can carry electric charge. This matter is usually electrons, each carrying a charge of $4.803 \times 10^{-10}$ esu. Electrons are very light, $9.109 \times 10^{-28} \mathrm{~g}$, and so can be moved with little effort. Protons and ions also carry charge and are sometimes important carriers, although protons are more than 1836 times heavier than electrons. Where both electrons and ions are available, however, the electrons carry the majority of the current due to their ability to pick up more kinetic energy from the electric field.

Electrical discharges have been studied since the middle of the 19th century, when vacuum pumps and sources of current electricity became available. These laboratory discharges in partially-evacuated tubes are very familiar, but there are also electrical discharges in nature, lightning being the primary example. There are also the aurora borealis and australis, St. Elmo's Fire, sparks from walking on a rug in dry weather and rubbing cats, crackling sounds when clothes fresh from the dryer are separated, and similar phenomena, many resulting from the high potentials of static electricity. In the technology sector we find more examples such as arc welding, the corona discharge on high-tension lines, fluorescent lamps, including their automatic starters, neon advertising signs, neon and argon glow lamps, mercury and sodium lamps, mercury-arc lamps for illumination and UV, carbon arc lights, vacuum tubes, including gas-filled rectifiers, Nixie numerical indicators and similar devices. 
In a discharge, the electrons, ions and neutral molecules are in incessant thermal motion, because their collisions are perfectly elastic. In equilibrium, the velocities are distributed according to the Maxwell distribution,

$$
f(v)=\left(\frac{m}{2 \pi k T}\right)^{\frac{3}{2}} 4 \pi v^{2} \mathrm{e}^{-\frac{m v^{2}}{2 k T}}
$$

which integrates to unity with respect to $d v$. The electron temperature $\mathrm{T}_{\mathrm{e}}$ is usually very different from the ion and neutral temperature $\mathrm{T}_{\mathrm{n}}$ at low pressures. This is because the electrons receive more energy from the electric fields in a discharge and can exchange kinetic energy with the neutrals only with great difficulty. The much greater mass of the ions and neutrals also means that they move at much lower velocities. Speeds given to the electrons by electric fields are often very much greater than thermal speeds, especially near the cathode, where the electric field is very high. These electrons, naturally, do not have a Maxwellian distribution until they have lost most of their energy in inelastic collisions and ionization.

For a discharge to occur, there must usually be a source of electrons at the cathode, and the nature of this source controls the form of the discharge. The electrons will migrate to the anode, the ions to the cathode, and a small current will flow.

Once an electron has acquired sufficient kinetic energy by being accelerated in an electric field, its collision with neutral gas molecules produces ionization of the latter. Each ionizing collision produces a new electron, and a positive ion that moves the other way, an ion pair. There are two ways this can be done. If the electron makes no collisions, even a small electric field will allow it to accumulate energy in a long-enough run. In this case, the kinetic energy is 


$$
\frac{m v^{2}}{2}=q \boldsymbol{E} x,
$$

where $\boldsymbol{E}$ is the field and $x$ is the distance travelled.

The average distance travelled by an electron before it collides with a neutral particle is called the mean free path, denoted by $L_{e}$. Then, the probability of collision of the electron in a distance $d x$ is $d x / L e$. If $L_{e}$ is much smaller than the distance $x$, then the trajectory of the electron is dominated by the collisions and its speed is characterized by an effective velocity called the drift velocity

$$
v_{d}=\mu_{e} E
$$

where $\mu_{e}$ is the electron mobility, the measure of how much the electron drifts with respect to the electric field. Then, the only way for the electron to accelerate is to find a larger field $\boldsymbol{E}$.

The mean free path $\mathrm{L}$ is inversely proportional to the pressure, so pressure has a great effect on how an electron gains energy. For example, the mean free path of air at $760 \mathrm{mmHg}$ and $273 \mathrm{~K}$ is $9.6 \times 10^{-6} \mathrm{~cm}$.

Many chemical processes take place in a discharge. Ionization is a principal reaction. The energy required to ionize an atom is called the ionization energy and measured in electron volts. A biproduct of this reaction is light. The emission of light is one of the principal characteristics of discharges. Light of a definite frequency, depending on the ionized gas, is emitted when an excited atom falls to a lower energy level. This radiation occurs when the collision frequency is low enough to allow for it where otherwise the radiation energy would be lost to another collision. 
If an electron collides and ionizes an atom it frees another electron, then these two can both free additional electrons, and so on. This creates an electron avalanche, which may send a burst of electrons toward the anode, leaving in their wake a cloud of slow positive ions that will make their way to the cathode. The net result is to multiply the original electron current. This, however, does not start a sustained discharge, but merely increases the current that otherwise would be available. This type of discharge produces little light, so it is called dark or Townsend discharge. A schematic of the mechanism of the townsend discharge is demonstrated in Figure 5.

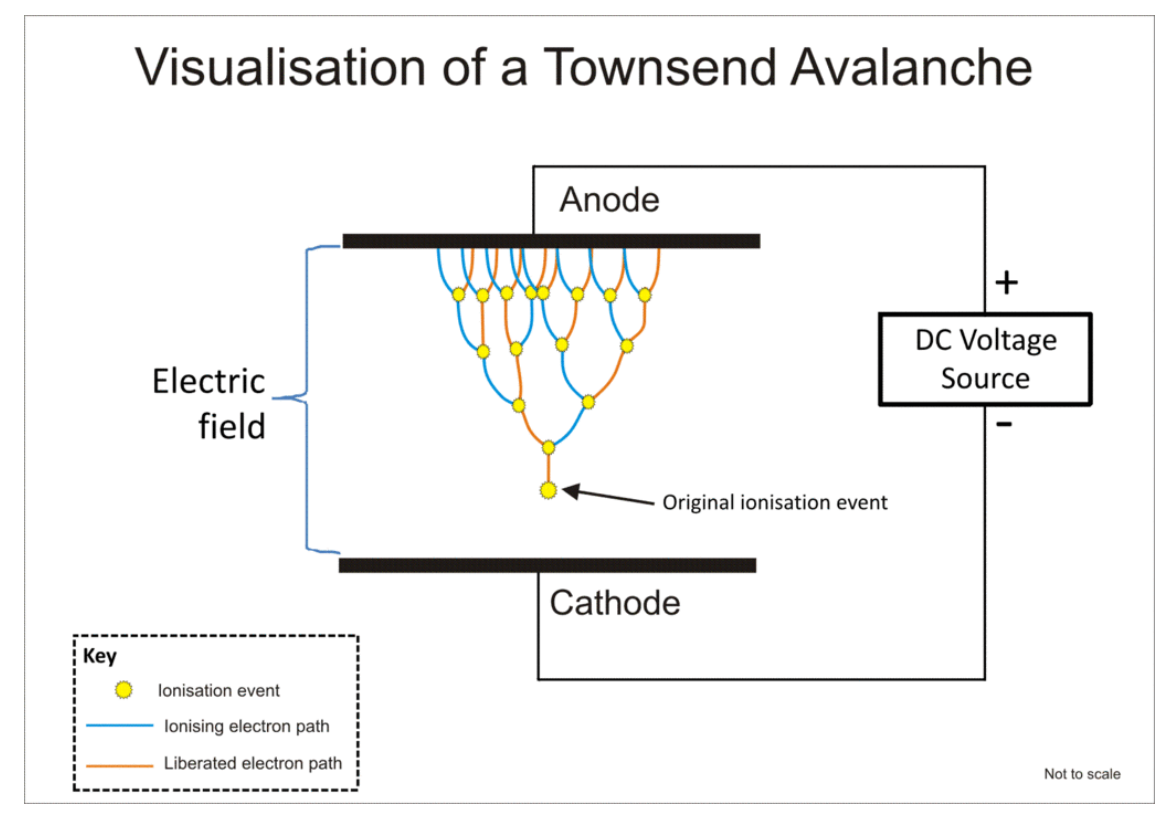

Figure 5 - Townsend Discharge. [60] 
That cloud of positive ions will sooner or later collide with the cathode. Recombination is a very difficult process, since only one particle is the outcome, rather than the three particles that come out of an ionization, so it is hard to conserve both momentum and energy. Therefore, most of the positive ions reach the cathode surface eventually where they recombine, and in some cases eject an electron. For $\mathrm{Ne}$ on an Fe cathode, one out of about every 45 ions produces an electron. The discharge can produce its own electrons and becomes self-maintained if the electron avalanche produces sufficient positive ions to replace the electron that originally left the cathode. When this happens, the discharge becomes evident through light or noise. The potential between anode and cathode at which this occurs is called the sparking potential $\mathrm{V}_{\mathrm{s} .}$ Now the whole path between anode and cathode becomes conducting because of the electrons and ions distributed along it, and the discharge increases rapidly and without bounds.

The ion bombardment heats up the cathode surface, which becomes incandescent, and begins to emit electrons thermionically. Any spot that becomes hotter than its neighbor, tends to become even hotter as the extra thermionic electrons attract the positive ions to the spot. This, the final state of the discharge, is called an arc. It requires very little potential difference to support the arc, mainly just enough to keep the path of the discharge supplied with ions to replace those lost in various ways. The arc discharge is a high-current, lowvoltage discharge, in contrast with the low-current, high-voltage glow discharge. It is characterized by a negative-resistance V-I characteristic, and high temperatures. Electrons for the discharge are supplied by a cathode spot that is a much more efficient electron emitter than the glow discharge cathode phenomena. The current density in the cathode spot is high and constant, so it adjusts its size to suit the discharge current. The electrons are liberated either by thermionic emission, or by high-field emission. The relative importance of these mechanisms has long been in dispute, but it is convenient to assume that the fixed cathode spot of refractory electrodes (such as carbon or tungsten) is thermionic, while the wandering 
cathode spot of low-melting-point cathodes (such as mercury) is high-field. A typical current density for a thermionic cathode spot is $470 \mathrm{~A} / \mathrm{cm}^{2}$, and of a high-field spot, $4000 \mathrm{~A} / \mathrm{cm}^{2}$.

The nature of a discharge depends on the method for supplying electrons at the cathode, and on how the discharge is confined. A discharge between metal electrodes in a glass tube that gets its electrons from positive-ion bombardment of the cathode, and is confined by the glass walls, is called a glow discharge. A discharge may exist in the vicinity of a sharp point, or other place with a small radius of curvature where the electric field is increased significantly from its average value. A negative potential on the point makes it a cathode, while the anode is an indefinite volume in the surrounding gas. A positive potential makes it an anode, and attracts electrons from an indefinite surrounding volume, which becomes the cathode. These two discharges look quite different with constant potentials, but with alternating current the opposites succeed one another and make an average impression. If the discharge occurs under DC current at about atmospheric pressure, it is called corona.

\subsection{The Voltage-CurRent Characteristics}

The characteristic curve between the voltage and current of a discharge is not at all linear and it depends of the plasma sources and operating regime. We can find that this relation is irregular and is shown by the curve in Figure 6. Point A is a stable point of operation. This can be seen as follows: if the current I is slightly reduced, then $\mathrm{V}$ becomes greater, while the voltage between anode and cathode becomes smaller. The difference in voltage acts to increase the current, restoring it to the value before the disturbance. If the current is slightly increased, we find a voltage deficit, which reduces the current, again bringing the operating point back to the original place. This will always happen if the V-I 
curve is more steeply inclined than the load line. At point $\mathrm{A}$, the current is no more than a microampere, the discharge is dark, and is not self-sustained. We are in the Townsend region.

Point A can move up the curve until the sparking potential is reached. Now the voltage is sharply reduced, and the operating point is $B$, which is stable. The discharge is now selfsustaining as a glow discharge, and cathode heating is not sufficient to cause transition to an arc. The current can be increased further by reducing the resistance of the circuit. The voltage across the discharge increases until point B' is reached. Although B' is stable with respect to small fluctuations, cathode heating may be enough to increase the electron supply and lower the discharge voltage. This change is cooperative, and the discharge quickly moves to point $\mathrm{C}$, where $\mathrm{V}$ is lower and I is greater. This is the arc, and operating point $\mathrm{C}$ is stable. However, if more current is supplied by reducing the resistance, the current will increase without bound until something melts. The regions where the discharge type changes are shown crosshatched, to show that the actual values may not be clearly defined. 


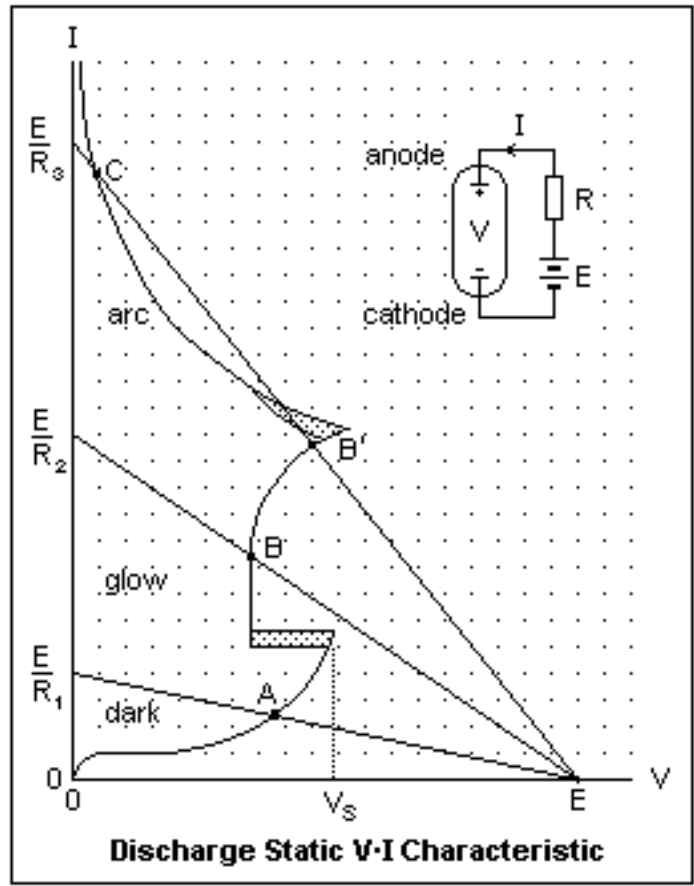

Figure 6 - Voltage-Current profile [61]

\subsection{TOWNSEND COEFFICIENT AND PASCHEN LAW}

To analyzing the initial breakdown of the discharge that produces the spark, we assume that every electron emitted from the cathode creates an avalanche, and that the positive ions from this avalanche return to the cathode and liberate new electrons to join the discharge. Suppose $n_{0}$ electrons start at the cathode, and at a distance $x$ they have multiplied to $n$. The electrons added to the avalanche in a distance $d x$ will be

$$
d n=\alpha n d x
$$


proportional both to the number of electrons, and to the distance $d x$. The factor $\alpha$ is the probability of creating a new electron per unit length (or, the average number of electrons created per cm of path) and is called the Townsend coefficient. If $\alpha$ is constant, to find that

$$
n=n_{o} e^{\alpha x}
$$

the equation for exponential growth.

The number of electrons that arrive at the anode will be

$$
n=n_{o} e^{\alpha x}
$$

where $d$ is the distance from the cathode to the anode. In general, $\alpha$ will be a function of the electric field $\boldsymbol{E}$, but here we assume $\boldsymbol{E}$ is constant, so our equation holds exactly only for plane-parallel electrodes and in the absence of space-charge effects. Nevertheless, it will give us order-of-magnitude results. The number of positive ions produced in the avalanche will be

$$
n-n_{o}
$$

We assume that all return to the cathode, where as they bombard the cathode surface they release new electrons with and efficiency $\gamma$. So, the number of secondary electrons is

$$
\gamma\left(n-n_{o}\right)
$$

This means that the net number of electrons leaving the cathode will be

$$
n_{o}+\gamma\left(n-n_{o}\right)
$$


and the number eventually reaching the anode will be

$$
n=\left[n_{o}+\gamma\left(n-n_{o}\right)\right] e^{\alpha d}
$$

If we solve for $n$, we find that

$$
n=n_{o} e^{\alpha d} /\left[1-\gamma\left(e^{\alpha d}-1\right)\right]
$$

If $e^{\alpha d}$ is much greater than 1 , we have simply

$$
n=n_{o} e^{\alpha d} /\left(1-\gamma e^{\alpha d}\right) .
$$

If $e^{\alpha d}$ increases to $1 / \gamma$, the denominator vanishes, and the number of electrons reaching the anode increases without limit. This is the sparking or breakdown point. The dependence of $\alpha$ on the electric field $\boldsymbol{E}$ is described by the empirical formula

$$
\frac{\alpha}{p}=A e^{-\frac{B p}{E}}
$$

where $A$ and $B$ are constants, $\mathrm{p}$ is the pressure, and $\mathrm{E}$ the electric field. The pressure comes in because the important thing is the energy gained in a mean free path, EL, and $L$ is inversely proportional to pressure. Therefore, if the pressure changes, $B p / E$ will remain constant. $\alpha$ itself depends on collisions, and will be proportional to the pressure for the same reason. Therefore, $\alpha / p$ will be constant, as will $A p$, as the pressure changes. Hence, the constants $A$ and $B$ need be determined for only one pressure. The dimensions of $A$ are $\mathrm{mm} / \mathrm{Hg}$ and $\frac{V}{\mathrm{~cm}-\mathrm{mmHg}}$, respectively. For air, $A=14.6$ and $B=365$, and for helium $A=2.8$ and $B=34$. These figures hold only over certain ranges of electric field, of course. The factor $\gamma$ for air on a nickel cathode is $\mathbf{0 . 0 3 6}$, for neon 0.023 , which are typical figures. We can now 
estimate the sparking potential by finding the value of $\boldsymbol{E}$ for which $e^{\alpha d}=1 / \gamma$. The condition is

$$
\ln \left(\frac{1}{\gamma}\right)=\alpha d=A p d e^{-\frac{B p d}{V s}}
$$

which we solve for $V_{s}$. This gives

$$
V s=\frac{B p d}{\ln \left[\frac{A p d}{\ln \left(\frac{1}{\gamma}\right)}\right]}
$$

or,

$$
\frac{C_{1}(p d)}{\ln \left[C_{2}(p d)\right]}
$$

in terms of new constants that can be tabulated.

This relation shows that the breakdown potential is a function of the product of the pressure and electrode distance only. This is called Paschen's Law. Below, in Figure 7, is a graph that shows the Paschen curve for some gases. 


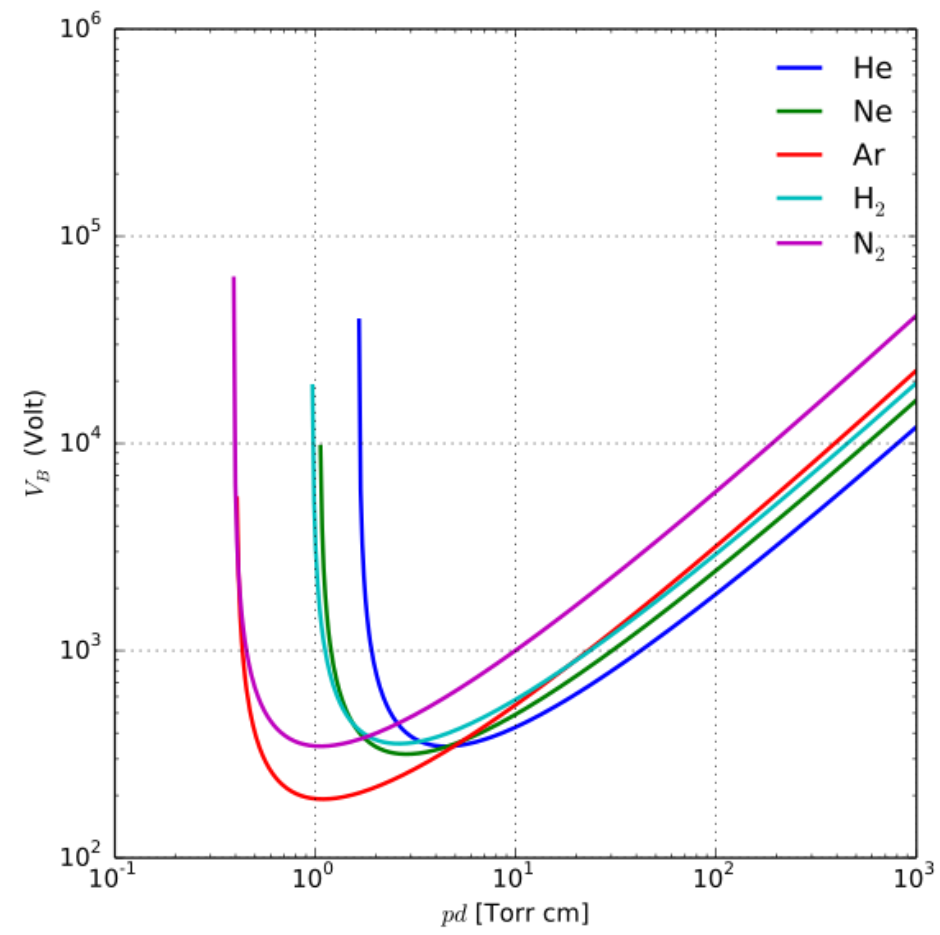

Figure 7 - Paschen curves for several gases. [55]

Moreover, by setting the derivative of $V_{s}$ with respect to $p d$ equal to zero, we find that the sparking potential has a minimum when

$$
p d=\frac{e \ln \left(\frac{1}{\gamma}\right)}{A}
$$




\subsection{THE GLOW DischaRGE}

If the gas pressure is reduced to between $1 \mathrm{mmHg}$ and $1 \mathrm{cmHg}$, we get a glow discharge that looks like the one in the diagram. If we started with the pressure at atmospheric, we would find it impossible to start a discharge with, say $E=300 \mathrm{~V}$. As we pumped the tube down to a lower pressure, at some point a discharge would start, filling the tube with pink light, if the gas was air, but the current would be low and the light not intense. As the pressure continues to decrease, the current would increase as the voltage across the tube decreased, and we would see a dark region coming out of the cathode. Continuing, the dark region would increase in width, and the cathode would seem to be covered with a soft bluish light. The light of the pink column may begin to fluctuate in moving waves. At the pressure mentioned above, the voltage across the tube would be least and the current greatest as shown in the diagram of Figure 8. 


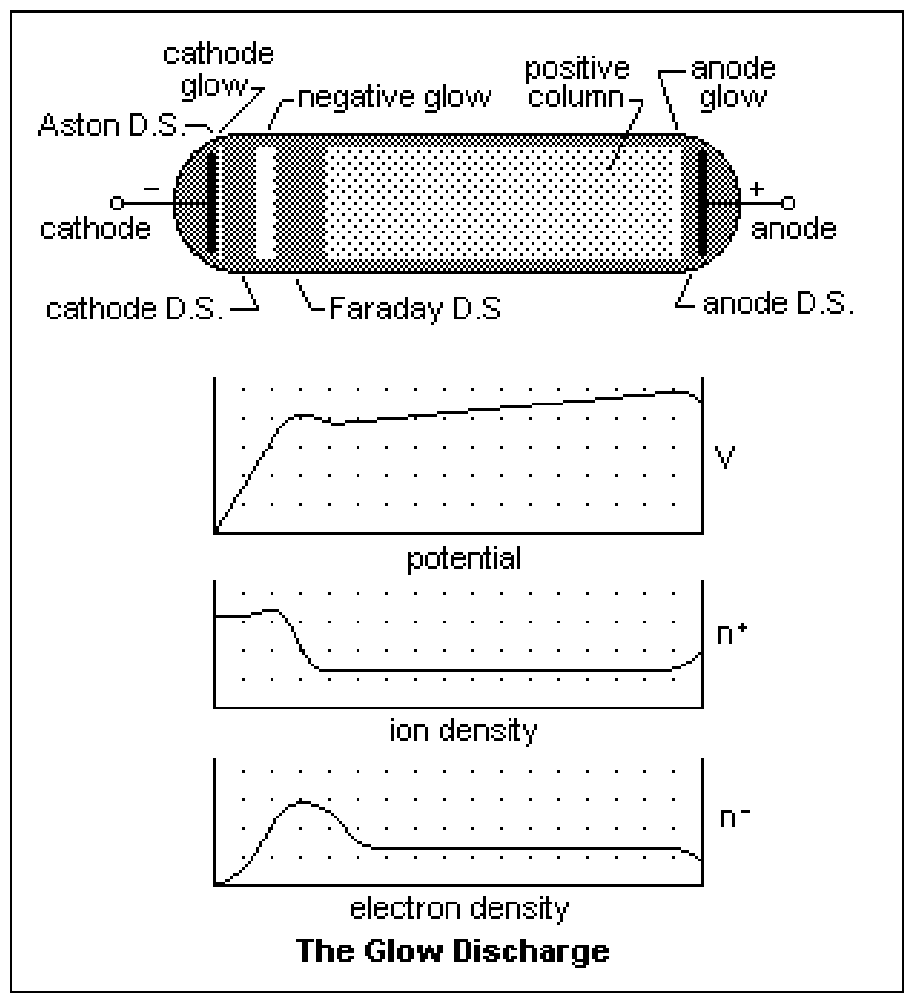

Figure 8 - Glow discharge characteristics [61]

At lower pressures, the dark region would expand proportionally to the reciprocal of the pressure, the glow around the cathode would also expand, and perhaps a dark region between it and the cathode would become evident. The pink column of light would grow steadily shorter, and eventually be swallowed up by the dark zone. Now the glass of the tube might begin to fluoresce green where fast electrons struck, and the voltage across the discharge would rise as the current fell. The electron mean free path is now comparable to the dimensions of the tube. Finally, the glow at the cathode would flicker and go out, and the discharge would cease, as the electrons could find no molecules to ionize as they traversed the tube from end to end. 


\section{Presuous woor}

A DC corona discharge was used for the first time by Malik et al (1983) in the flat plate to manipulate the boundary layers, resulting in a drag reduction of about $20 \%$ for speeds up to $30 \mathrm{~m} / \mathrm{s}$ with $15 \mathrm{kV}$ applied voltage. The efficiency of the actuator would mainly depend on the voltage used across the electrodes. furthermore, the drag reduction decreased with increasing flow velocity and decrease the potential difference between electrodes [10]. In later studies, glow discharge plasmas were used to control the flow boundary layer on flat plates and it was observed that asymmetrical configurations of the electrodes produced thrust generated symmetric configuration while an increase in drag [11]. The effects were attributed to the combination of mass transport and vortex-induced electrohydrodynamic forces (EHD). Some applications of plasma actuators have been investigated include separation control of low $\operatorname{Re}[29,31,33,35,40,42,43]$, in support of improving airfoils [30,34], virtual flaps and slats to control the flow airfoil [28], control of flow separation propeller at low pressure turbine [32,39], the control flow separation with foil actuators plasma [36], and the noise reduction gear [41].

A variety of other DBD plasma actuator geometries exist, for example the double barrier DBD plasma actuator, where both electrodes are covered with dielectric, [12], or the annular DBD plasma actuator, in which the electrodes have a shape of concentric rings, [13]

While most of the above applications is restricted to incompressible flows, some applications in high-speed flows have been reported as axisymmetric jet using plasma [14]. 
In later experiments, [15] several findings were presented on the behavior of the plasma actuators. Based on various measurements of pressure, tension and plasma emission, the authors make several interesting conclusions:

1. the input power, $\mathrm{P}$, into the plasma is non-linear with the voltage drop, $\Delta \mathrm{V}$,

2. the induced speed and thrust are proportional to the input power.

The final conclusion is that the plasma induces an electrostatic force (which can be treated as a force of body or body force: A force of body, as opposed to a contact force is a force that operates throughout the body volume) in around the fluid, which is proportional to the net charge density (net charge density) and strength of the electric field. It was also noted that the direction of flow induced plasma can be adapted by the arrangement of the electrodes.

Speed measurements induced at the beginning and end of discharge show that the ionic wind in a DBD actuator is generated periodically, indicating that the actuator does not behave the same in positive and negative parts of the cycle of the input AC voltage.

It has been observed that several attributes of the actuator, including the power and input voltage, input frequency, electrode geometry, orientation of the actuator, dielectric material, dielectric thickness, freestream, Re, pressure gradient, the chemical composition of plasma, and humidity were essential variables that determined the behavior of the actuator.

Porter et al [16] later experiments measured the thrust produced during the ongoing operation of a plasma actuator, and examined the effects of individual variables: the AC input voltage and frequency. it was concluded that the average body strength is: 
a. linearly proportional to the input $\mathrm{AC}$ frequency between 5 and $20 \mathrm{kHz}$ (for constant input voltage), and

b. non-linearly with the input voltage (for a constant frequency).

Normally driven by a sinusoidal voltage profile, however other shapes (triangular, positive and negative sawtooth) have also been tested. [17]. Sometimes DBD plasma actuators are driven by high voltage nanosecond pulses, [18]

Furthermore, it was observed that the actuator 'push' (with a relatively higher magnitude) and 'pull' (with a relatively lower magnitude) the fluid in opposite directions during each cycle.

Other experiments (Roth et Dai, 2006) studied the effects of change of the dielectric material, the electrode geometry, frequency and voltage applied to the flow velocity induced by the actuator. The thickness of the dielectric varies over a wide range from $100 \mu \mathrm{m}$ to 6.35 mm It was observed that the choice of dielectric material affects the volume of plasma, the distribution of electric field lines (governed by the dielectric constant) and the heat loss (which in turn is proportional to the frequency of the alternating current input and the area electrode). In general, a material which has been recommended to combine the following properties:

a. greater dielectric constant (aluminum, for example),

b. greater dielectric strength (eg Kapton)

c. and a lower thermal conductivity (for example, quartz, Teflon). 
Compared with quartz, teflon was used to generate a higher speed and lower flow induced energy input, and was used as the dielectric material for other studies. The width of the electrodes was chosen to have the best electrohydrodynamic effect. The separation distance between the edges of the upper and lower electrodes has been found to have a significant effect on the speed-induced, and an optimal configuration of width (1-2mm) was found. Figure 9 shows the charge distribution for different gap lengths as found by Enloe et al [15].
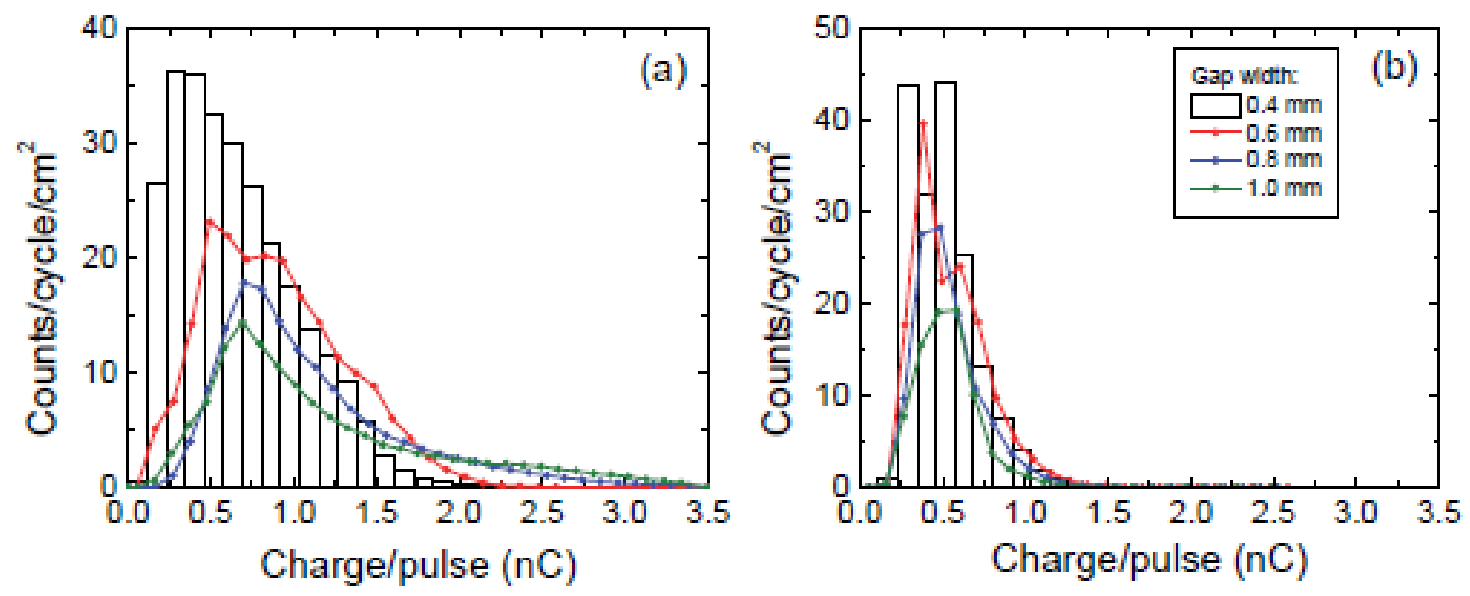

Figure 9 - Charge distribution for (a) positive current and (b) negative current in an asymmetric DBD in air with a gap width of $0.6 \mathrm{~mm}$ and the secondary electrode covered by 0.6 to $2.0 \mathrm{~mm}$ alumina. The applied voltage amplitude is $8.0 \mathrm{kVpp}$ [15]

It was noted that increasing the frequency and keeping the voltage constant, or increasing the tension and keeping the frequency constant, induced an increase in speed, 
which briefly stabilized, reaching a certain threshold, and decreasing soon after while continuing increasing the voltage or frequency.

Enloe et al [15] speculated that the lifetime of the plasma was related to the presence of oxygen ions in the air. Anderson and Roy [20] demonstrated that the drag coefficient produced by a plasma actuator mounted on a flat plate varies with the relative humidity.

It is known that water vapor is a strong electro-negative gas. High humidity increases the breakdown voltage and decreases the ionization level and size of plasma. Benard et al, [21], showed that the DBD induced ow velocity decreases by a factor of 2 when the relative humidity goes from $40 \%$ to $85 \%$ and another factor of 2 at $98 \%$ relative humidity. VanDyken et al (2004) it was also observed that a thick dielectric would be able to handle a higher input voltage, and this has an ideal frequency specifies.

While most of the literature on flow control through the plasma is essentially experimental in nature, several methodologies for the numerical modeling of plasma actuators were investigated. The majority of current models typically use a term EHD body force to simulate the effect of an actuator on the external flow.

It has been evident that the DBD plasma actuator performance can change from day to day due to its dependence on humidity. Temperature dependence can lead to other effects. For example, if the actuator is running for a long time it heats up. That means its performance will change with time as the actuator is run. The results will also differ if it is a cold run or if it was run just recently and the dielectric is still hot. External flows can provide additional cooling. Another important dependence is voltage frequency. For example, if the DBD is driven by $10 \mathrm{kHz}$ sinusoidal voltage, the dielectric will have one dielectric constant for the 10 $\mathrm{kHz}$ electric field and another, lower one, for fast electric field changes caused by $10 \mathrm{~ns}$ breakdowns. The Figure 10 below lists the general DBD characteristics found in literature. 


$\begin{array}{llll}\text { Lifetime } & 1-20 \mathrm{~ns} & \text { Filament radius } & 50-100 \mu \mathrm{m} \\ \text { Peak current } & 0.1 \mathrm{~A} & \text { Current density } & 0.1-1 \mathrm{kA} \mathrm{cm}^{-2} \\ \text { Electron energy } & 1-10 \mathrm{eV} & \text { Electron density } & 10^{14}-10^{15} \mathrm{~cm}^{-3} \\ \text { Total transported charge } & 0.1-1 \mathrm{nC} & \text { Gas temperature } & \text { Close to average, about } 300 \mathrm{~K} \\ \text { Total dissipated energy } & 5 \mu \mathrm{J} & \text { Reduced electric field } & \mathrm{E} / \mathrm{n}=(1-2)(\mathrm{E} / \mathrm{n}) \text { Paschen } \\ \text { Overheating } & 5 \mathrm{~K} & & \end{array}$

Figure 10 - Characteristics of Dielectric Barrier Discharge [22].

\subsection{SinUSOIDAl vS PULSE EXCITATION}

When the applied voltage rises to a certain value of $\mathrm{V}_{\mathrm{bd}}$, the discharge begins with some filaments distributed on the dielectric wall, but the intensity of the visible light emitted from the discharge gap was very low. When the applied voltage is increased further, the number of filaments increased and finally gets diffused. This observation has been reported by many experiments found in the literature [62]. The typical discharge signal measured was found to be in the form shown in Figure 11. 


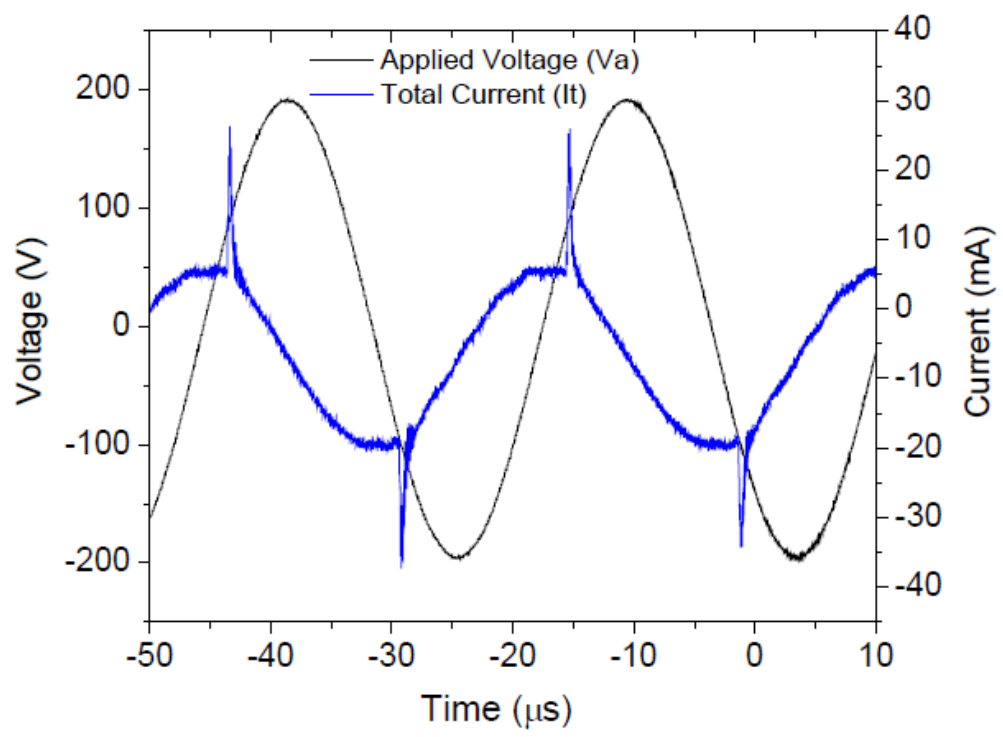

Figure 11 - Typical discharge signal showing both positive and negative discharge. [62]

From the unipolar excitation to the DBD, it has been observed that two discharges occur for per pulse of the applied voltage. The discharge and measured current waveform from the DBD source shows, there is first discharge during the rising flank (negative because of negative voltage waveform) whereas second discharge occurs at the falling flank of the applied voltage. On the application of the voltage, initially the gap voltage increases with the applied voltage. Then the current pulse occurs at rising part during discharge, which sequentially charges the dielectric and induces a significant drop in the gap voltage which results in the extinction of the primary discharge. Figure 12 shows the current behavior in a unipolar voltage excitation. 


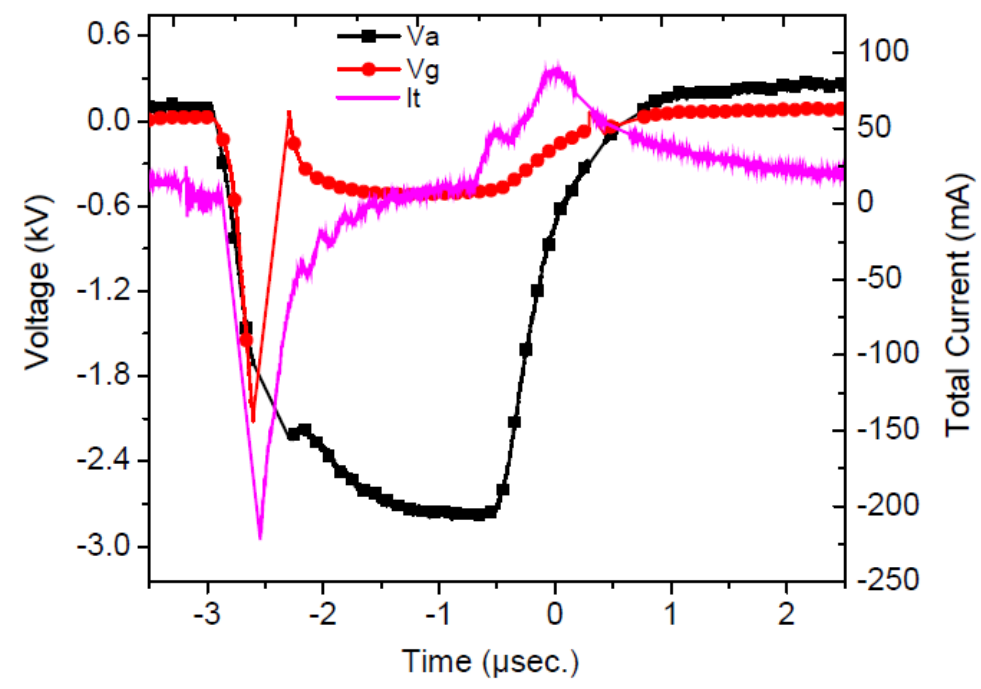

Figure 12 - Pulse excitation showing 2 discharges per cycle. [62]

After the occurrence of the first discharge current pulse, the discharge current is almost zero until the falling flank of the voltage waveform. The secondary discharge is initiated due to already charged dielectric, which induces a gap voltage for falling one and adds in a way that it is sufficient to ignite the secondary discharge after primary discharge termination. 


\subsection{ForCE GENERATION DIFFERENCE BETWEen DBD AND CoRONA DISCHARGE}

In the corona-based devices, where the input actuation is DC, due to the constant nature of the DC input, the body force is also constant and is always directed from the H.V. electrode to the grounded electrode. On the other hand, in the AC-DBD actuation, due to the oscillating nature of the input $\mathrm{AC}$, the body force is also oscillatory. In the first half cycle of the actuation, where the exposed electrode is negatively charged, the electrons are emitted from the exposed electrode and deposited onto the dielectric surface. In the second half cycle of the actuation, where the exposed electrode is positively charged, the deposited electrons on the dielectric surface are emitted from the dielectric surface to the exposed electrode. There is a difference in electron emission in two half cycles. Because of the connectivity of the exposed electrode to an infinite source of electrons (power supply), the rate of electron emission in the first half cycle of actuation is significantly higher than the second half cycle.

In the second half cycle only the deposited electrons (on the dielectric surface), which are finite, can emit to the exposed electrode. Due to this asymmetry in the electron emission rate, a net body force is applied to the particles. The direction of the body force is always from the upper exposed electrode to the lower covered electrode [59]. Figure 13 shows a comparison between the velocity of the induced jet by corana and DBD as found by Tathiri et al

Font et al., $[25,26]$ suggested that in the first half cycle, where the electrons are emitted from the upper electrode and positive ions are absorbed to this electrode, the net force is not zero and because of the dominance of ions, is directed towards the upper electrode. In the second half cycle the direction of the electric field is reversed. 
Due to the force applied from positive ions, which are emitted from the upper electrode, the direction of the resultant force is from the upper electrode to the lower electrode. The magnitude of the body force in the second half cycle is much greater than the first half cycle. Thus the direction of the total net force in one cycle is toward the covered electrode. The theory suggested by Orlov et al. [59], is named "push-push" and the theory suggested by Font et al., is called "pull-push".

Figure 14 shows a schematic of the two theories.

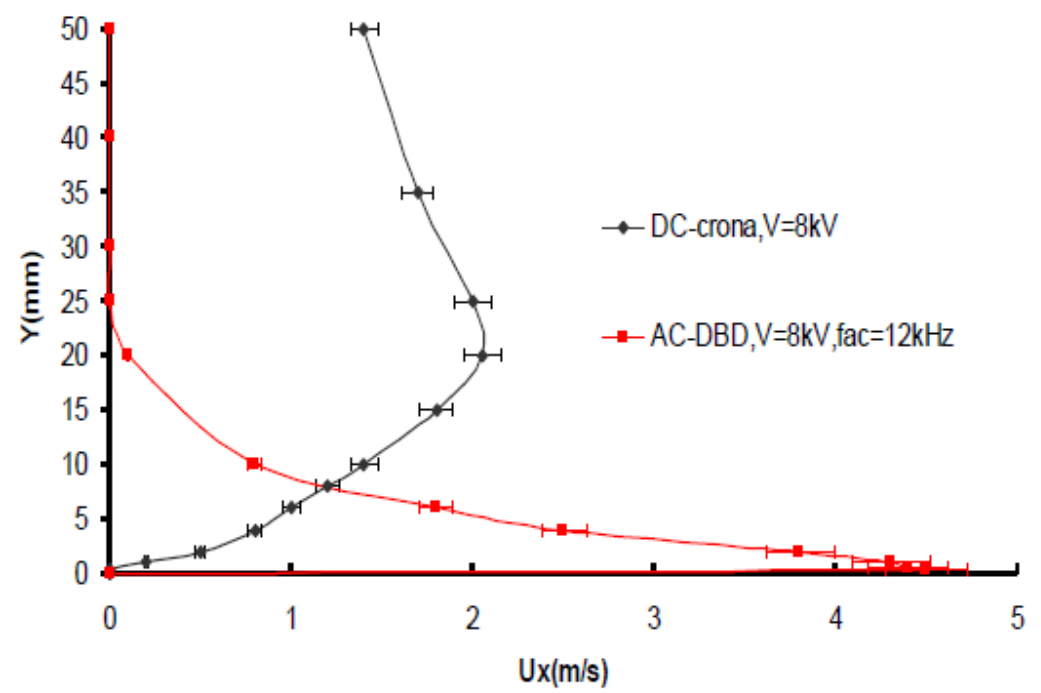

Figure 13 - Velocity profile comparing DBD and CORONA discharges. [27] 


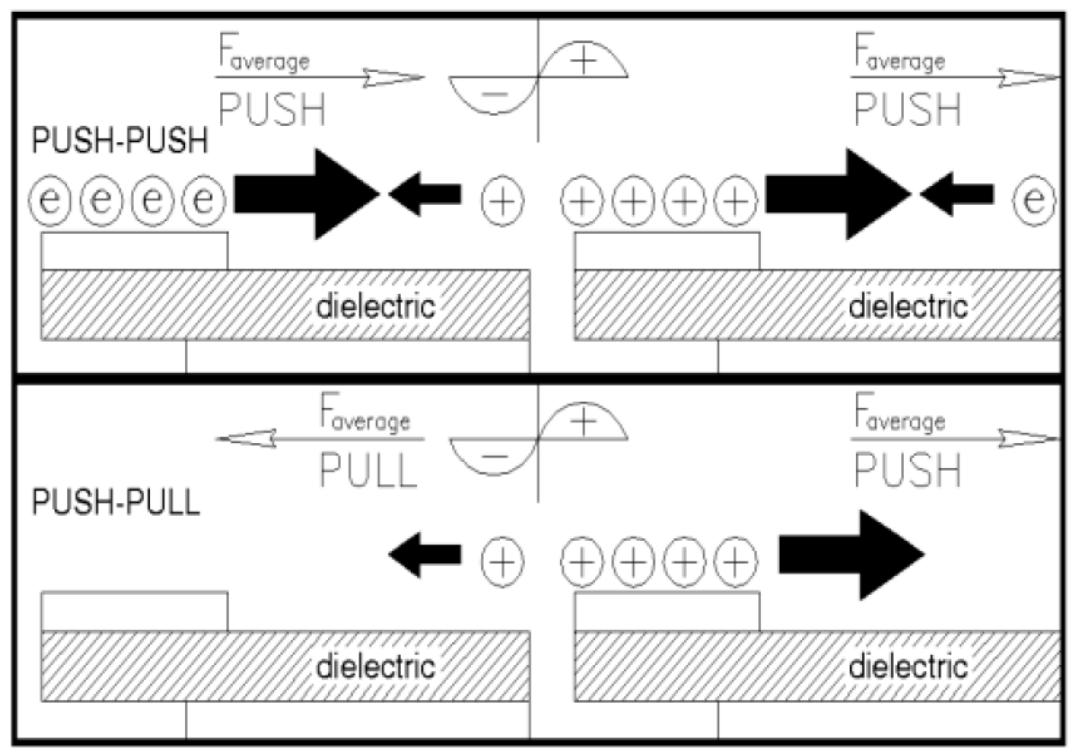

Figure 14 - Push-Push and Push-Pull theories represented schematically. [27]

\subsection{MULTIPLE ELECTRODE CONFIGURATIONS}

Some multiple electrode configurations have been tested. One configuration (Figure 15) tested the existence of multiple encapsulated anodes. This setup showed how some positions and dimensions of the encapsulated anode is better that others. However, although this configuration succeeded in delivering more velocity, it also prompted more electric energy consumption.

Although it makes use of a third grounded electrode, this system does not tackle the problem of the memory charge accumulation and thus the backward force resulting in the second half cycle. 
Another set up, shown in Figure 16, uses a cascade configuration for further acceleration of the induced jet. Although this can deliver higher final velocities, the efficiency of the individual coupled electrodes is not changed. The plasma force acting during each current half cycle is the same as the traditional electrode DBD. There is a backward force in the second half cycle, always, and this evidently, doesn't converse with the effect we desire to study in this thesis.

a

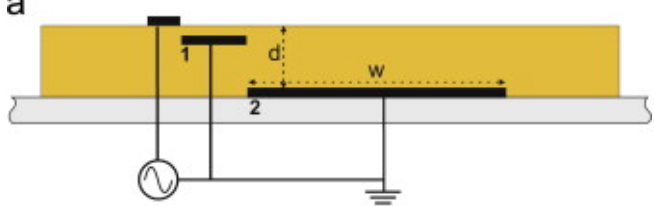

b

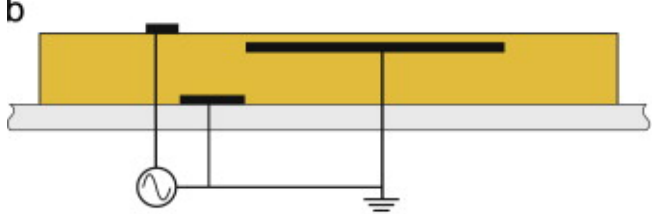

C

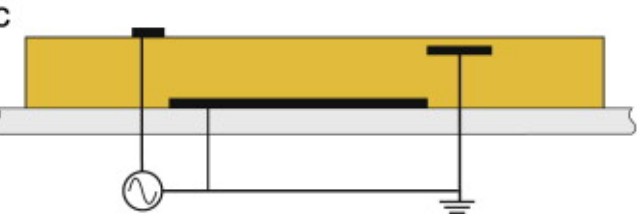

d

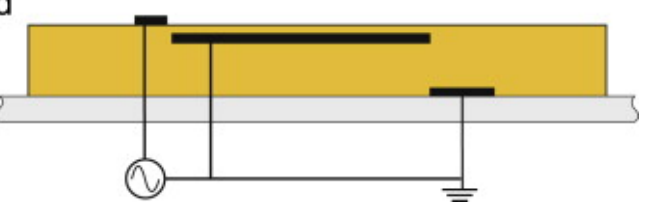

Figure 15 - Four permutations for a multi electrode system with various encapsulated electrodes. [23] 


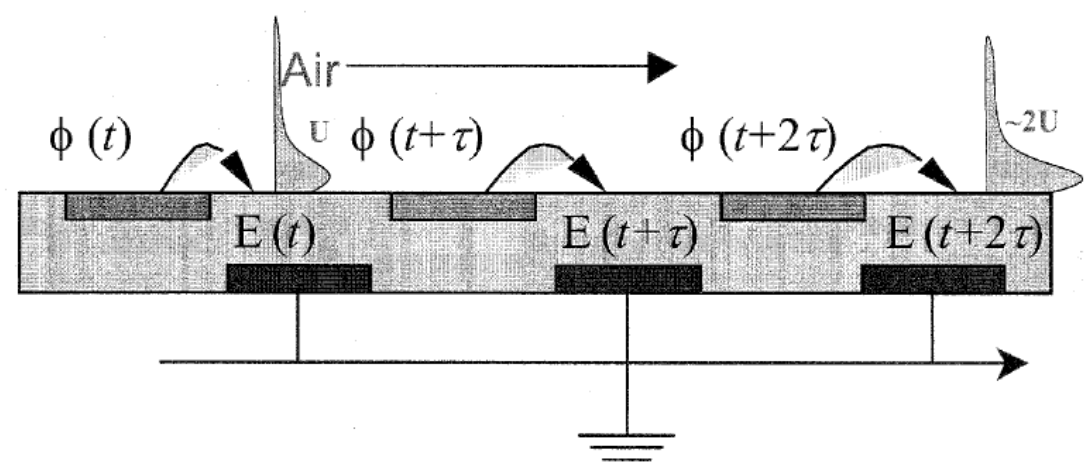

Figure 16 - Subrata Roy, Patent Application Publication Number: US 2010/0102174 A1. April 29, 2010 [24]

\subsubsection{STATEMENT OF RESEARCH OBJECTIVE}

From the plasma discharge model described in chapter 2 and 3, we were inspired to think of a manner to revert the backward force and redirect it in order to have a forward direction. For this purpose, we would limit the backward migration of the electric species in the second half-cycle by creating a potential gradient that would push them further downstream. Hence, we arrived at the idea that an additional exposed grounded electrode would create a secondary path for the memory charges to flow back into. This electrode would be positioned in front of the encapsulated electrode, thus creating a forward path for the species. 
In or der to test the idea, it was necessary to construct some instruments that would serve our purpose. A high voltage circuit is need to drive the discharge which occurs at an alternating several kilo volts. We would also need a sensitive enough pressure sensor to measure the relatively low flow velocities induced by the actuator. And finally, an electromechanical positioner system that would allow us to take the measurements at precise increments along the vertical axis. Hence, we would have the x-velocity profiles along ng the y axis for both 2-electrode configuration and 3-electrode configuration. Any migration of the memory charges the 3rd electrode will generate more forward momentum and we should be able to measure a pressure difference and thus a higher velocity with the new configuration. In chapter 5 , we shall demonstrate the experimental construction and setup that will allow us to perform the adequate measurements. 


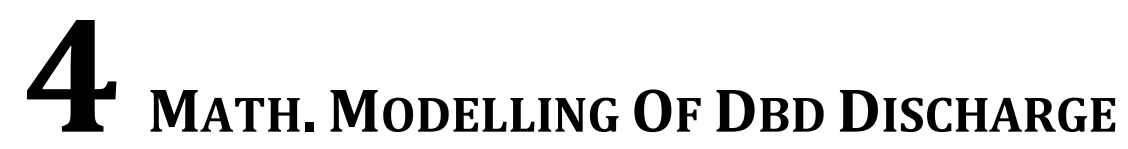

In this section we shall present the complete mathematical description of plasmas. Then discuss some numeric techniques suitable for different plasma regimes. The plasma simulation is presented with its input data and variables. Finally, the results are presented and discussed.

\subsection{A Complete Mathematical Plasma Description}

The self-consistent description of a plasma starts by noticing that once we know the forces that act on each particle, we can know the position and velocity of all particles by using Newton's law, for all particles. More precisely, the mass times the acceleration equal to the forces that are acting on each particle.

As we are dealing with electrically charged particles will be given by

$$
\overrightarrow{F_{l}}=m_{i} \frac{d^{2} \vec{r}_{l}}{d^{2} t} q_{i}\left[\vec{E}_{(r i, t)}+\vec{v}_{i} \times \vec{B}_{(r i, t)}\right]
$$

Once we know the position and the velocity of all particles we can evaluate the charge density and the current density. The charge density will be equal to the sum over all particles, of their charge qi times a delta function $\delta\left(r-r_{i}\right)$ that takes into account that the particles are located at the position ri, and therefore the contribution of the charge will be equal to zero everywhere else but at their own position. 


$$
\rho=\sum_{i=1}^{N} q_{i} \delta\left(\vec{r}-\vec{r}_{l}\right)
$$

Similarly, for the current density we will have that this will be equal to the sum -over all particles-, of the charge of all particles, then their velocity vi times the delta function that takes into account that particles are located ri.

$$
\vec{\jmath}=\sum_{i=1}^{N} q_{i} \overrightarrow{v_{l}} \delta\left(\vec{r}-\overrightarrow{r_{l}}\right)
$$

Once we know the charge density and the current density, we can evaluate the electric and magnetic fields. This can be done by using Maxwell's equations:

$$
\begin{gathered}
\nabla \cdot \vec{E}=\rho / \varepsilon_{0} \\
\nabla \times \vec{E}=-\partial \vec{B} / \partial t \\
\nabla \cdot \vec{B}=0 \\
\nabla \times \vec{B}=\mu_{0}\left(\vec{J}+\varepsilon_{0} \partial \vec{E} / \partial t\right)
\end{gathered}
$$

Once we have evaluated the electric and magnetic fields by solving Maxwell's equations, we can actually evaluate the force that acts on each particle. In fact, the force that acts on each particle will be given by the electric force with the electric field evaluated at ri plus the Lorentz force. The system of equations described here is able to represent carefully and completely the dynamics of the plasma. It's able to describe the evolution and the motion of all the particles that constitute a system in the electric and magnetic fields that are selfconsistently generated by their presence. However accurate this description of plasma is, it's 
not practical. To describe the evolution of a huge number of particles, as is usually the case for plasma systems, is a tremendous task both numerically and analytically.

\subsection{Numerical APPROACHES For Plasma Simulation}

Numerical modelling of the plasma discharge phenomenon was carried out on the Finite Volume Analysis software COMSOL. The plasma module in COMSOL can perform analysis in all space dimensions-1D, 2D, and 3D-although it is very rare in the plasma modeling community to do 3D modeling. Plasma systems are, by their very nature, complicated systems with a high degree of nonlinearity. Small changes to the electrical input or plasma chemistry can result in significant changes in the discharge characteristics.

Plasma modelling is an extremely difficult task especially because of the presence of plasma effects that take place of time scales as short as 1 nanosecond and as long as minutes. Hence, one must me very selective as to which plasma effect one wants to simulate and, in the process, many estimations are necessary. Figure 17 shows the wide timescales of the different physical phenomena occurring in plasma.

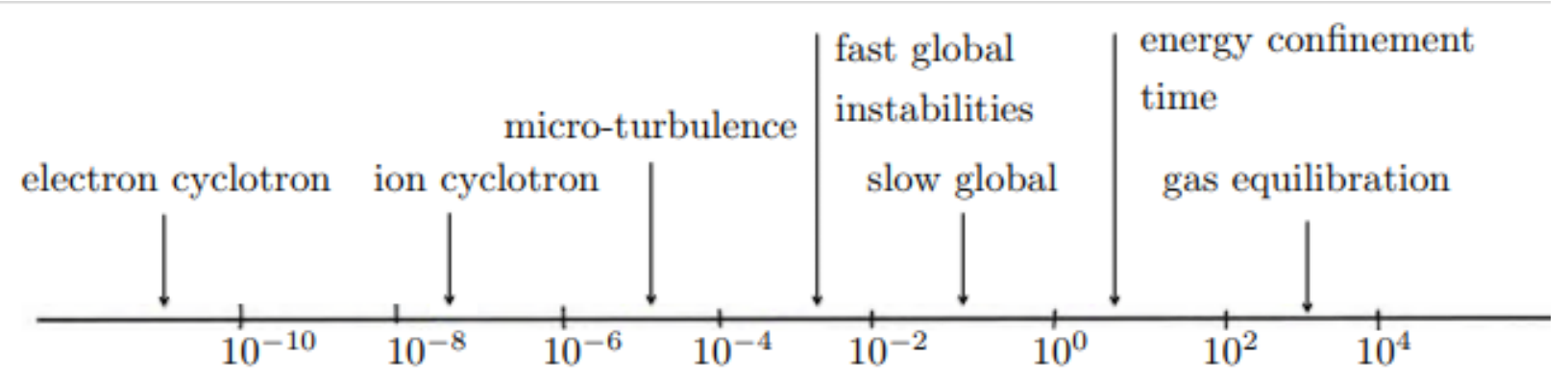

Figure 17 - Plasma timescales (in seconds) deliver an extremely challenging numerical complexity. 
There are three methods typically employed to model plasmas. Kinetic, Fluid approximation, and a hybrid module. All methods essentially involve solving an appropriate transport equation along with Maxwell's equations.

The Kinetic approach solves for the distribution function for the ions and electrons in a plasma by solving either the Boltzmann equation or an approximation, like the FokkerPlanck equation. The distribution function can also be computed using a Lagrangian approach, where ordinary differential equations are solved for the electron position and velocity, as is the case in particle-in-cell (PIC) codes. The advantage of this approach is that it allows for the electron energy distribution function to take an arbitrary shape in energy space and can also show effects that are not captured by fluid models. Drawbacks include difficulties associated with implementing arbitrary plasma chemistries and high computational cost. In the PIC method, Maxwell's equations are solved to calculate the forces acting on the charged particles. The motion of the particles can then be determined based on the Lorentz equation of motion and the particle's positions are then updated. However, the PIC method deals with a collision-less plasma which implies that a change in the trajectory of the particles due to collisions with other particles is not accounted for.

The Fluid approximation describes the plasma in terms of macroscopic quantities by assuming a specific form of the distribution function and taking velocity moments of the Boltzmann equation. This results in a set of coupled partial differential equations that can be solved using the finite element method. Advantages of the fluid approximation are that it is efficient to solve the resulting equations and straightforward to define arbitrarily complex plasma chemistries. It is also easy to couple the electron dynamics to the electromagnetic fields, which are also computed using the finite element method.

Hybrid methods treat some of the components of a plasma as a fluid and others kinetically. Usually, the electrons are treated kinetically by solving the Fokker-Planck 
equation or using a Monte Carlo method, and the ions and other radical species are computed using a fluid model. In this sense, hybrid methods offer a compromise between the fidelity of kinetic models and the speed and convenience of fluid models.

\subsection{Comsol Plasma Model}

The electron density and mean electron energy are computed by solving a pair of drift diffusion equations for the electron density and mean electron energy. Convection of electrons due to fluid motion is neglected. Here, the variation of the electron density with respect to time is related to the flux of the electron drift (first term inside the divergence operation), diffusion (second term inside divergence operation), and electron source.

$$
\begin{gathered}
\frac{\partial n_{e}}{\partial t}+\nabla \cdot\left[-n_{e}\left(\mu_{e} \cdot \boldsymbol{E}\right)-\boldsymbol{D}_{e} \bullet \nabla n_{e}\right]=R_{e} \\
\frac{\partial n_{\varepsilon}}{\partial t}+\nabla \cdot\left[-n_{\varepsilon}\left(\mu_{\varepsilon} \bullet \boldsymbol{E}\right)-\boldsymbol{D}_{\varepsilon} \bullet \nabla n_{\varepsilon}\right]+\boldsymbol{E} \cdot \Gamma_{e}=R_{\varepsilon}
\end{gathered}
$$

The electron source $R e$ and the energy loss due to inelastic collisions $R \varepsilon$ are defined later. The electron diffusivity, energy mobility, and energy diffusivity are computed from the electron mobility using:

$$
\begin{gathered}
\boldsymbol{D}_{e}=\mu_{e} T_{e} \\
\mu_{\varepsilon}=\frac{5}{3} \mu_{e} \\
\boldsymbol{D}_{\varepsilon}=\mu_{\varepsilon} T_{e}
\end{gathered}
$$


The source coefficients in the above equations are determined by the plasma chemistry using rate coefficients. Suppose that there are $M$ reactions that contribute to the growth or decay of electron density and $P$ inelastic electron-neutral collisions. In general, $P$ >> $M$. In the case of rate coefficients, the electron source term is given by:

$$
R_{e}=\sum_{j=1}^{M} x_{j} k_{j} N_{n} n_{e}
$$

where $x j$ is the mole fraction of the target species for reaction $j, k j$ is the rate coefficient for reaction $j$ (SI unit: $\mathrm{m} 3 / \mathrm{s}$ ), and $N n$ is the total neutral number density (SI unit: $1 / \mathrm{m} 3$ ). The electron energy loss is obtained by summing the collisional energy loss over all reactions:

$$
R_{\varepsilon}=\sum_{j=1}^{P} x_{j} k_{j} N_{n} n_{e} \Delta \varepsilon_{j}
$$

where $\Delta \varepsilon j$ is the energy loss from reaction $j$ (SI unit: V). The rate coefficients can be computed from cross section data by the following integral:

$$
k_{k}=\gamma \int_{0}^{\infty} \varepsilon \sigma_{k}(\varepsilon) f(\varepsilon) d \varepsilon
$$

where $\gamma=(2 q / m e)^{1 / 2}$ (SI unit: $\mathrm{C}^{1 / 2} / \mathrm{kg}^{1 / 2}$ ), $m e$ is the electron mass (SI unit: $\mathrm{kg}$ ), $\varepsilon$ is energy (SI unit: V), $\sigma_{k}$ is the collision cross section (SI unit: $\mathrm{m} 2$ ), and $f$ is the electron energy distribution function. In this case a Maxwellian EEDF is assumed. 
For non-electron species, the following equation is solved for the mass fraction of each species.

$$
\frac{\rho \partial}{\partial \mathrm{t}}\left(w_{k}\right)+\rho(\text { u. } \nabla) w_{k}=\nabla \cdot j_{k}+R_{k}
$$

The electrostatic field is computed using the following equation:

$$
-\nabla \cdot \varepsilon_{0} \varepsilon_{r} \nabla V=\rho
$$

The space charge density $\rho$ is automatically computed based on the plasma chemistry specified in the model using the formula:

$$
\rho=\mathrm{q}\left(\sum_{K=1}^{N} Z_{k} n_{k}-n_{e}\right)
$$

Electrons are lost to the wall due to random motion within a few mean free paths of the wall and gained due to secondary emission effects, resulting in the following boundary condition for the electron flux:

$$
n . \Gamma_{e}=\left(\frac{1}{2} v_{e, t h} n_{e}\right)-\sum_{p} \gamma_{p}\left(\Gamma_{p} . n\right)
$$

and the electron energy flux:

$$
n . \Gamma_{\varepsilon}=\left(\frac{5}{6} v_{e, t h} n_{\varepsilon}\right)-\sum_{p} \varepsilon_{p} \gamma_{p}\left(\Gamma_{p} \cdot n\right)
$$


The second term on the right-hand side of the second to last equation is the gain of electrons due to secondary emission effects, $\gamma_{p}$ being the secondary emission coefficient. The second term in the last equation is the secondary emission energy flux, $\varepsilon_{p}$ being the mean energy of the secondary electrons. For the heavy species, ions are lost to the wall due to surface reactions and the fact that the electric field is directed toward the wall:

$$
\boldsymbol{n} \cdot \boldsymbol{j}_{k}=M_{w} R_{k}+M_{w} c_{k} Z \mu_{k}(\boldsymbol{E} \cdot \boldsymbol{n}) \quad\left[Z_{k} \mu_{k}(\boldsymbol{E} \cdot \boldsymbol{n})>0\right]
$$

Surface charge accumulation is added to the dielectric surfaces that are adjacent to the gap where the plasma forms by way of the following boundary condition:

$$
\boldsymbol{n} \cdot\left(\boldsymbol{D}_{1}-\boldsymbol{D}_{2}\right)=\rho_{S}
$$

where $\rho_{s}$ is the surface charge density, which is computed by solving the following distributed ODE on the surfaces:

$$
\frac{d \rho_{s}}{d t}=\boldsymbol{n} \boldsymbol{J}_{\boldsymbol{i}}+\boldsymbol{n} \cdot \boldsymbol{J}_{\boldsymbol{e}}
$$

where $\mathbf{n} \cdot \mathbf{J} i$ is the normal component of the total ion current density at the wall, and $\mathbf{n} \cdot \mathbf{J} e$ is the normal component of the total electron current density at the wall. The discharge is driven by a sinusoidal electric potential applied to the exterior boundary of one of the dielectric plates:

$$
V=V_{0} \sin (w t)
$$

where the applied peak voltage, $V 0$ is $10 \mathrm{kV}$ and the angular frequency, the $\mathrm{RF}$ frequency being $8 \mathrm{kHz}$. The other dielectric plate is grounded. 


\subsection{Plasma Chemistry}

The cross section data, electron energy distribution, and townsend coefficient are calculated online on Ist Lisbon database, www.lxcat.net, for an approximation of $80 \% \mathrm{~N} 2$ and 20\% 02 constitutions of Air. Argon and $\mathrm{CO} 2$ calculations are left out for simplicity, otherwise the number of calculations would be enormous and unreasonably expensive. The data represented below is used as input variables to the COMSOL simulation. Ionization of the neutral atoms is a necessary condition to have a plasma as have been discussed earlier in chapter 2. Ionization is an example of inelastic collisions. Figure 18 shows the most important reactions taking place in a plasma, impact and radiative reactions.

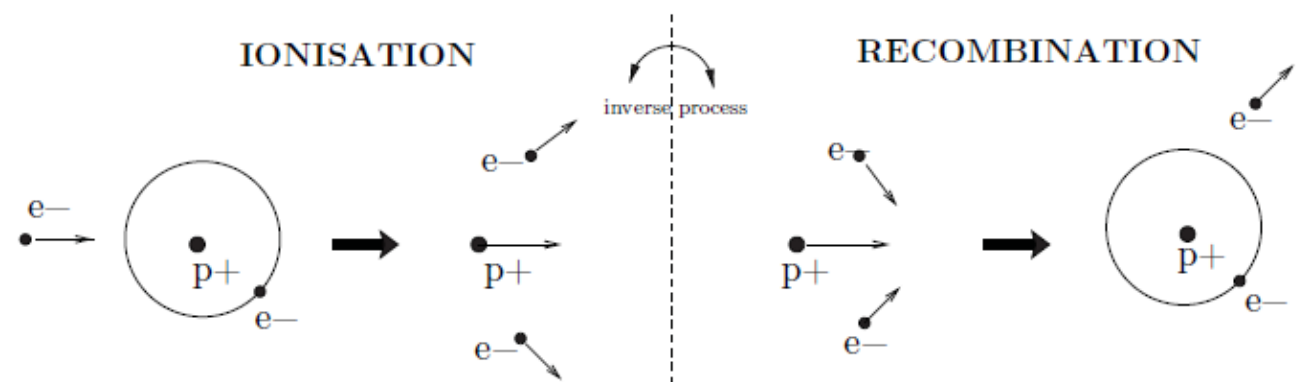

(a) impact ionisation

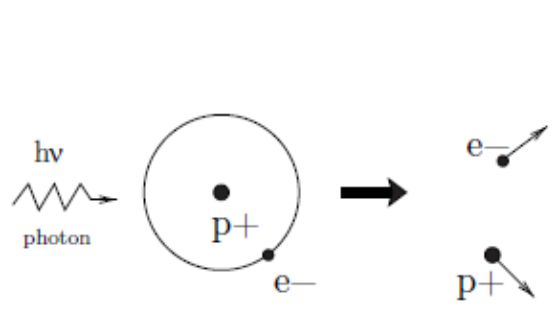

(c) Radiative ionisation (b) Three-body recombination

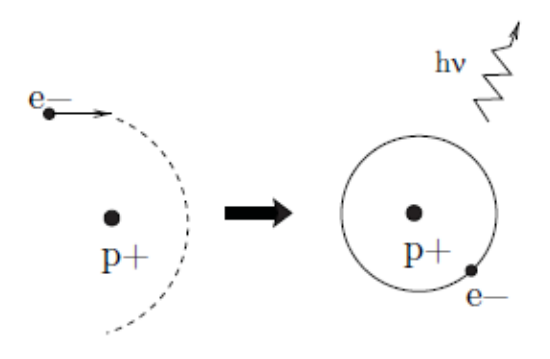

(d) Radiative recombination

Figure 18 - Schematic of the impact and radiative ionization and recombination reactions in a plasma. 
High energy photons are required for the radiative ionization. $(\mathrm{Ei}=13.6 \mathrm{eV}$ for hydrogen). In the absence of strong UV fluxes, impact ionization is the dominant mechanism for plasma production as is the case for our laboratory DBD plasma. SO we can only consider the ionization reactions, including excitation and attachment reactions. We shall list these reactions for both nitrogen dioxide and Oxygen dioxide which represent a total of $98 \%$ of the air chemistry. (20\% for oxygen and $78 \%$ for Nitrogen).

\subsubsection{Data Group $\left[\mathrm{N}_{2}\right] \mathrm{E} / \mathrm{N}_{2}$}

1. Effective $\mathrm{E}+\mathrm{N}_{2} \rightarrow \mathrm{E}+\mathrm{N}_{2}(\mathrm{~m} / \mathrm{M}=0.0000195921$, complete set $) \mid[e+N 2(X)->e+$ N2(X), Effective] Pitchford L C and Phelps A V 1982 Bull. Am. Phys. Soc. 27109 Tachibana K and Phelps A V 1979 JCP 71 3544. Updated: 14 November 2017.

2. Excitation $\mathrm{E}+\mathrm{N}_{2} \rightarrow \mathrm{E}+\mathrm{N}_{2}(\mathrm{v}=0-\mathrm{v}=1)(\mathrm{E}=0.3 \mathrm{eV}$, complete set $) \mid[e+N 2(X, v=0)<-$ $>e+N 2(X, v=1)$, Vibrational] Pitchford L C and Phelps A V 1982 Bull. Am. Phys. Soc. 27 109; Tachibana K and Phelps A V 1979 JCP 71 3544; Schulz G J 1962 Phys. Rev. 125 229; Schulz G J 1964 Phys. Rev. 135 A988; Schulz GJ 1973 Rev. Mod. Phys. 45 423; Engelhardt A G, Phelps A V and Risk C G 1964 Phys. Rev. 135 A1566; Pavlovic Z, Boness M J W, Herzenberg A and Schulz G J 1972 Phys. Rev. A 6 676. Updated: 3 September 2017.

3. Ionization $\mathrm{E}+\mathrm{N}_{2} \rightarrow \mathrm{E}+\mathrm{E}+\mathrm{N}_{2}+(\mathrm{E}=15.6 \mathrm{eV}$, complete set $) \mid[e+N 2(X)->e+e+$ N2(+,X), Ionization] Rapp D and Englander-Golden P 1965 J. Chem. Phys. 43 1464. Updated: 3 September 2017. 


\subsubsection{Data Group $\left[\mathrm{O}_{2}\right] \mathrm{E} / \mathrm{O}_{2}$}

1. Attachment $\mathrm{E}+\mathrm{O}_{2} \rightarrow \mathrm{O}^{-}+\mathrm{O}(\mathrm{E}=0 \mathrm{eV}$, complete set) | Phelps A V 1985 Technical Report 28 JILA Information Center Report, University of Colorado, Boulder, Colorado, USA; extended following Biagi v8.9. Updated: 20 April 2014.

2. Effective $\mathrm{E}+\mathrm{O}_{2} \rightarrow \mathrm{E}+\mathrm{O}_{2}(\mathrm{~m} / \mathrm{M}=0.0000171$, complete set) | Phelps A V 1985 Technical Report 28 JILA Information Center Report, University of Colorado, Boulder, Colorado, USA. Updated: 20 April 2014.

3. Excitation $\mathrm{E}+\mathrm{O}_{2} \rightarrow \mathrm{E}+\mathrm{O}_{2}(\mathrm{v}=0-\mathrm{v}=1)(\mathrm{E}=0.19 \mathrm{eV}$, complete set $) \mid$ Phelps A V 1985 Technical Report 28 JILA Information Center Report, University of Colorado, Boulder, Colorado, USA; extended following Phelps at resonance and extrapolated up to $1 \mathrm{keV}$. Updated: 20 April 2014.

4. Ionization $\mathrm{E}+\mathrm{O}_{2} \rightarrow \mathrm{E}+\mathrm{E}+\mathrm{O}_{2}{ }^{+}(\mathrm{E}=12.1 \mathrm{eV}$, complete set $) \mid$ Phelps A V1985 Technical Report 28 JILA Information Center Report, University of Colorado, Boulder, Colorado, USA. Updated: 20 April 2014.

The results of the calculations are presented in Figure 19, Figure 20, Figure 21, Figure 22, and Figure 23 where the Cross section values, the species reaction rates, the species mobility coefficient, the diffusion coefficient, and the townsend coefficient, are all plotted with respect to the plasma energy in $\mathrm{eV}$. 


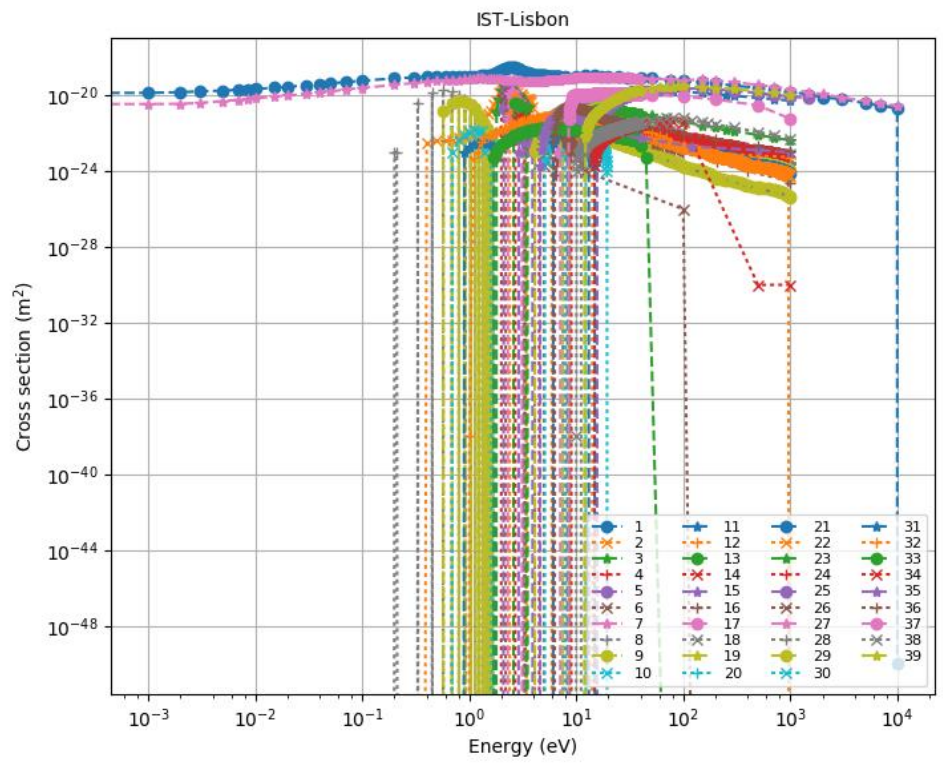

Figure 19 - Cross section Values relative to plasma energy. [37]

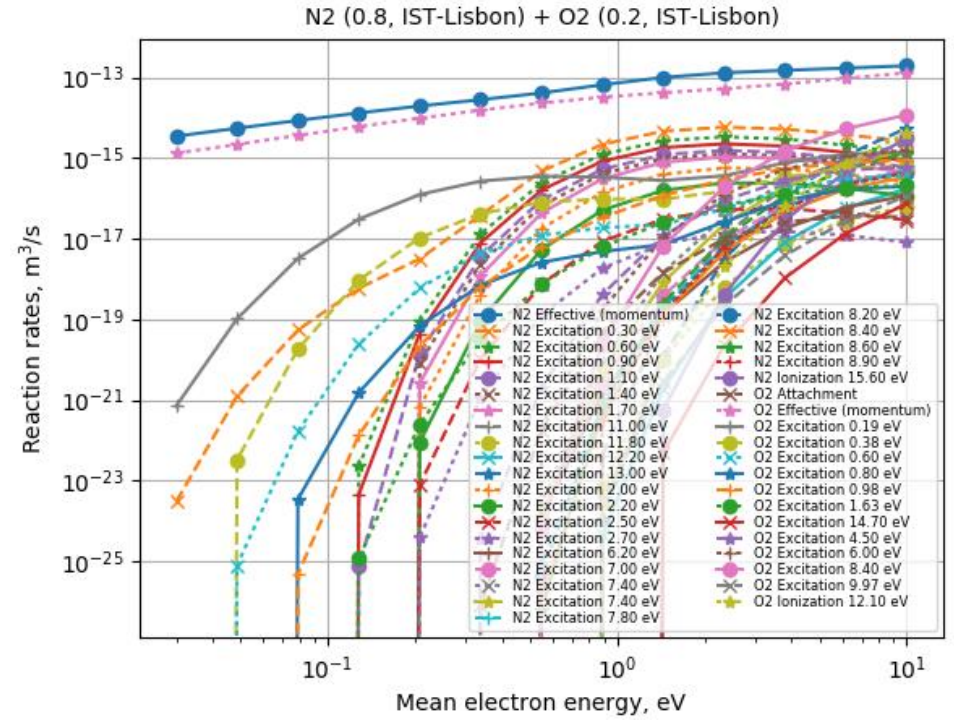

Figure 20 - The species reaction rates relative to the plasma electron energy. [37] 


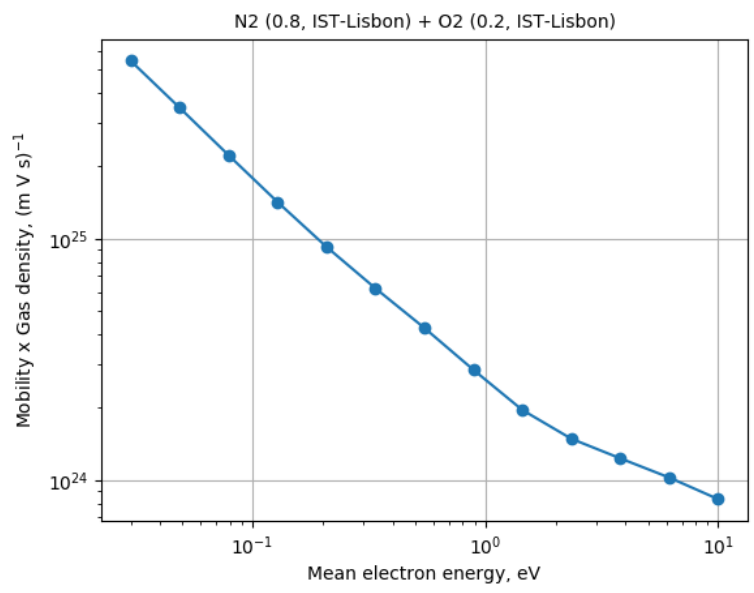

Figure 21 - The Plasma mobility*Density relative to the plasma electron energy. [38]

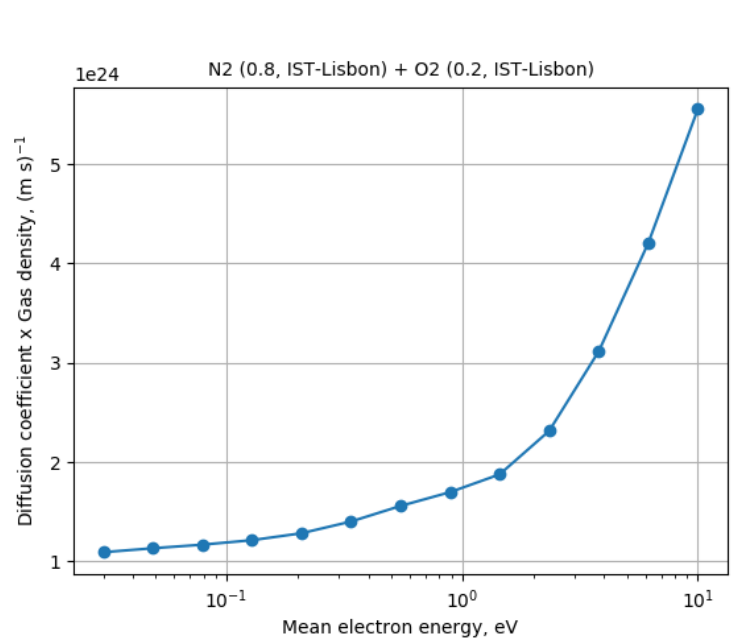

Figure 22 - The plasma diffusion coefficient relative to the Plasma electron energy. [38] 


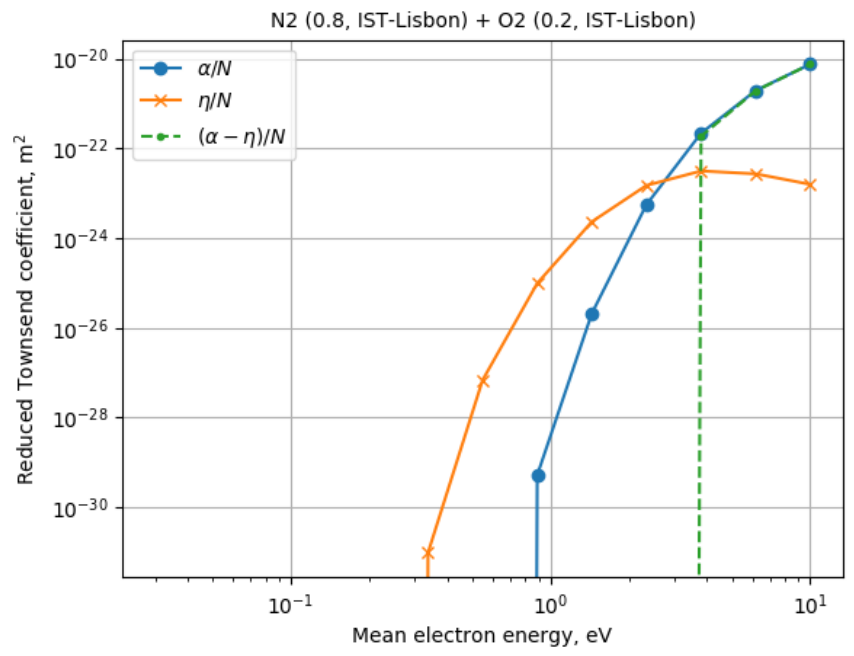

Figure 23 - The reduced Townsend coefficient relative to the plasma electron energy.[38]

\subsection{Simulation Parameters}

The input parameters defined in the comsol model are shown in Figure 24. The geometry set-up is shown in Figure 25. Here, the anode and cathode are modeled as onedimensional line electrodes for computational simplicity. The numerical calculations showed a sheer difficulty in convergence, so the problem was approached by beginning with a coarse enough mesh, and then gradually experimenting with a finer mesh until a satisfactory result was reached. 


\begin{tabular}{|c|c|c|c|}
\hline "Name & Expression & Unit & Description \\
\hline freq & $10 \mathrm{e} 3[\mathrm{~Hz}]$ & $\mathrm{Hz}$ & RF Frequency \\
\hline omega & $2^{*}$ pifreq & $\mathrm{Hz}$ & Angular frequency \\
\hline Vif & $10 \mathrm{e} 3[\mathrm{~V}]^{\star}\left(\sin \left(\right.\right.$ omega $\left.\left.^{\star} \mathrm{t}\right)\right)$ & V & Applied voltage \\
\hline thplate & $0.24[\mathrm{~m}]$ & $\mathrm{m}$ & \\
\hline As & thplate & $\mathrm{m}$ & \\
\hline mueN & 3.74e24*(plas.Erd*1e21)^ $-0.22\left[1 /\left(V^{*} m^{*} s\right)\right]$ & & Reduced electron mobility \\
\hline muiN & $6 \mathrm{e} 21\left[1 /\left(V^{\star} \mathrm{s}^{\star} \mathrm{m}\right)\right]$ & $1 /(V \cdot m \cdot s)$ & Reduced ion mobility \\
\hline $\mathrm{rnp}$ & $2 \mathrm{e}-6\left[\mathrm{~cm}^{\wedge} 3 / \mathrm{s}\right]$ & $\mathrm{m}^{3} / \mathrm{s}$ & ion-ion recombination \\
\hline rei & $5 \mathrm{e}-8\left[\mathrm{~cm}^{\wedge} 3 / \mathrm{s}\right]$ & $\mathrm{m}^{3} / \mathrm{s}$ & electron-ion \\
\hline po & $760[$ torr] & $\mathrm{Pa}$ & Gas Pressure \\
\hline to & $600[\mathrm{~K}]$ & K & Gas Temperature \\
\hline ni0 & $1 \mathrm{e} 17\left[\mathrm{~m}^{\wedge}-3\right]$ & $1 / \mathrm{m}^{3}$ & Initial ion number density \\
\hline ne0 & $1 \mathrm{e} 10\left[\mathrm{~m}^{\wedge}-3\right]$ & $1 / \mathrm{m}^{3}$ & Initial electron number desity \\
\hline
\end{tabular}

Figure 24 - Input parameters for COMSOL simulation.

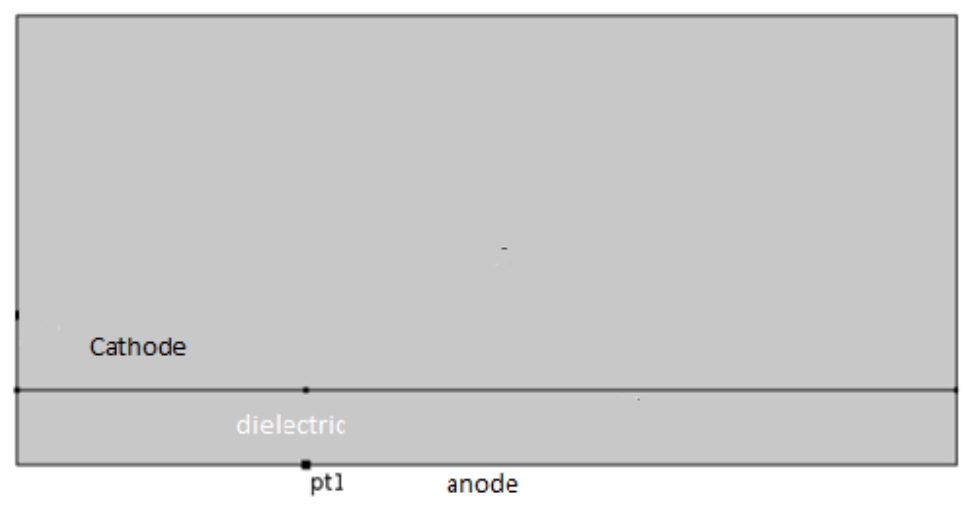

Figure 25 - Computational Geometry displaying both line electrodes encapsulating the dielectric. 
The complete triangular mesh consists of 5031 domain elements and 224 boundary elements. It has a 0.276 maximum element size to 0.00156 minimum element size. For a smooth continuity the element growth rate was set to 1.3. The mesh is shown in Figure 26.

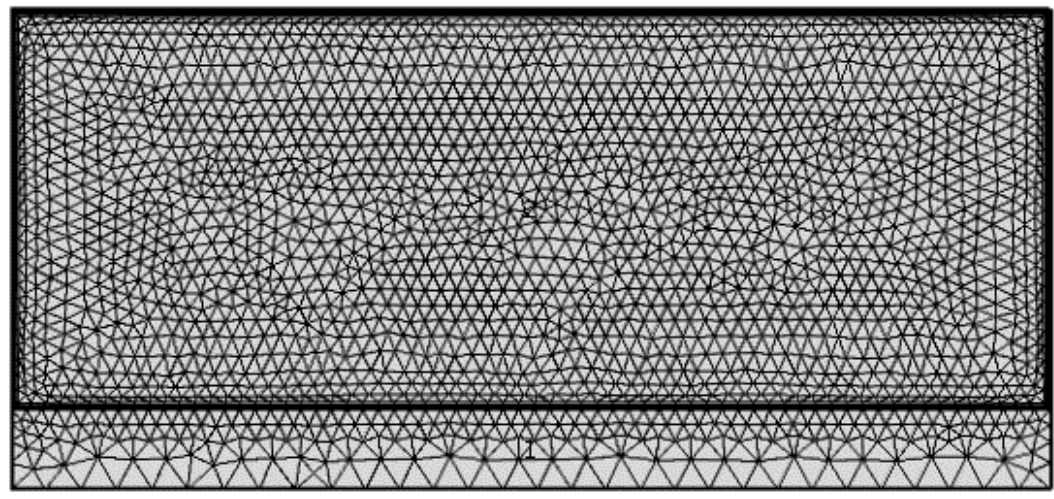

Figure 26 - Mesh as used on COMSOL simulation.

The calculation was performed for the time range of 0 to $4 \mathrm{e}-4 \mathrm{~s}$, which is the time covering 4 complete periods, and with a time step of $0.1 \mathrm{e}-4 / 200 \mathrm{~s}$.

\subsection{RESULTS}

The simulation results in Figure 27 show clearly the migration of electrons to the cathode in the negative half cycle. 


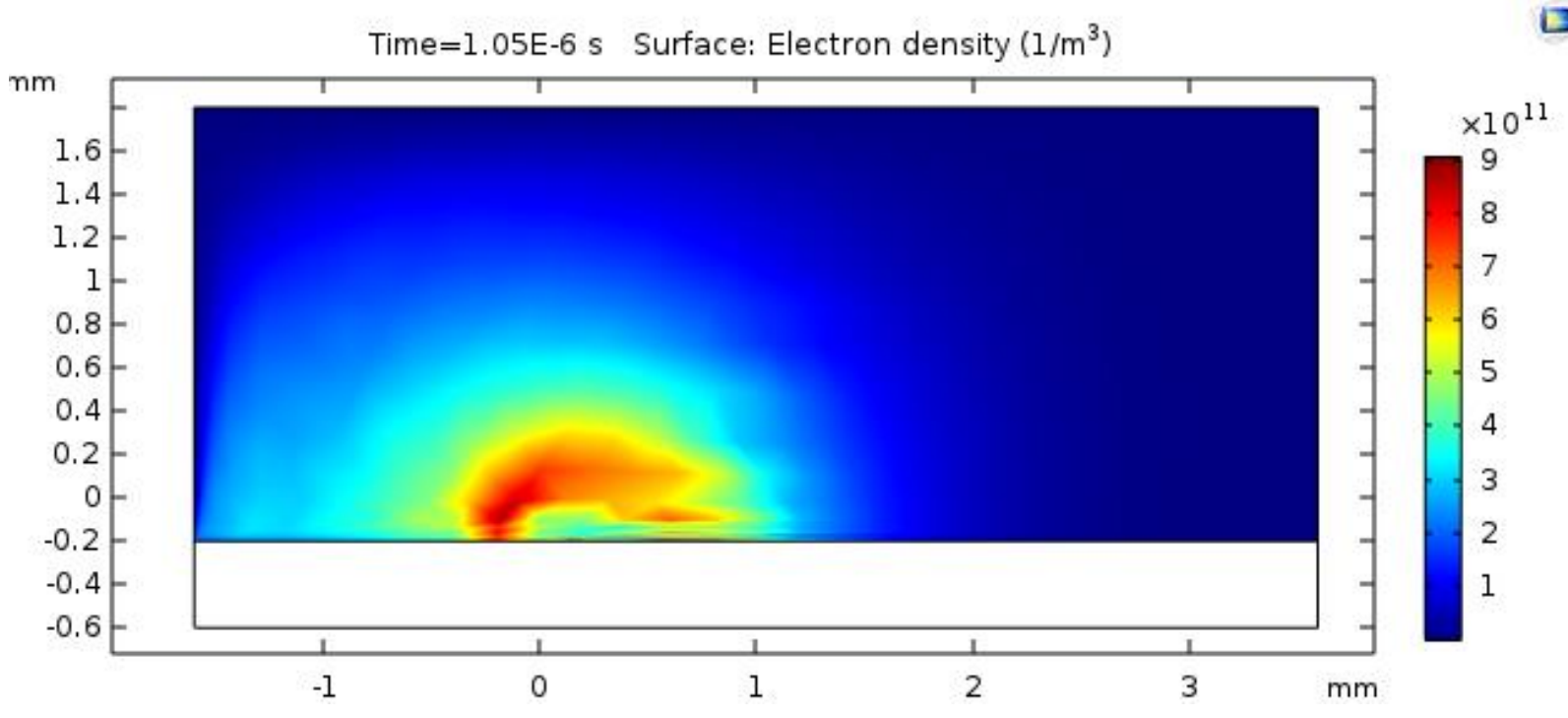

Figure 27 - Electron number density as calculated in Comsol.

This is happening because of the secondary discharges that are induced by the bombardment of the ions with the cathode edge, producing more electrons into the discharge. This highly concentrated electron region is visible in the experiment as a pink light along the electrode edge. It follows that the electron temperature at this point is highest and we can see that in Figure 28 with a maximum electron temperature of $0.8 \mathrm{eV}$. This electron concentration is seen experimentally as the plasma glow line on the edge of exposed electrode. 


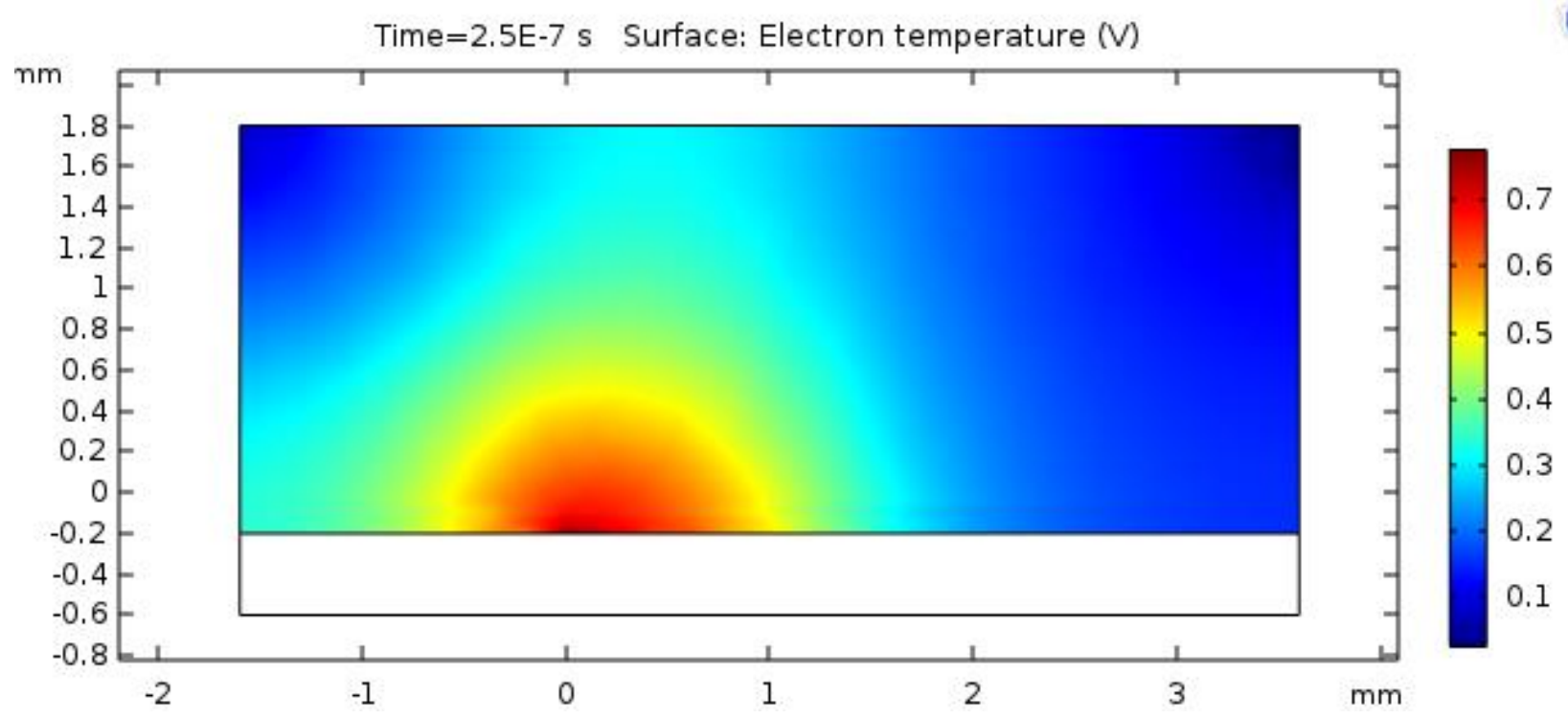

Figure 28 - Electron temperature in $\mathrm{eV}$ as calculated by COMSOL.

As the electrodes are asymmetrically aligned, it is expected to see our electric potential lines distorted accordingly. These lines of potential follow the contour of the electrodes. This distribution can be seen in Figure 29. 


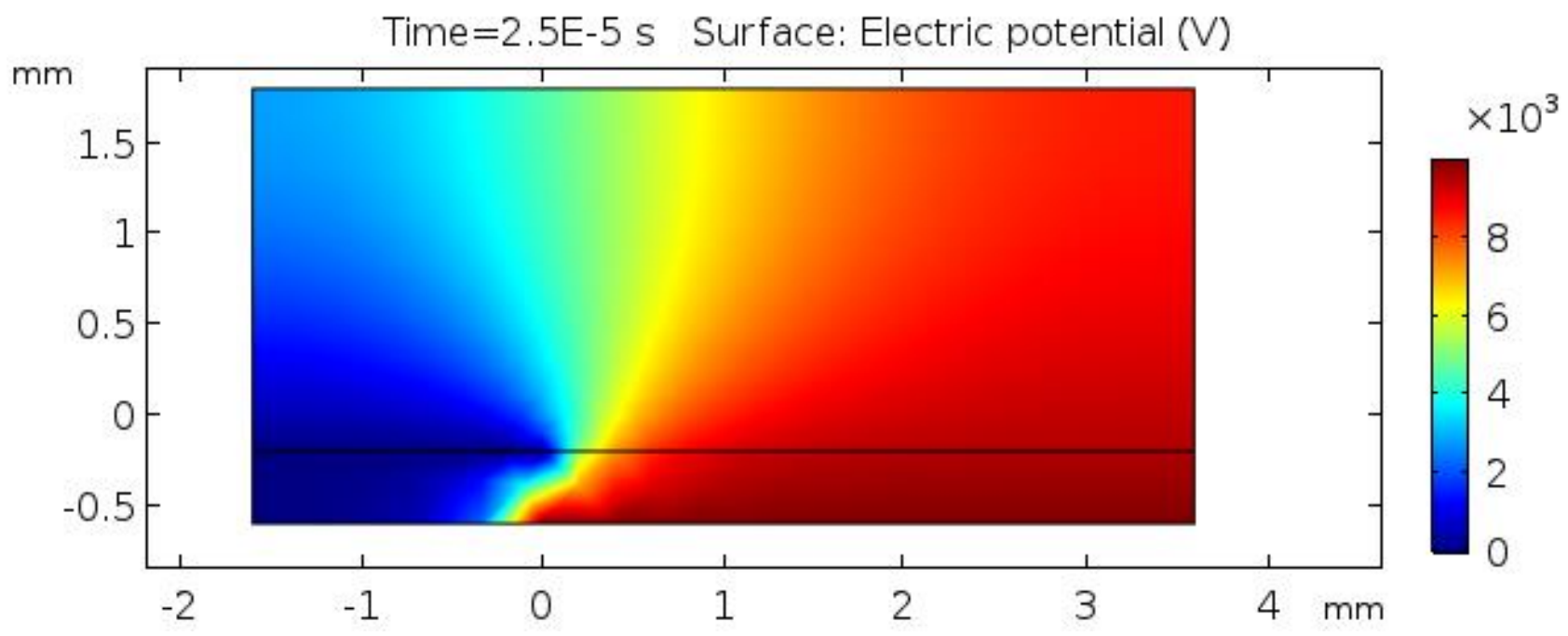

Figure 29 - Electric potential follows the electrode geometry.

So, we expect an electron migration in the direction opposite of the potential. In the negative half cycle, this means electron flux lines leaving the exposed electrode and depositing on the dielectric surface shown in Figure 30. Note the presence of a rotation right at the electrode edges. At the same time, the flux of ions happens in the opposite direction, migrating towards the exposed electrode as shown in Figure 31. In the positive half cycle, the electron and ion flux is in the opposite direction as shown in Figure 32 and Figure 33. 


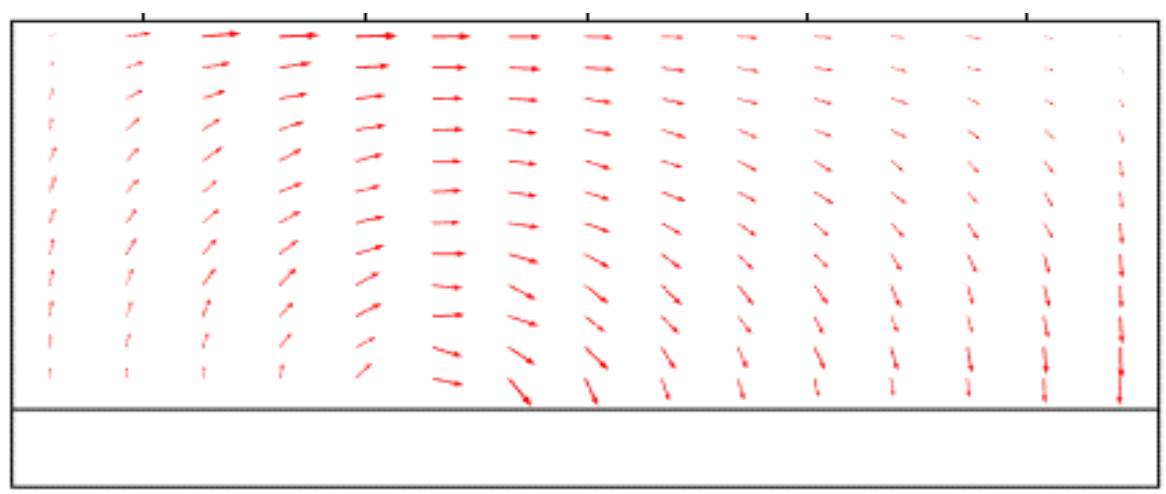

Figure 30 - Electron flux in the negative cycle leaving the exposed electrode before depositing on the dielectric surface.

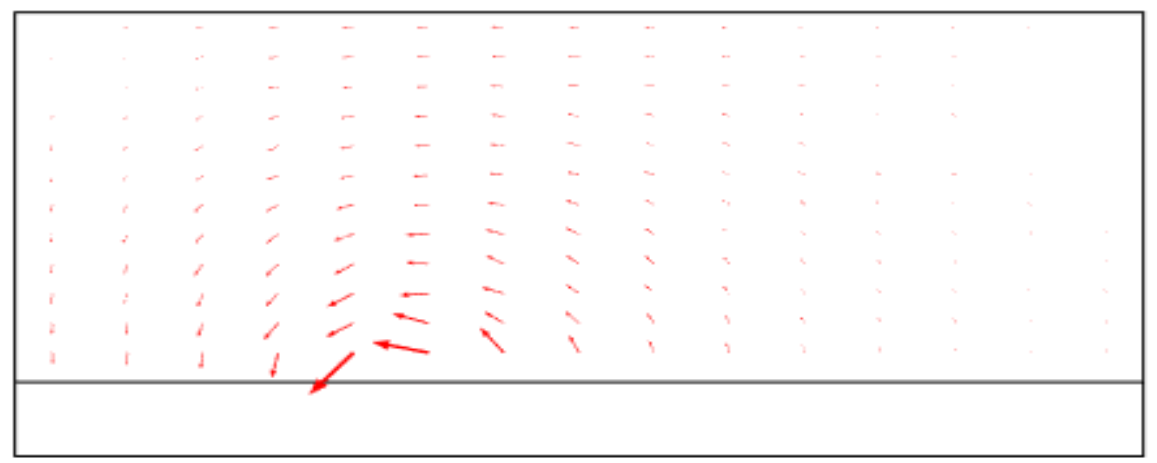

Figure 31 - Ion flux in the negative cycle migrating towards the exposed electrode. 


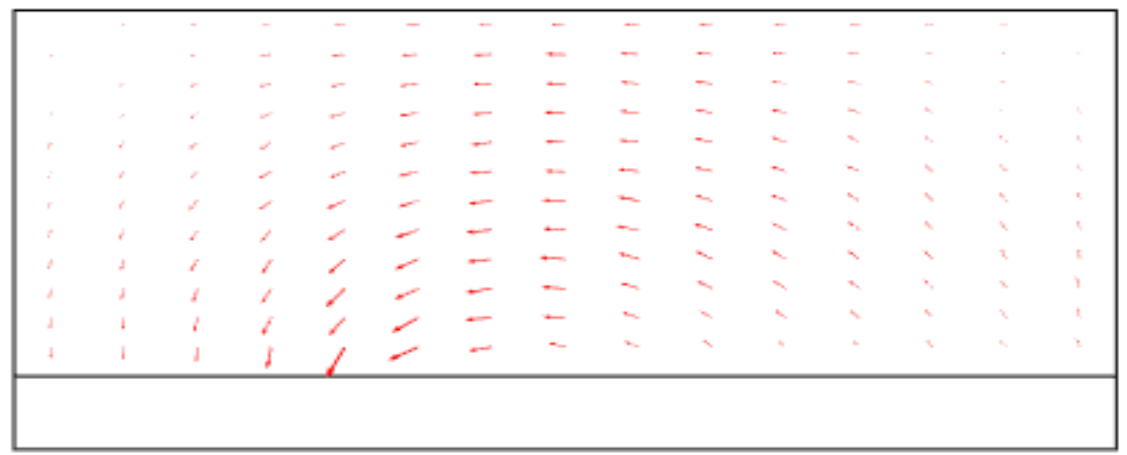

Figure 32 - Electron Flux during the positive half cycle.

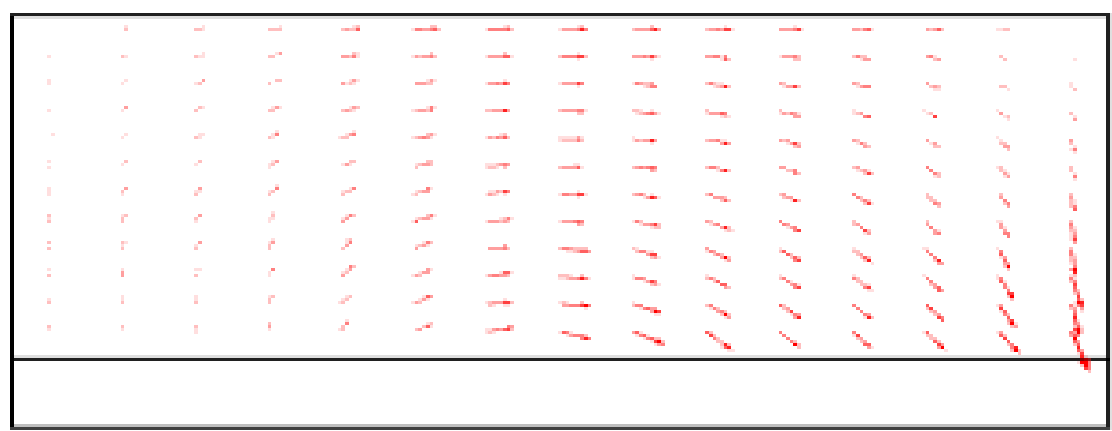

Figure 33 - Ion flux during the positive half cycle.

If we examine the electric field lines in Figure 34, we find the that the tend to concentrate right at the electrode gap, receding rapidly as we move further away from that region. This would tell us that the force generated by the device is acting on the charged particles in a very small region and that most of the momentum generated for producing an air jet is exchanged happens not only in a small interval of time, but at a small distance too. 


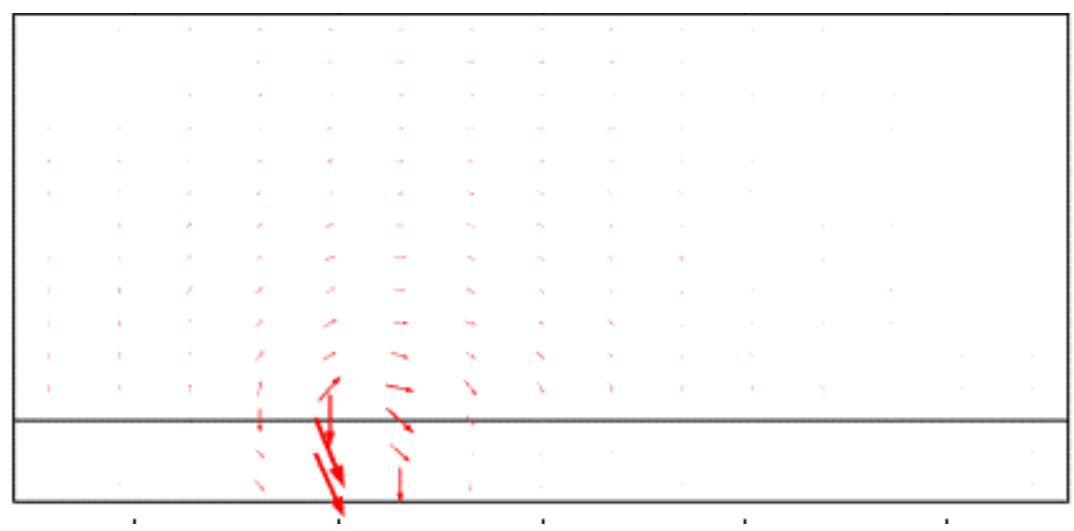

Figure 34 - Electric field lines concentrated between the electrode gap. 


\section{EXPERIMENTAL SETUP}

In this chapter we shall present some properties of Kapton tape that make it suitable for our purpose as a dielectric for the barrier discharge. We then describe the design and assembly of the high voltage generator used for plasma creation. Afterwards, we present the pitot mount and the electromechanical positioner along with the pressure sensor and its calibration. Finally, we present the 3 -electrode configuration.

\subsection{KAPTON TAPE PROPERTIES}

Kapton ${ }^{\circledR}$ polyimide film possesses a unique combination of properties that make it ideal for a variety of applications in many different industries. The ability of Kapton ${ }^{\circledR}$ to maintain its excellent physical, electrical, and mechanical properties over a wide temperature range has opened new design and application areas to plastic films. Kapton $₫$ is synthesized by polymerizing an aromatic dianhydride and an aromatic diamine. It has excellent chemical resistance; there are no known organic solvents for the film. Kapton $®$ is self extinguishing as it has the highest UL-94 flammability rating: V-0. The outstanding properties of Kapton ${ }^{\circledR}$ permit it to be used at both high and low temperature extremes where other organic polymeric materials would not be functional. Adhesives are available for bonding Kapton $®$ to itself and to metals, various paper types, and other films. Kapton ${ }^{\circledR}$ polyimide film can be used in a variety of electrical and electronic insulation applications: wire and cable tapes, formed coil insulation, substrates for flexible printed circuits, motor slot liners, magnet wire insulation, transformer and capacitor insulation, magnetic and pressure-sensitive tapes, and tubing. Many of these applications are based on the excellent 
balance of electrical, thermal, mechanical, physical, and chemical properties of Kapton® over a wide range of temperatures. It is this combination of useful properties at temperature extremes that makes Kapton® a unique industrial material.

\subsubsection{Electrical Properties OF KAPTON}

Like all organic materials, Kapton $\AA$ is attacked by a corona discharge and when exposed continuously to it will ultimately fail dielectrically. At moderate levels of corona exposure, devices insulated with Kapton ${ }^{\circledR}$ have survived up to $3000 \mathrm{~h}$, giving reasonable assurance that brief exposure to a corona will not significantly affect the life of a properly designed insulation system based on Kapton $®$. Corona threshold voltage and intensity are functions of many parameters, including insulation thickness, air gap thickness, and device shape. The most common electrical properties of Kapton® polyimide film of various gauges are shown in Table 1 . These values were measured at $23^{\circ} \mathrm{C}\left(73^{\circ} \mathrm{F}\right)$ and $50 \%$ relative humidity. 


\begin{tabular}{|c|c|c|c|c|}
\hline Property Film Gauge & \multicolumn{2}{|c|}{ Typical Value } & Test Condition & Test Method \\
\hline $\begin{array}{l}\text { Dielectric Strength } \\
25 \mu \mathrm{m}(1 \mathrm{mil}) \\
50 \mu \mathrm{m}(2 \mathrm{mil}) \\
75 \mu \mathrm{m}(3 \mathrm{mil}) \\
125 \mu \mathrm{m}(5 \mathrm{mil})\end{array}$ & $\begin{array}{c}\mathbf{V} / \mu \mathrm{m}(\mathbf{k V} / \mathrm{mm}) \\
303 \\
240 \\
205 \\
154\end{array}$ & $\begin{array}{c}(\mathrm{V} / \mathrm{mil}) \\
(7700) \\
(6100) \\
(5200) \\
(3900)\end{array}$ & $\begin{array}{c}60 \mathrm{~Hz} \\
1 / 4 \text { in electrodes } \\
500 \mathrm{~V} / \mathrm{sec} \text { rise }\end{array}$ & ASTM D-149 \\
\hline $\begin{array}{l}\text { Dielectric Constant } \\
25 \mu \mathrm{m}(1 \mathrm{mil}) \\
50 \mu \mathrm{m}(2 \mathrm{mil}) \\
75 \mu \mathrm{m}(3 \mathrm{mil}) \\
125 \mu \mathrm{m}(5 \mathrm{mil})\end{array}$ & \multicolumn{2}{|c|}{$\begin{array}{l}3.4 \\
3.4 \\
3.5 \\
3.5\end{array}$} & $1 \mathrm{kHz}$ & ASTM D-150 \\
\hline $\begin{array}{l}\text { Dissipation Factor } \\
25 \mu \mathrm{m}(1 \mathrm{mil}) \\
50 \mu \mathrm{m}(2 \mathrm{mil}) \\
75 \mu \mathrm{m}(3 \mathrm{mil}) \\
125 \mu \mathrm{m}(5 \mathrm{mil})\end{array}$ & \multicolumn{2}{|c|}{$\begin{array}{l}0.0018 \\
0.0020 \\
0.0020 \\
0.0026\end{array}$} & $1 \mathrm{kHz}$ & ASTM D-150 \\
\hline $\begin{array}{l}\text { Volume Resistivity } \\
25 \mu \mathrm{m}(1 \text { mil }) \\
50 \mu \mathrm{m}(2 \mathrm{mil}) \\
75 \mu \mathrm{m}(3 \mathrm{mil}) \\
125 \mu \mathrm{m}(5 \mathrm{mil})\end{array}$ & \multicolumn{2}{|c|}{$\begin{array}{l}\Omega \cdot \mathrm{cm} \\
1.5 \times 10^{17} \\
1.5 \times 10^{17} \\
1.4 \times 10^{17} \\
1.0 \times 10^{17}\end{array}$} & & ASTM D-257 \\
\hline
\end{tabular}

Table 1 - Electrical Properties of Kapton Tape (fonte:2017 DuPont ${ }^{\mathrm{TM}}$. Kapton.com)

\subsection{HIGH VOLTAGE GENERATOR CIRCUIT}

A high voltage generator for a plasma discharge is not readily available in the market so in order to achieve a sufficiently high voltage to ionize the plasma actuator, an amplifier circuit was constructed. The circuit, shown in the Figure 35 below, is a relatively simple design and can be divided into 4 steps. Signal production and control, circuit isolation, push pull mechanism, a power transistor, and a transformer. 


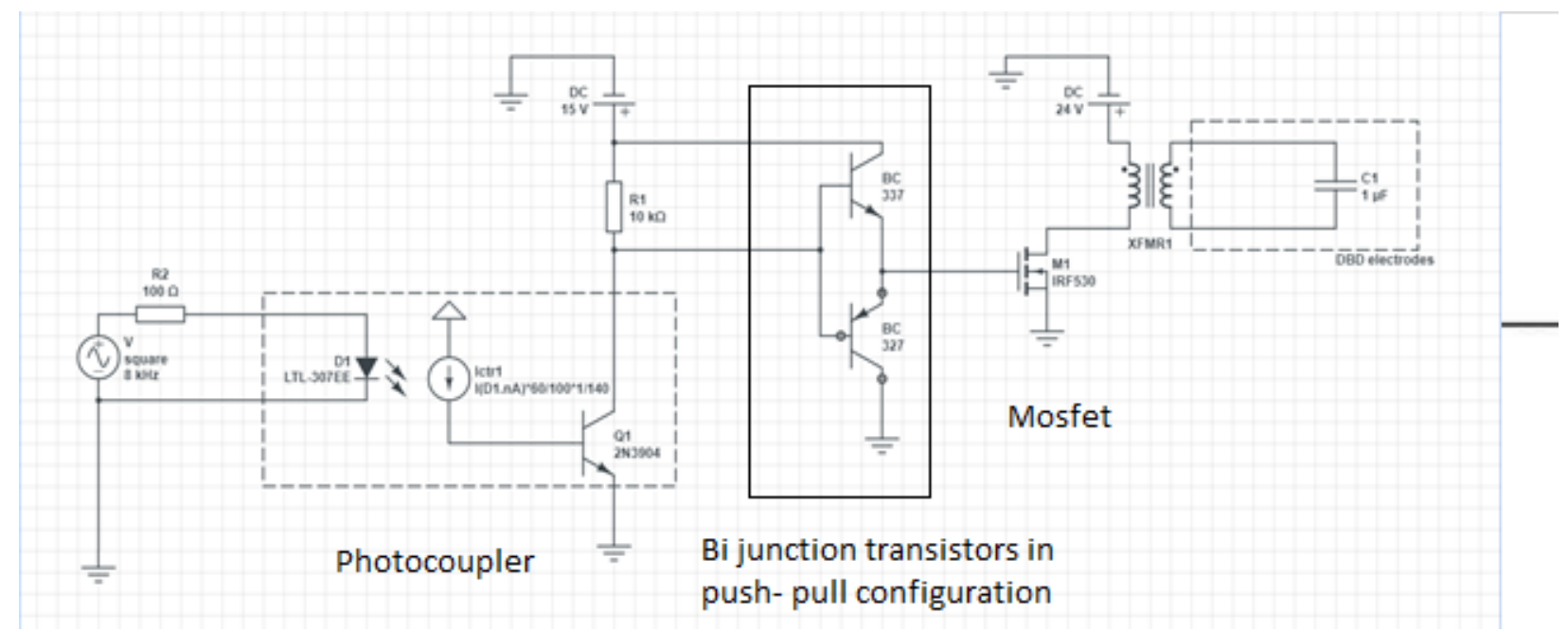

Figure 35 - High Voltage Circuit generator.

The circuit is divided into 3 steps. First, the signal generation. A photocoupler is used to isolate the circuit from the signal generator for security reasons, in case of a high current surge. A push pull mechanism is implemented by coupling 2 BJT(Bi junction transistors) of the P type, BC 337, and the N type BC327. The signal is then then fed to a IRF460 MOSFET where the signal is amplified enough to be fed to the high voltage transformer. The transformer used is a car ignition coil of the type Magnet Marelli B10016MM C116. The complete electric diagram is shown in Figure 36. The constructed circuit can be seen in Figure 37. 


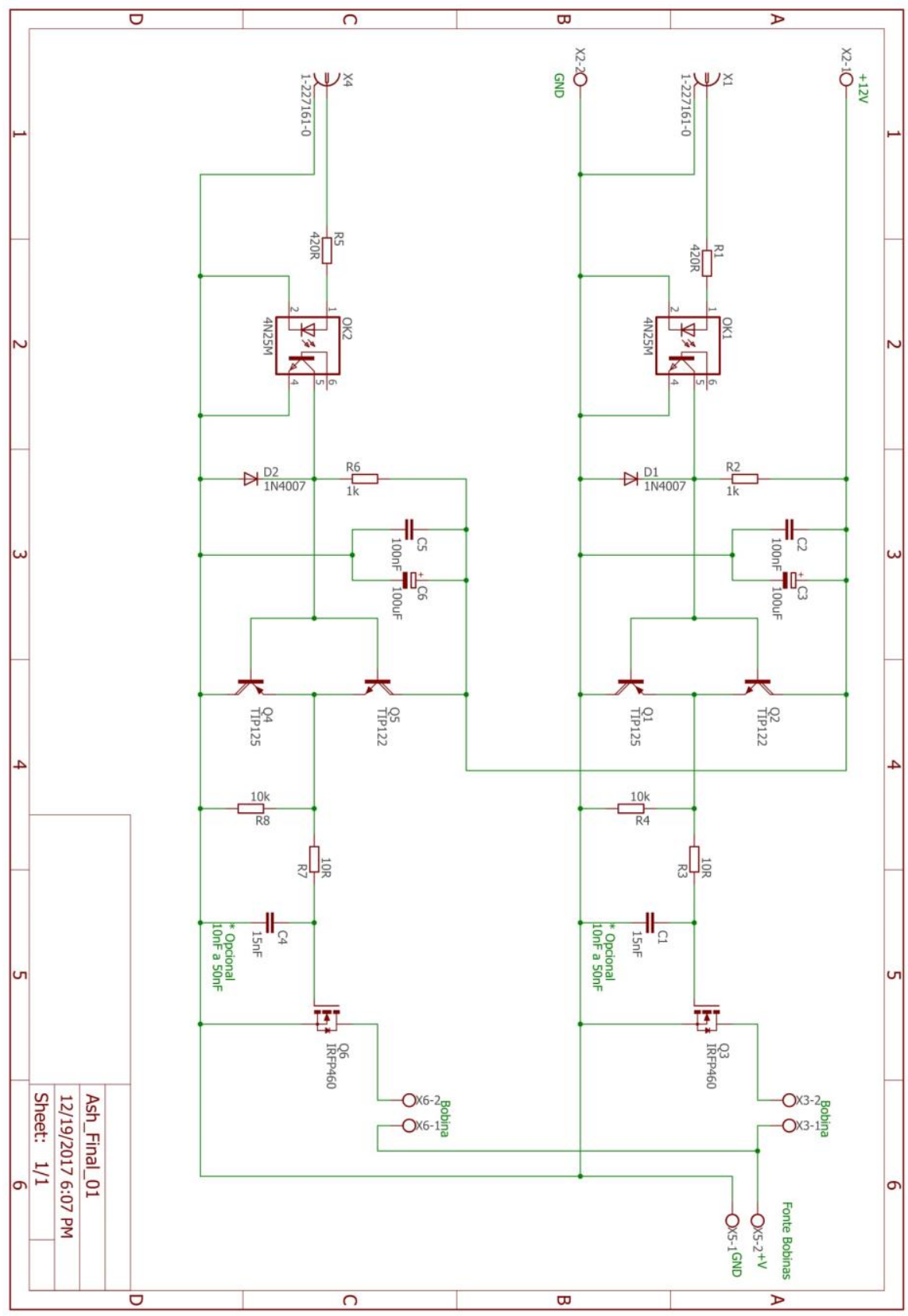

Figure 36 - Circuit diagram showing the two circuits with the same input going into two different transformers at the output. 


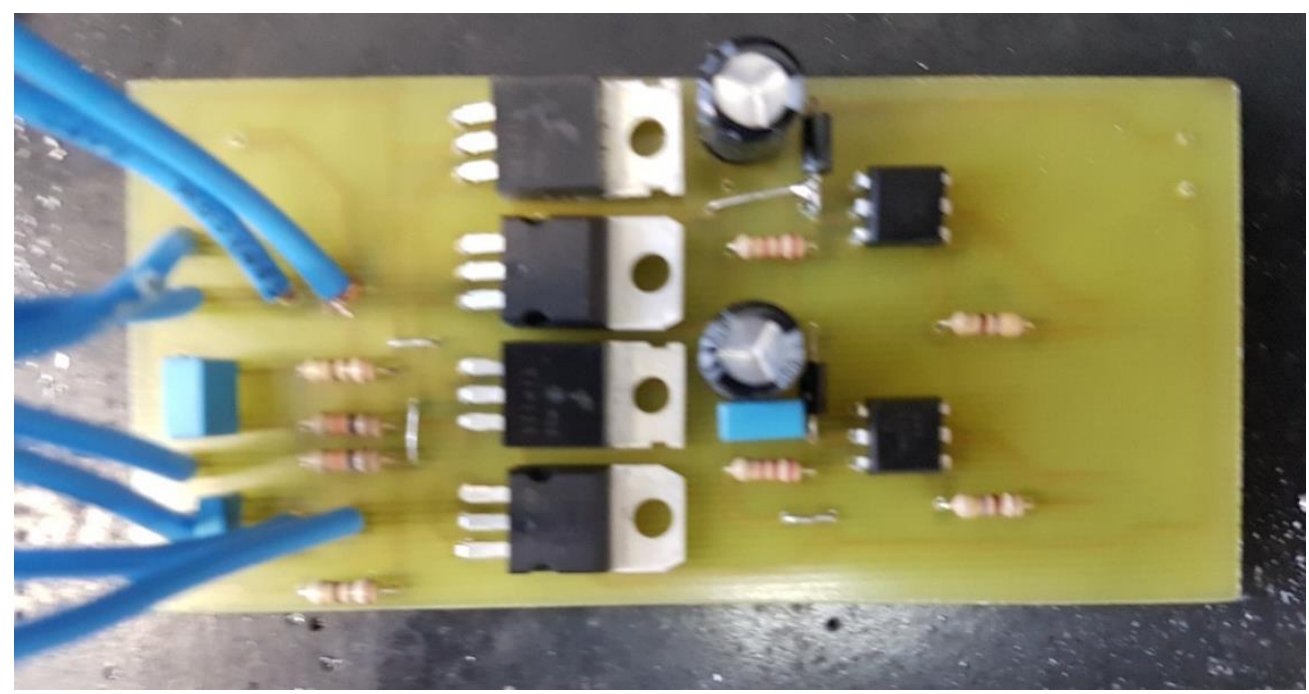

Figure 37 - The actual circuit of the high voltage signal, without the mosfet and transformer.

The circuit was then placed in a case with multiple connectors for easy operation (Figure 38).

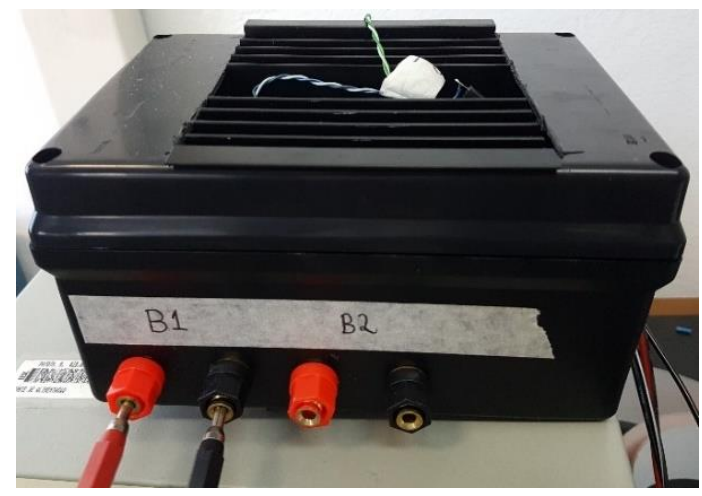

Figure 38 - High voltage circuit connector case.

The circuit output is then in need of high amplification. For this purpose an ignition coil found in Figure 39 was used. 


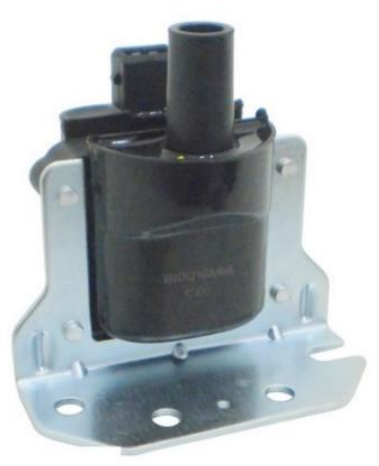

Figure 39 - Car ignition coil used as a high voltage transformer.

Ignition coils work on the transformer principle. They basically consist of a primary winding, a secondary winding, the iron core and a housing with isolation material, nowadays two-component epoxy resin. On the iron core of individual thin steel sheets two coil elements are applied e.g.: The primary winding is made of thick copper wire with approx. 160 windings. The secondary winding is made of thin copper wire with approx. 20,000 windings. The ignition coil properties are listed in Table 2.

\begin{tabular}{cc}
\hline PRIMARY & $0.200 \mathrm{ohms}(\Omega)$ \\
RESISTANCE & \\
\hline SECONDARY & $8,800 \mathrm{ohms}(\Omega)$ \\
RESISTANCE & \\
\hline MAXIMUM & 48,000 volts $(\mathrm{V})$ \\
VOLTAGE & \\
\hline TURNS RATIO & $132: 1$ \\
\hline
\end{tabular}

Table 2 - Electronic ignition coil characteristics. 
A square pulse signal is generated by a DSO-X 2002A Digital Storage Oscilloscope shown in Figure 40, with a square pulse of frequency of $10 \mathrm{kHz}$.

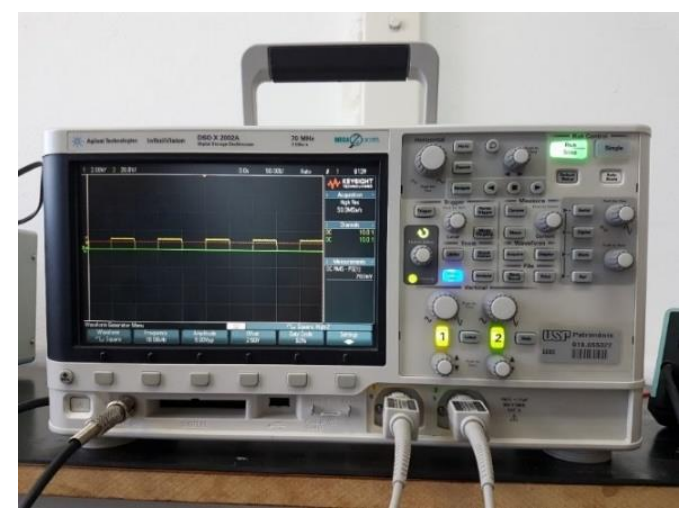

Figure 40 - Oscilloscope used for signal generator as input into the high voltage circuit,

\subsubsection{High Voltage Circuit Behavior And Calibration}

The Output voltage of the circuit is measured without the transformer in order to determine the behavior of the circuit. The result is shown in the Figure 41. The Yellow plot is the response measured after the MOSFET $V_{D S}$ while the Green line represents the voltage before it $V_{\text {Gs. }}$ 


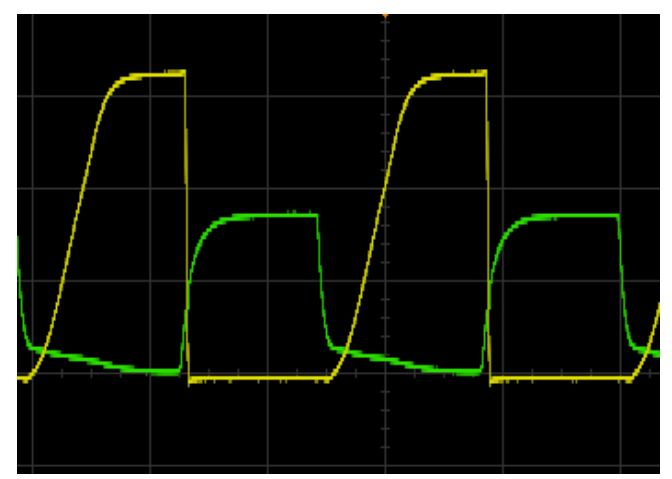

Figure 41 - Input and output signal without transformer.

Notice that the output response represents a very close similarity to the input signal with a high cutoff time which is important for synchronizing the two circuits later. Although the rise time is relatively slower compared to the cutoff, it will not be determinant in our experiment.

The same measurement was conducted with the transformer connected to the circuit. The result is shown in Figure 42.

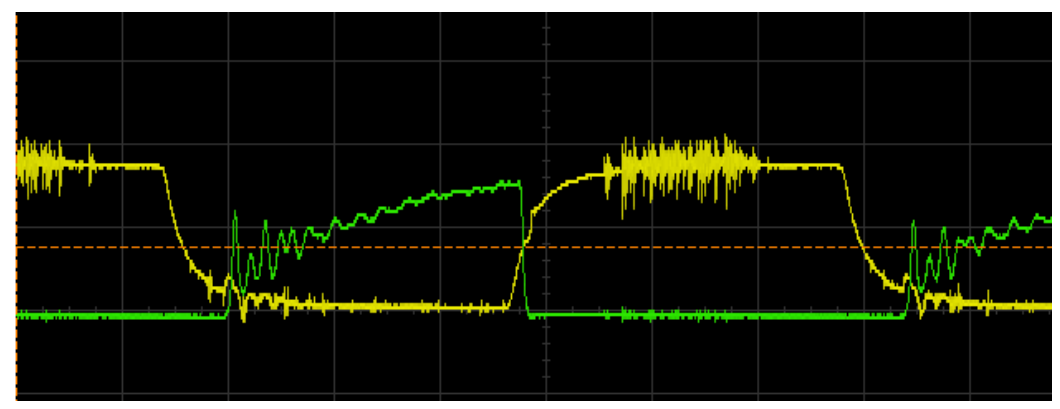

Figure 42 - Input and output signal with transformer. 
We can see that the discharge on the secondary part of the transformer is able to produce an interference easily visible on the signal. For this reason, a $15 \mathrm{nF}$ capacitor is added to filter out these high frequency interferences. The result is shown in Figure 43. (Here the signal is inverted only for better visualization)

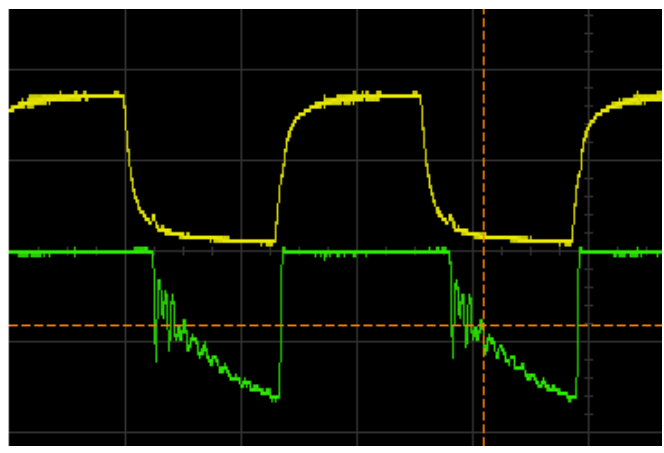

Figure 43 - Input and output signal with transformer and with filter applied.

\subsection{PITOT SETUP AND PRESSURE SENSOR CALIBRATION}

In order to obtain the velocity profile of the induced ionic wind, it was necessary of measure the pressure along the vertical axis at multiple distances from the electrodes. To accomplish this, the electromechanical positioner shown in Figure 44 and Figure 45 was constructed, where one can find the pitot mounted to a step motor that is controlled by an Arduino push button circuit. The motor steps where calibrated to have a vertical displacement of $0.5 \mathrm{~mm}$ per step. 


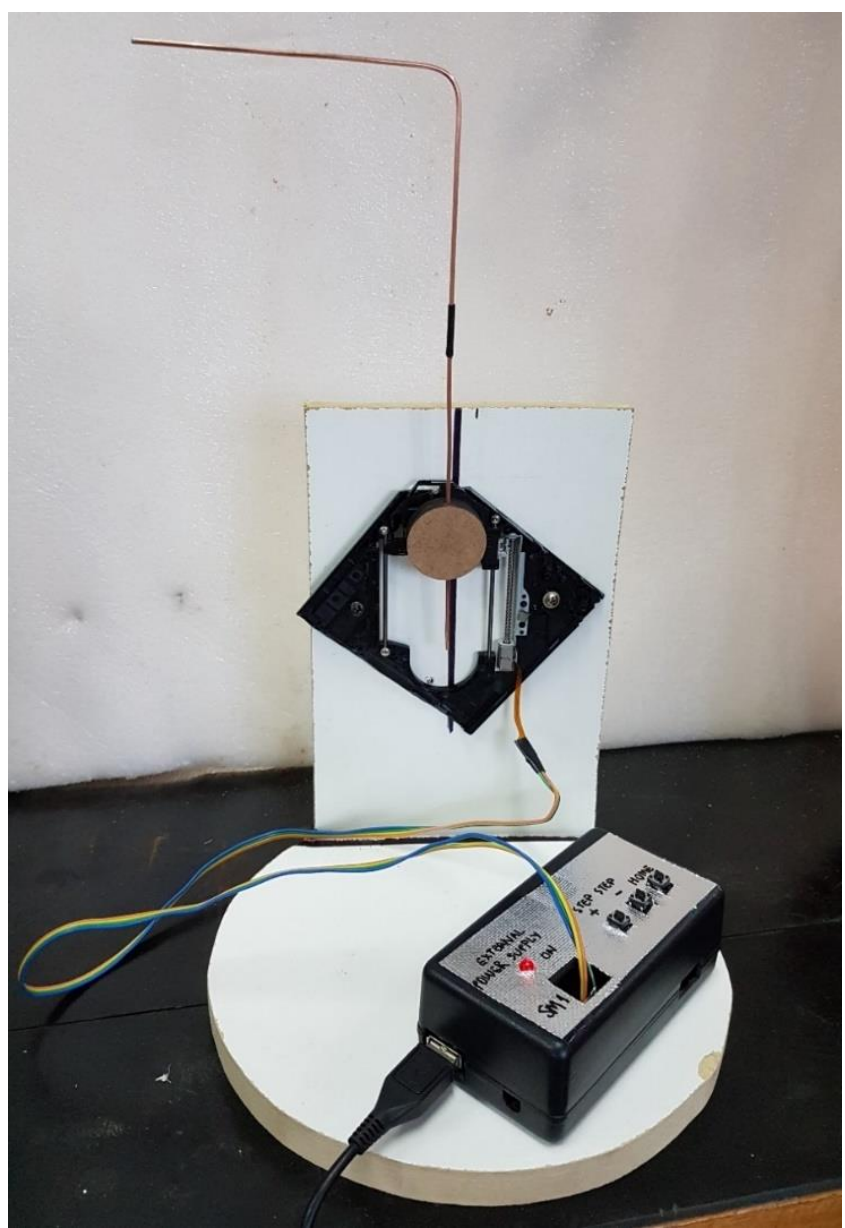

Figure 44 - Pitot mounted on the step positioner with the control interface. 


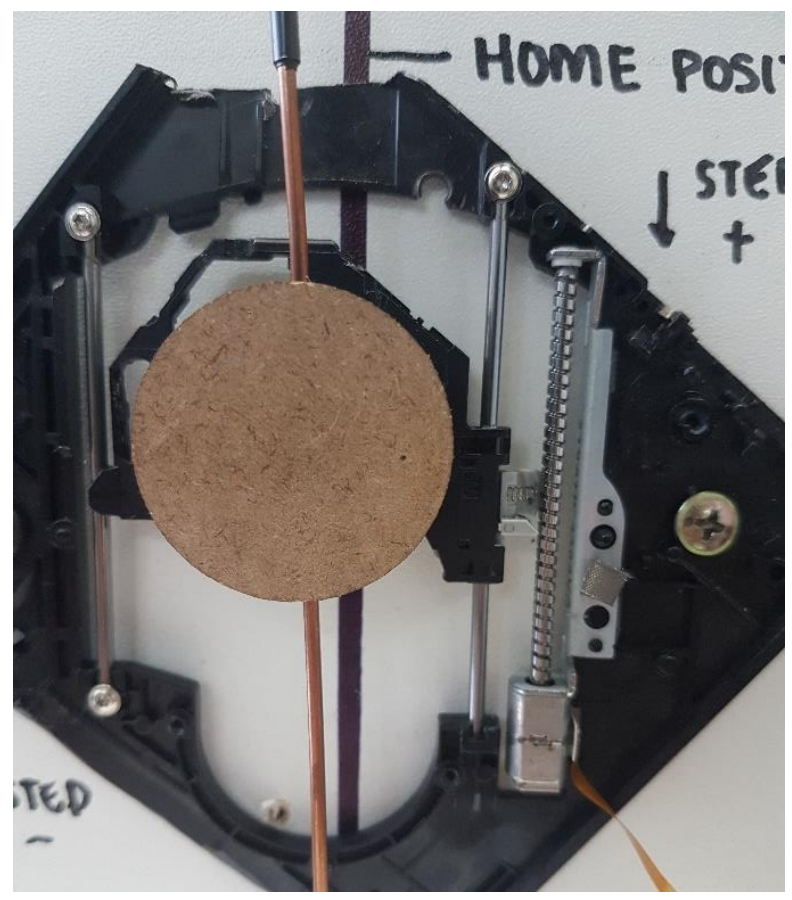

Figure 45 - The pitot tube mounted onto the shaft controlled by step motor on the right.

The back end of the pitot is connected to the pressure sensor that would record the pressure data in Volts. The pressure sensor used was an Amplified series of Low Pressure sensor with the specifications for working conditions and sensitivity listed in Table 3. The Amplified line of low pressure sensors are based upon a proprietary technology to reduce all output offset or common mode errors. This model provides a ratiometric 4-volt output with superior output offset characteristics. Output offset errors due to change in temperature, stability to warm-up, stability to long time period, and position sensitivity are all significantly reduced when compared to conventional compensation methods. In addition, the sensor utilizes a silicon, micromachined, stress concentration enhanced structure to provide a very linear output to measured pressure. These calibrated and temperature compensated sensors 
give an accurate and stable output over a wide temperature range. This series is intended for use with non-corrosive, non-ionic working fluids such as air, dry gases and the like. The output of the device is ratiometric to the supply voltage over a supply voltage range of 4.5 to 5.5 volts. The pressure sensor ratings are found in Table 3.

\section{Pressure Sensor Rating}

\begin{aligned} & \hline Supply Voltage VS +4.5 to $5.5 \mathrm{VDC} \\ &$\hline Common-mode pressure -10 to $+10 \mathrm{psig} \\ &$\hline $\begin{array}{r}\text { Lead Temperature, max } \\ \text { (soldering } 2-4 \mathrm{sec} \text { ) }\end{array} 250^{\circ} \mathrm{C} \\ &$\hline $\begin{array}{r}\text { Compensated Temperature } \\ \text { Range }\end{array} 5^{\circ}$ to $50^{\circ} \mathrm{C} \\ &$ Accuracy $0.05 \% \\ &$\hline $\begin{array}{r}\text { Humidity Limits Temperature } \\ \text { Range }\end{array} 0$ to $95 \% \mathrm{RH} \\ &$\hline Operating Temperature Range -25 to $85^{\circ} \mathrm{C} \\ &$\hline\end{aligned}

Table 3 - HDI pressure sensor specifications.

Figure 46 shows the final construction of the pressure sensor with the proper connections. 


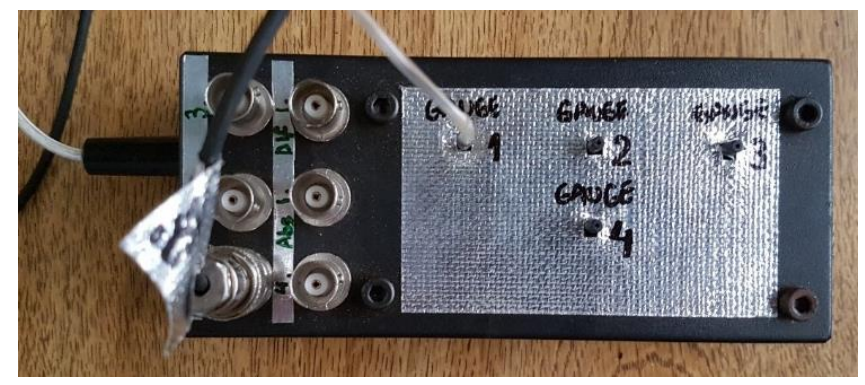

Figure 46 - Transducer reading the pitot Total and static pressure.

The pressure sensor output the goes into a transducer with a DAQ port (Figure 47) and was readily available at the department of Aeronautics at USP.

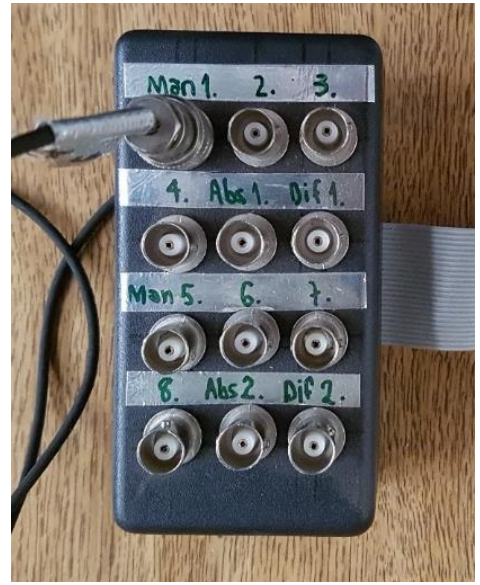

Figure 47 - Transducer with DAQ port 
The data acquisition was done by means of the NI 9214 (Figure 48), which is a highdensity thermocouple module for CompactDAQ and CompactRIO systems designed for use in higher-channel-count systems that also need high accuracy, the NI 9214 increases overall accuracy with a front-mount terminal block (TB-9214), several CJC sensors in the terminal block, and a component layout that minimizes thermal gradients.

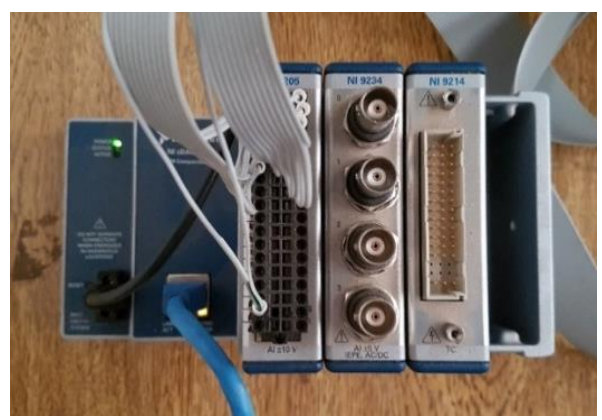

Figure 48 - DAQ NI9214 used for data acquisition.

\subsubsection{CALibration}

Before running the measurements, the sensor output signal needed calibration. The Calibration process involved running the wind tunnel available at the EESC department of aeronautics at increments of $50 \mathrm{rpm}$ while taking several measurements of the dynamic pressure using an electronic manometer (Figure 49) in parallel with the HDI pressure sensor with the set up mentioned above. 


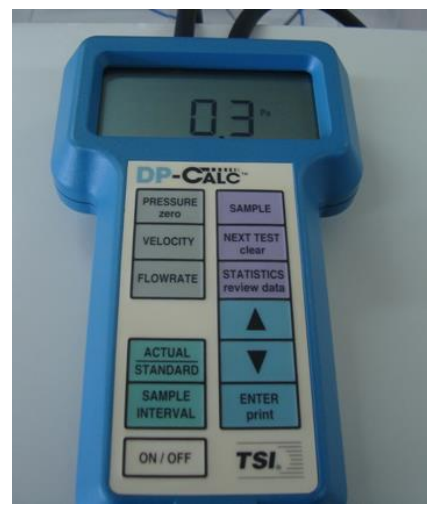

Figure 49 - Digital manometer used for calibration.

The pressure values from the manometer are then compared to the voltage measurements recorded by the HDI sensor. The results are shown below in Figure 50 and Figure 51. 


\section{Pressure sensor calibration}

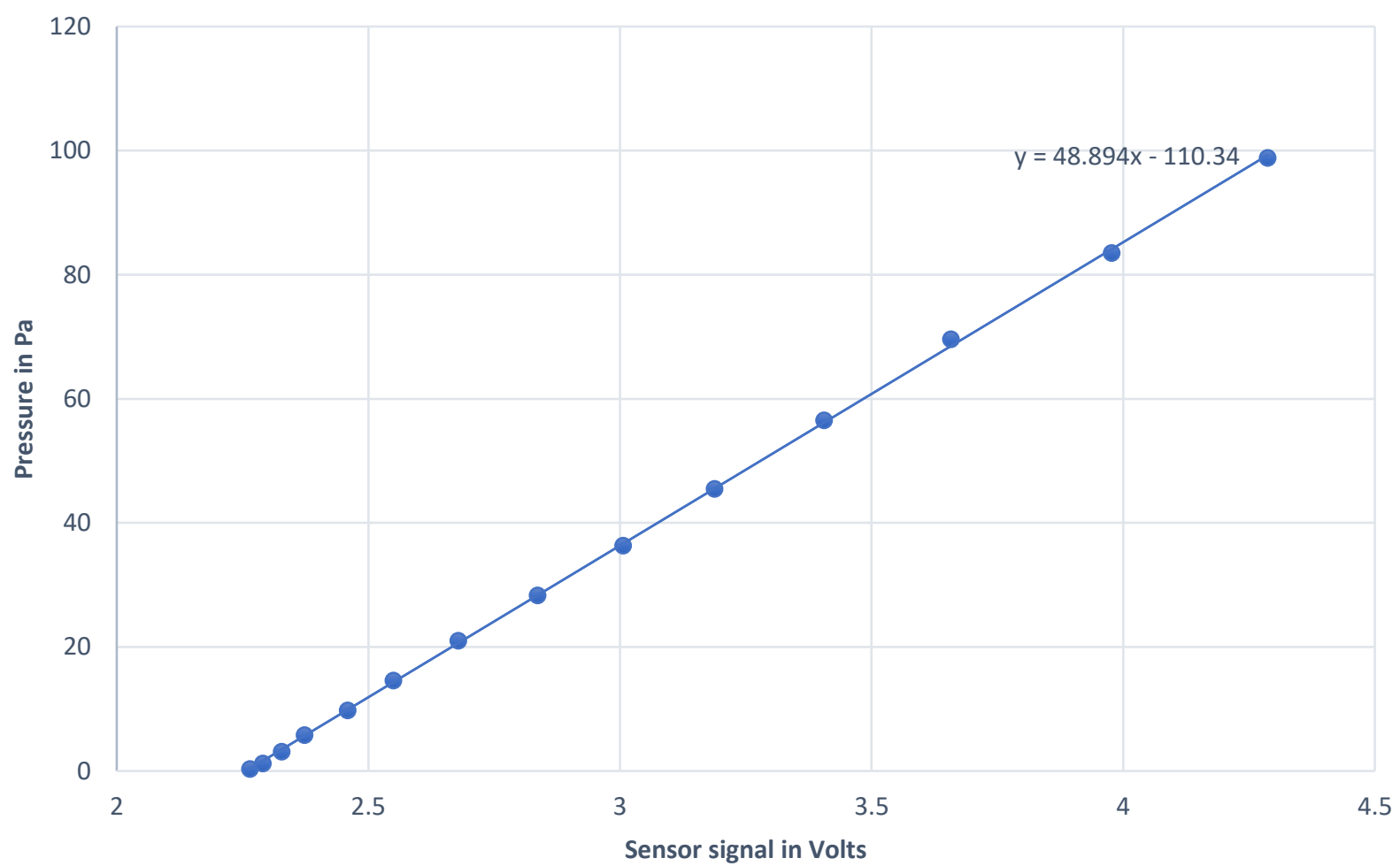

Figure 50 - curve fitting relating pressure sensor voltage to the dynamic pressure.

One can see clearly a very linear behavior of the pressure sensor. This shows a considerable sensitivity capable of capturing the low velocity fluctuations of the plasma jet. 


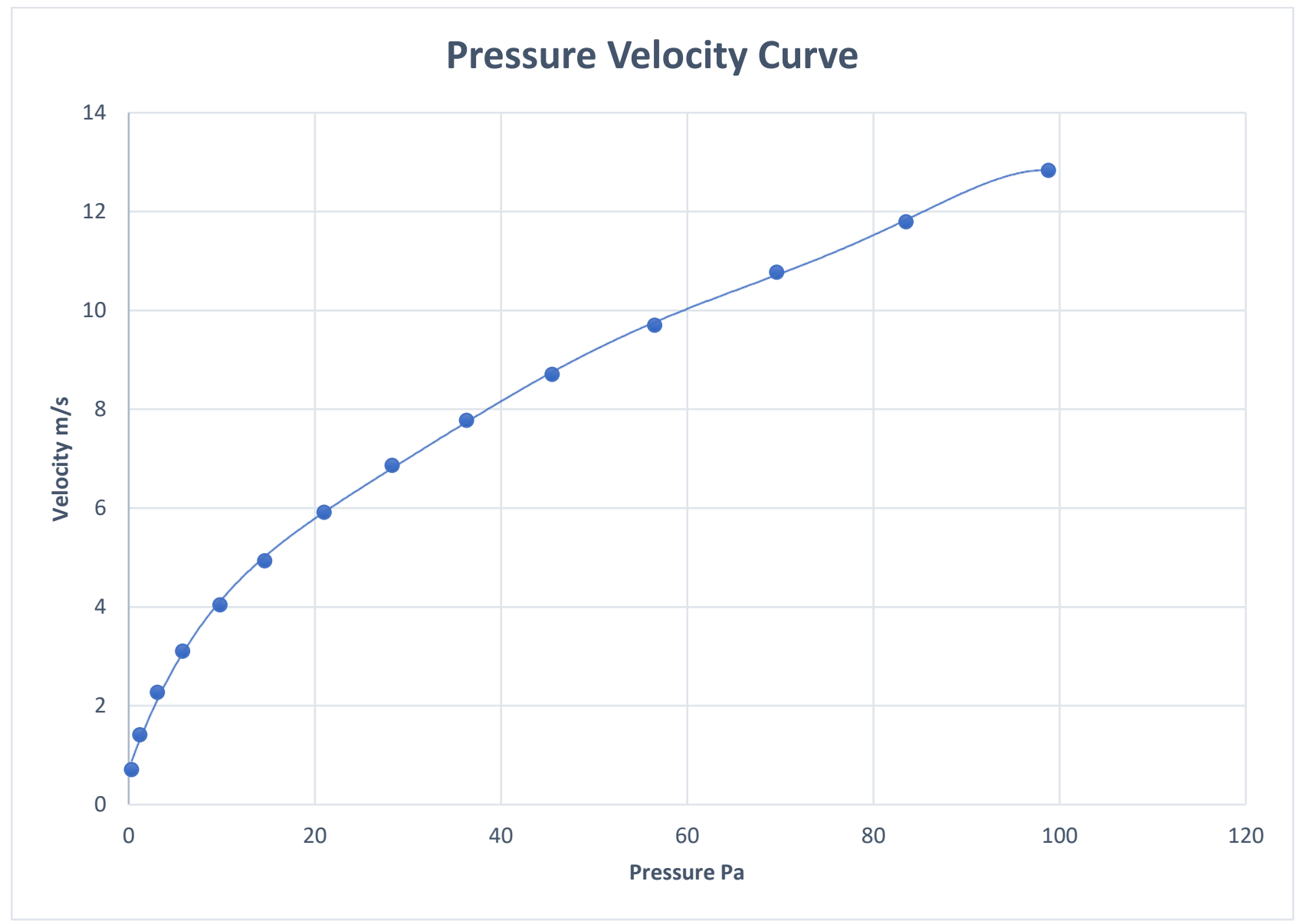

Figure 51 - calibration plot relating the wind speed to the pressure sensor voltage.

Here as well, the velocity curve exhibits a smooth profile adequate to our purpose. 


\subsubsection{Plasma ACtuator Set-Up And Configuration}

The Plasma actuator was made of this copper foils coupled asymmetrically with 3 layers of Kapton tape in between. The electrode length was $10 \mathrm{~cm}$ with the cathode (exposed electrode) having a width of $5 \mathrm{~mm}$ and the anode having $10 \mathrm{~mm}$, with about $2 \mathrm{~mm}$ gap in between. the third electrode was also exposed and had a width of $15 \mathrm{~mm}$. this is shown in Figure 52 below.

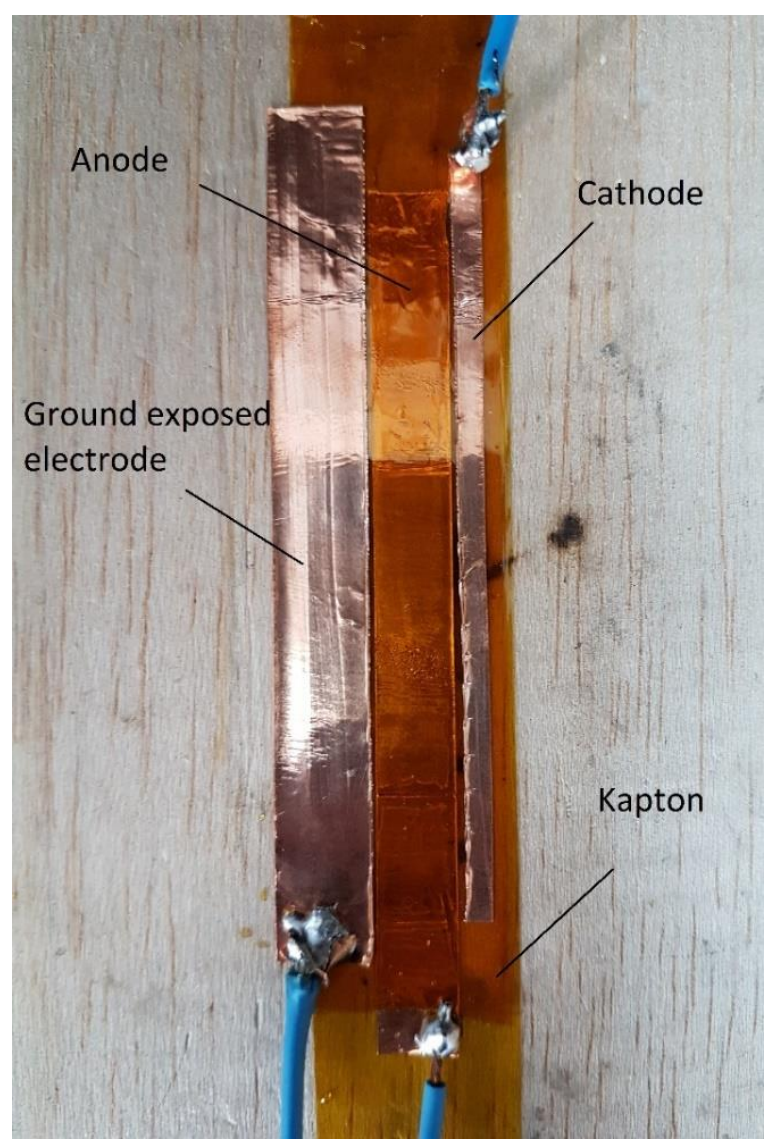

Figure 52 - Plasma actuator configuration. 
When the system is on, the discharge happens at the edge of the cathode with concentrates filaments along the columns as shown in the Figure 53 below.

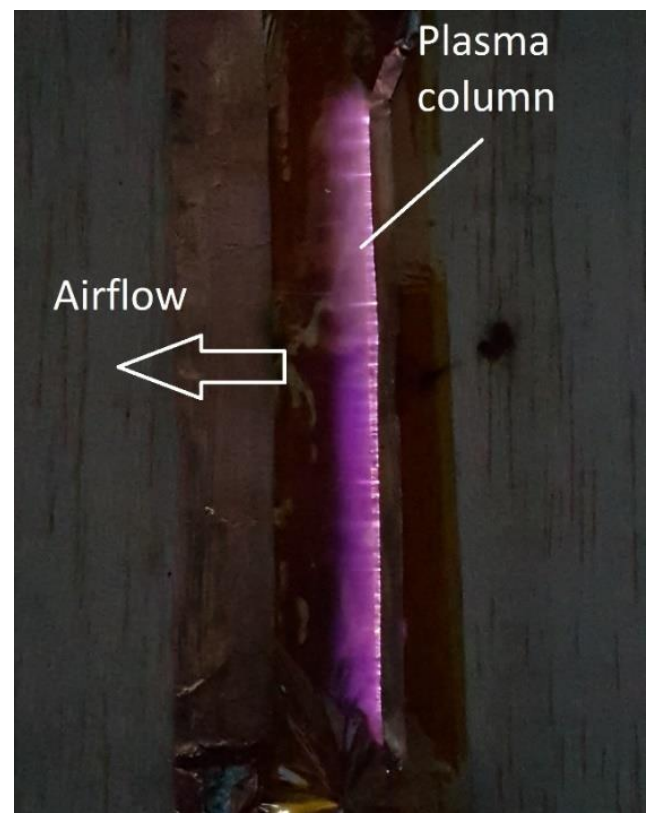

Figure 53 - Plasma filamentary formation at the cathode edge. The airflow is in the direction of the covered electrode.

The schematic in Figure 54 shows the setup clearly. 


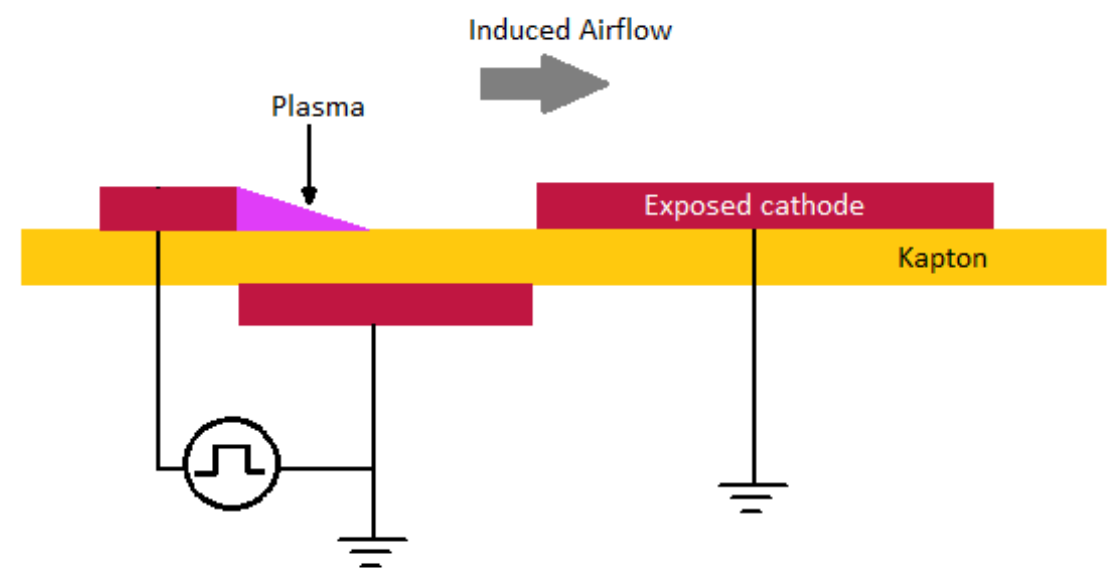

Figure 54 - Schematic showing the actuator configuration.

The voltage and current supply recorded by the voltage generator was of 31.4 Volts and 0.57 Amperes as shown in Figure 55.

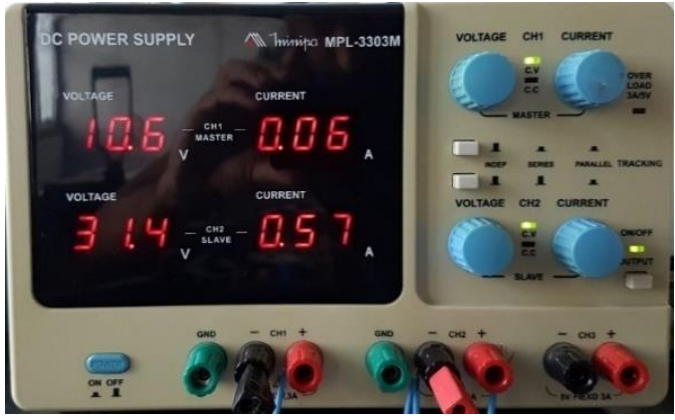

Figure 55 - Plasma actuator electric consumption. the display shows the Voltage and current delivered into the primary coil of the transformer. 
In the experiment, the pressure measurements made with the constructed pitot (mentioned in the earlier section) were taken at 3 distances from the edge of the first electrode: $5 \mathrm{~mm}, 10 \mathrm{~mm}$, and $15 \mathrm{~mm}$. For each $\mathrm{x}$-position, the pressure profile is then measured in the vertical y direction in increments of $0.5 \mathrm{~mm}$. This is demonstrated in Figure 56 and Figure 57.

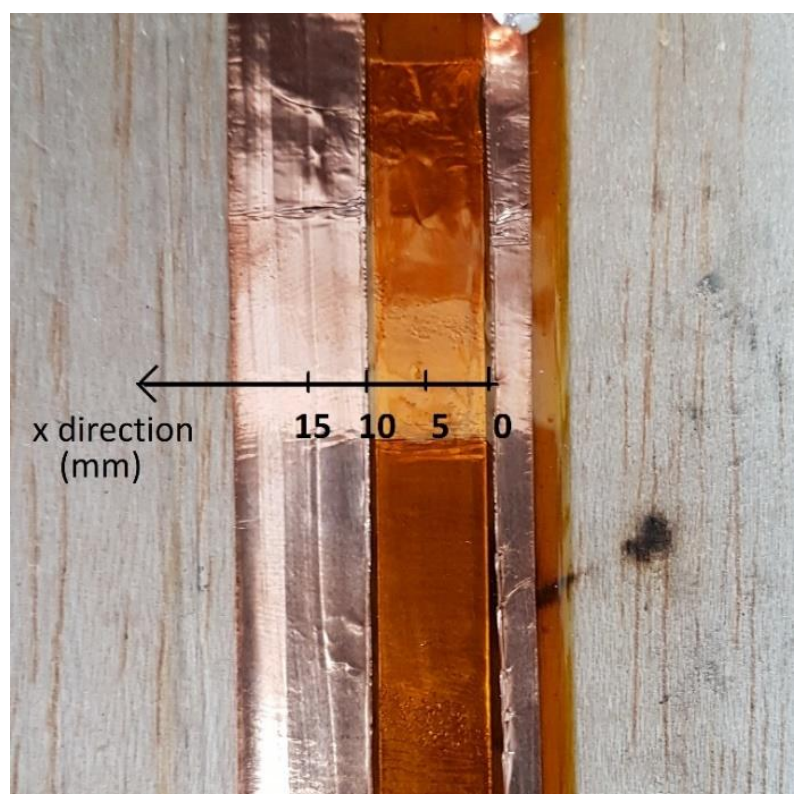

Figure 56 - Spatial discretization in the $\mathrm{x}$ direction. 


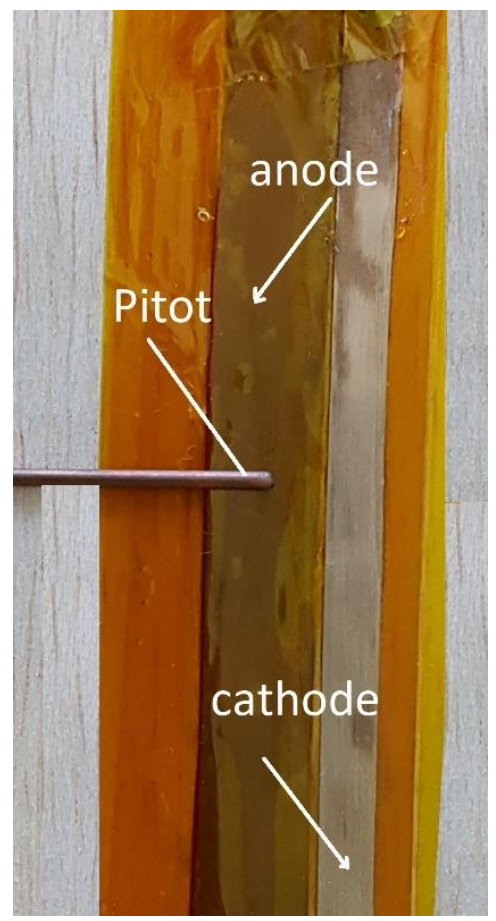

Figure 57 - Showing the pitot placement for pressure measurements for a two electrode DBD discharge. 


\section{Experimental Conditions And Results}

The measurements were taken at a humidity level varying between $32 \%$ and $65 \%$, temperature between 20 and 27 degrees Celsius, and an atmospheric pressure between 916.1 hPa and $1017.1 \mathrm{hPa}$. The pressure acquisition is set to 200000 samples per second, and the acquisition time is 5 seconds.

The flow speed was calculated from the incompressible fluid relation between the dynamic pressure and the flow velocity,

$$
p=\frac{1}{2} \rho u^{2}
$$

where (using SI units):

$\mathrm{p}=$ dynamic pressure in pascals,

$\rho=$ fluid density in $\mathrm{kg} / \mathrm{m} 3$

$\mathrm{u}=$ flow speed in $\mathrm{m} / \mathrm{s}$.

and the air density is calculated from the ideal gas law:

$$
\rho=\frac{p}{R_{\text {specific }} T}
$$

$\rho=\operatorname{air}$ density $\left(\mathrm{kg} / \mathrm{m}^{3}\right)$

$\mathrm{p}=$ absolute pressure $(\mathrm{Pa})$ 
$\mathrm{T}=$ absolute temperature $(\mathrm{K})$

Rspecific $=$ specific gas constant for dry air $(\mathrm{J} /(\mathrm{kg} \cdot \mathrm{K}))=287.058 \mathrm{~J} /(\mathrm{kg} \cdot \mathrm{K})$

A typical good measurement showed a uniform distribution of voltage values along the time axis as in Figure 58. It is important to check if there are any unusual oscillations in the measured data, being from electromagnetic interference or construction error that can lead to disturbances in the discharge.

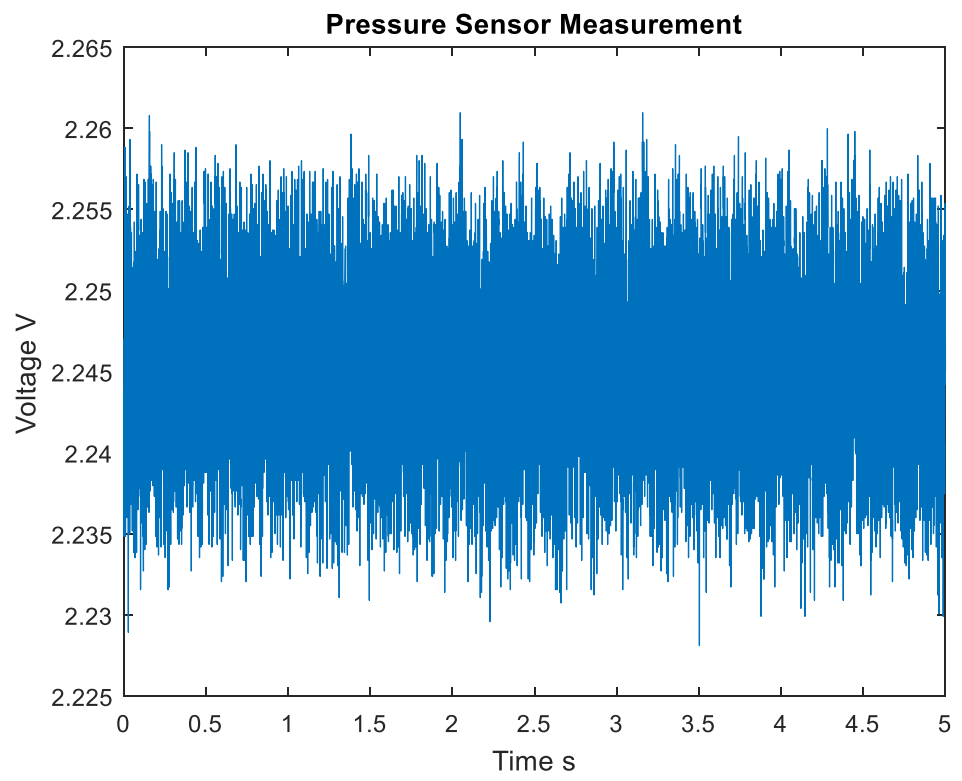

Figure 58 - Sample measurement displaying acquisition over 5 seconds of 200,000 samples. 
We can see how these uniform measurements can be translated into a normal distribution if plotted as a function of frequency in Figure 59. This is a very good indication that our measurements are as precise as we are able to get.

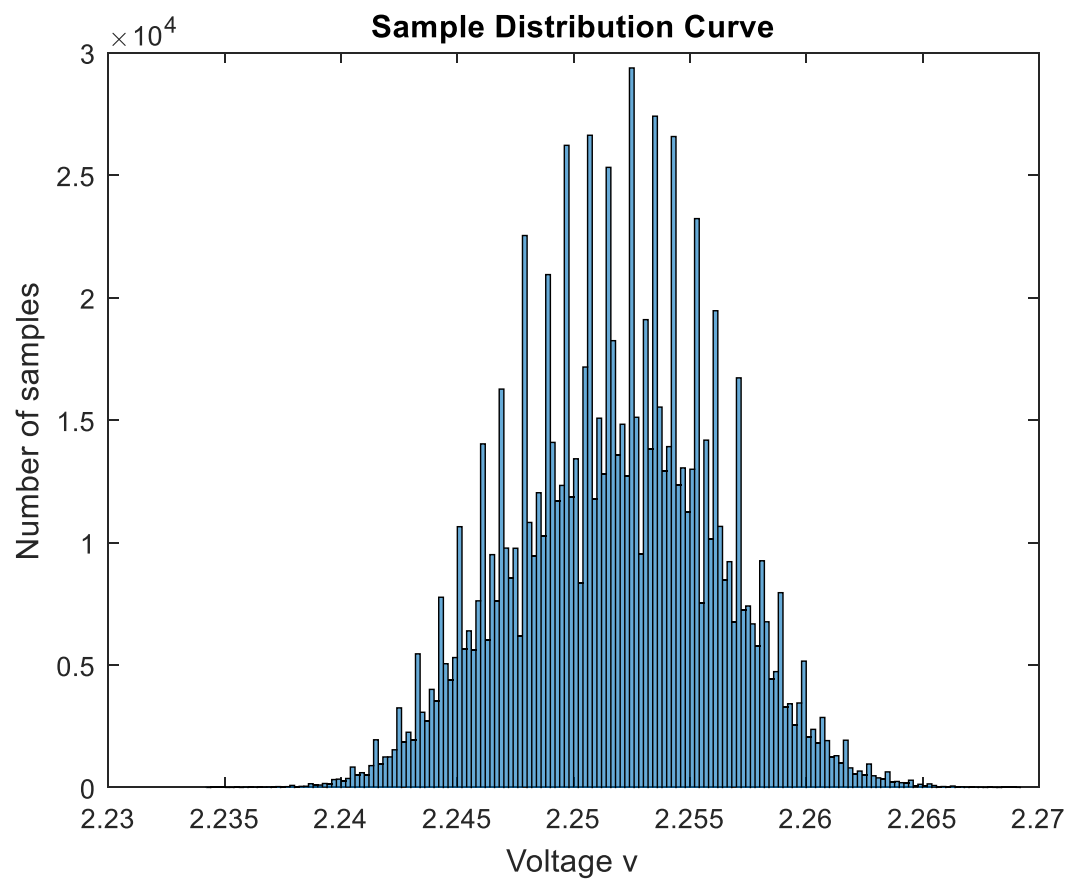

Figure 59 - sample distribution showing a normal curve distribution

In the experiment, there were two major difficulties in obtaining the right measurements. First, after the discharge had been on for a few minutes, an air bubble would start do develop from beneath the kapton tape bulging out of the actuator as seen in Figure 60. 


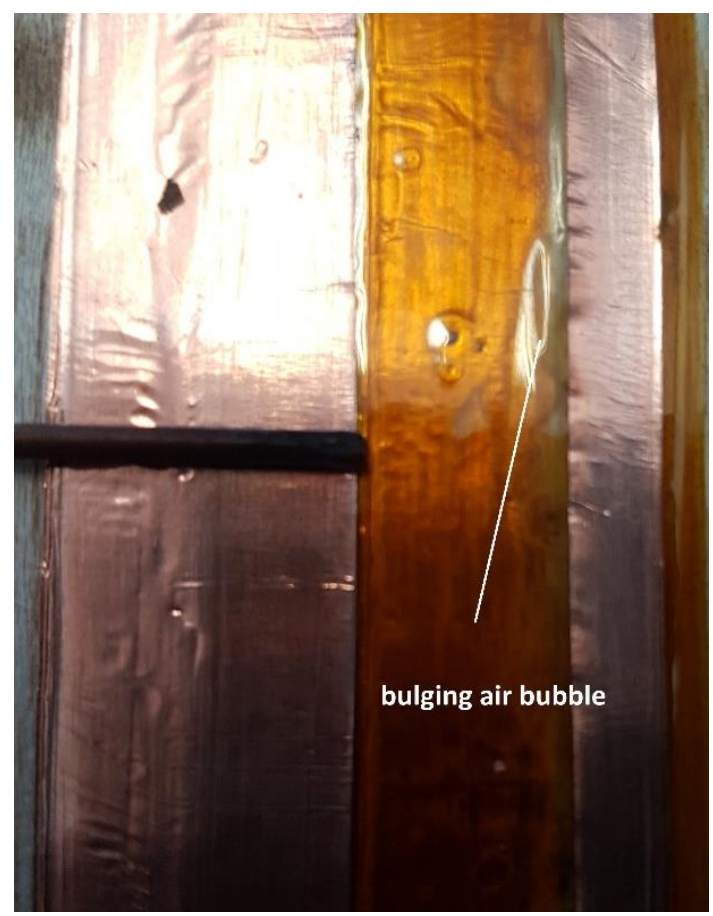

Figure 60 - Bulging air bubble at the plasma discharge regime.

This happens as heat buildup occurs at points were the thermos-ionic emission grows considerably. At this particular point, due to the physical deformation, the discharge becomes weaker and there is a sudden drop in the induced flow velocity. The effect of this bulging was also observed in the voltage data measurements as big oscillations as seen in Figure 61. At this point, the actuator had to be reconstructed and the measurements rerun. 


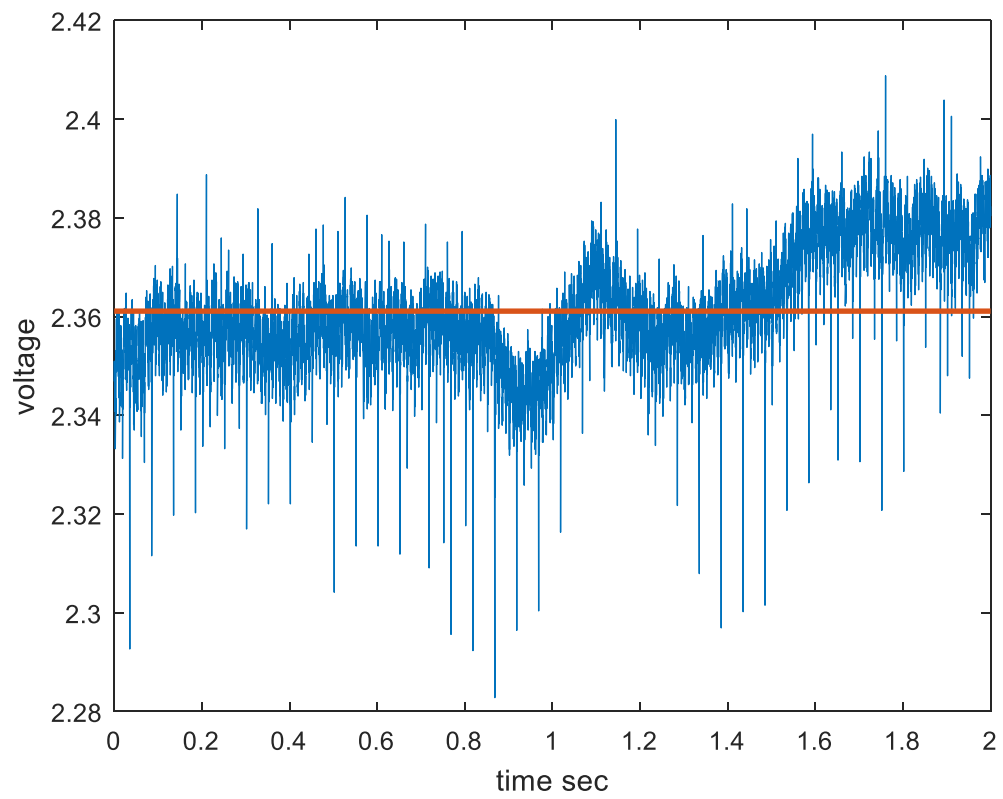

Figure 61 - Voltage measurement oscillation due to bubble formation at the plasma sheath.

Another important and recurring issue with experiment was the formation of an arc and the cessation of the glow discharge. At certain points were the thermos-ionic emissions get high enough, the excess heat causes the formation of an electric arc. This is a high current arc that rips through the Kapton layers and find its way to the anode, Figure 62. When this happens, plasma formation stops and the actuator needs to be reconstructed. 


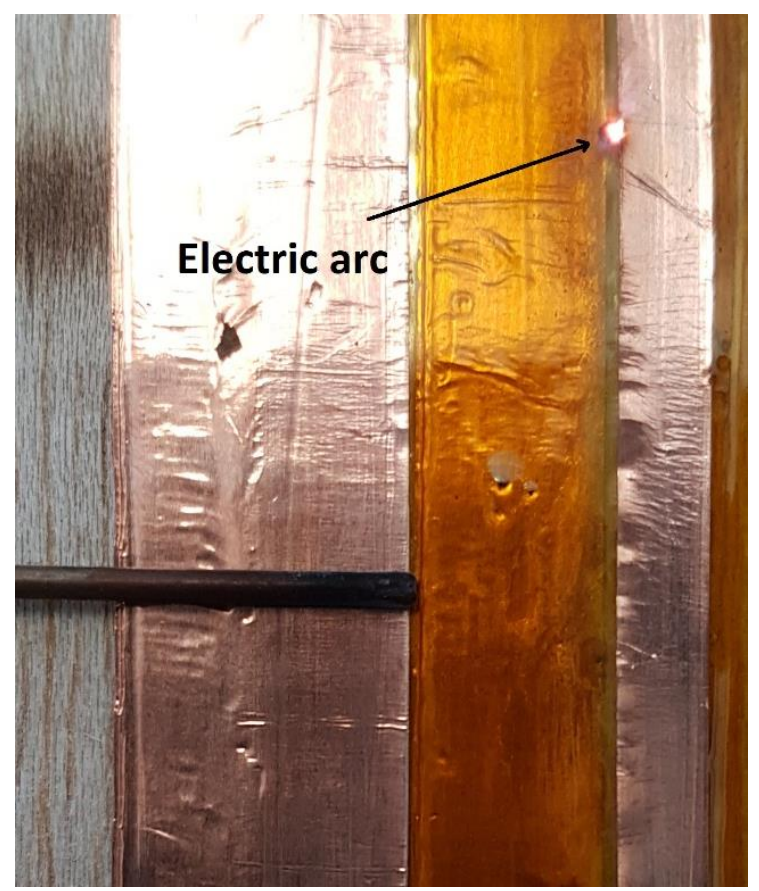

Figure 62 - The electric arc formation at high thermo-ionic emission points.

The pressure graph in volts, Figure 63, shows clearly this abrupt stop in the flow production. 


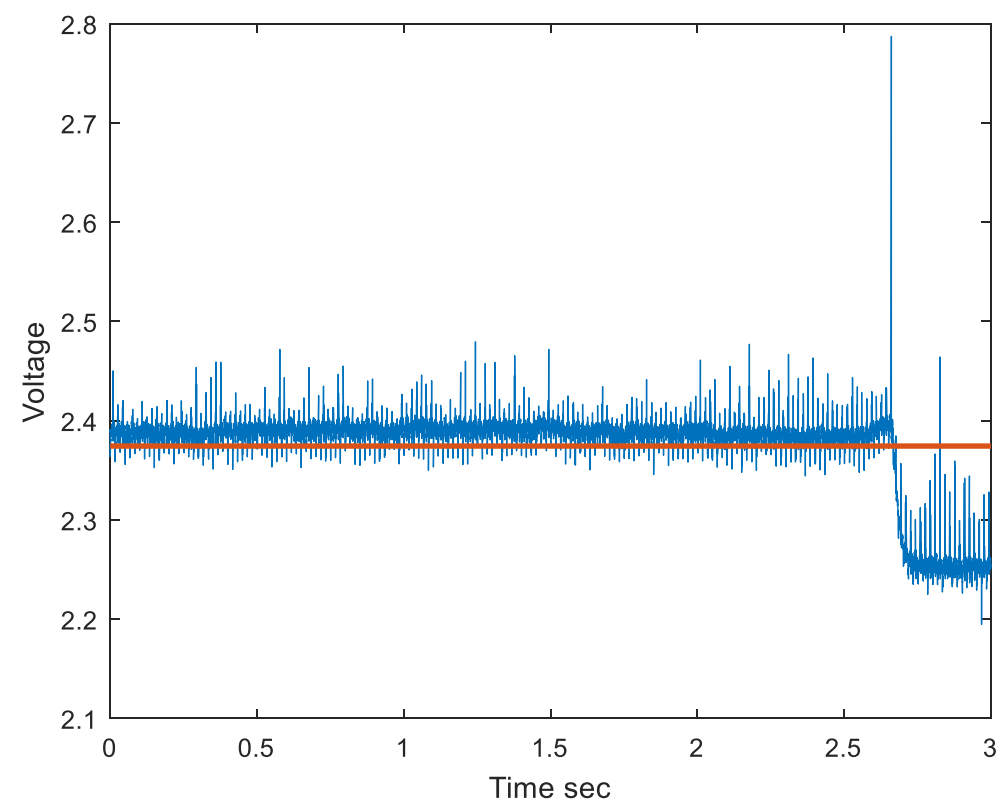

Figure 63 - Pressure measurement showing a total cessation of air flow due to arcing.

After many trials and actuators reconstructions, the measurements needs were successfully taken. First, surface measurements were taken at $\mathrm{x}=10 \mathrm{~mm}$, both with 2 and 3electrode configurations. The plot in Figure 64 reports the velocity at different frequencies along with the input power per electrode length consumed at each frequency. 


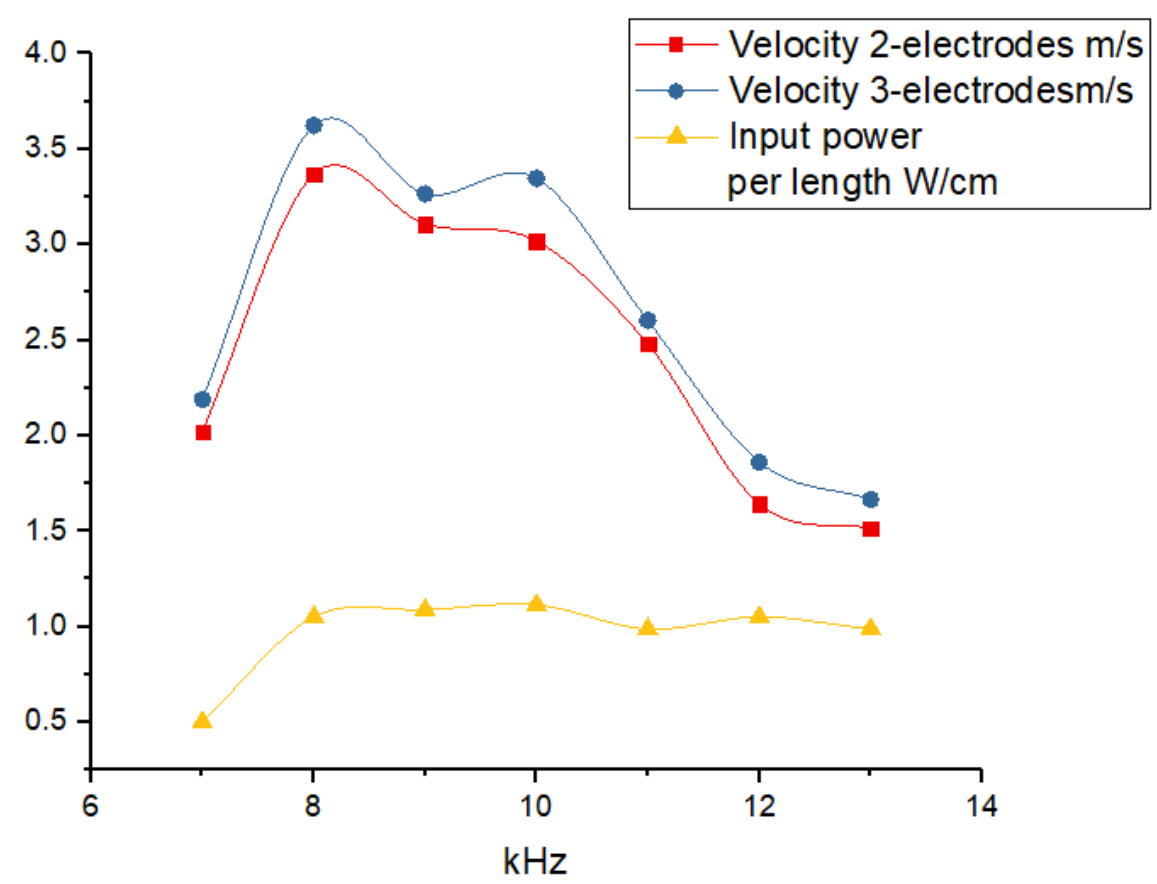

Figure 64 - Velocity plot comparison for 2 and 3-electrode configurations for several frequencies, along with the input power.

We can see a dominant behavior of the 3-electrode configuration for all frequencies. However, at certain frequencies, the effect of the third electrode is more prominent, i.e. inducing a higher velocity, with a peak velocity at $8 \mathrm{kHz}$. It was a bit challenging to proceed and take vertical velocity profiles as $8 \mathrm{kHz}$ because of the more intense discharge that would cause an electric arc very frequently. Instead, measurements were taken at the less intense $9 \mathrm{kHz}$. The pressure was measured from the electrode surface $(0.5 \mathrm{~mm}$ due to pitot offset $)$ to a vertical distance of $6 \mathrm{~mm}$ at an interval of $0.5 \mathrm{~mm}$. The results in Figure 65, Figure 66, and Figure 67 show the velocity plot at $x=5 \mathrm{~mm}, x=10 \mathrm{~mm}$, and $x=15 \mathrm{~mm}$. The precision of the values has $95 \%$ certainty in an average interval of $0.04 \mathrm{~m} / \mathrm{s}$. The Certainty interval for each point on the vertical y axis is shown in Table 4. 


\begin{tabular}{cl}
\hline Y mm & $\begin{array}{c}\text { Interval } \\
\mathbf{m} / \mathbf{s}\end{array}$ \\
\hline $\mathbf{0 . 5}$ & 0.03501 \\
\hline $\mathbf{1}$ & 0.03289 \\
\hline $\mathbf{1 . 5}$ & 0.0367 \\
\hline $\mathbf{2}$ & 0.04161 \\
\hline $\mathbf{2 . 5}$ & 0.05376 \\
\hline $\mathbf{3}$ & 0.07494 \\
\hline $\mathbf{3 . 5}$ & 0.08522 \\
\hline $\mathbf{4}$ & 0.10985 \\
\hline $\mathbf{4 . 5}$ & 0.11785 \\
\hline $\mathbf{5}$ & 0.12185 \\
\hline $\mathbf{5 . 5}$ & 0.12571 \\
\hline $\mathbf{6}$ & 0.12102 \\
\hline
\end{tabular}

Table 4 - Interval of confidence of $95 \%$ for jet speed measurements on the y axis.

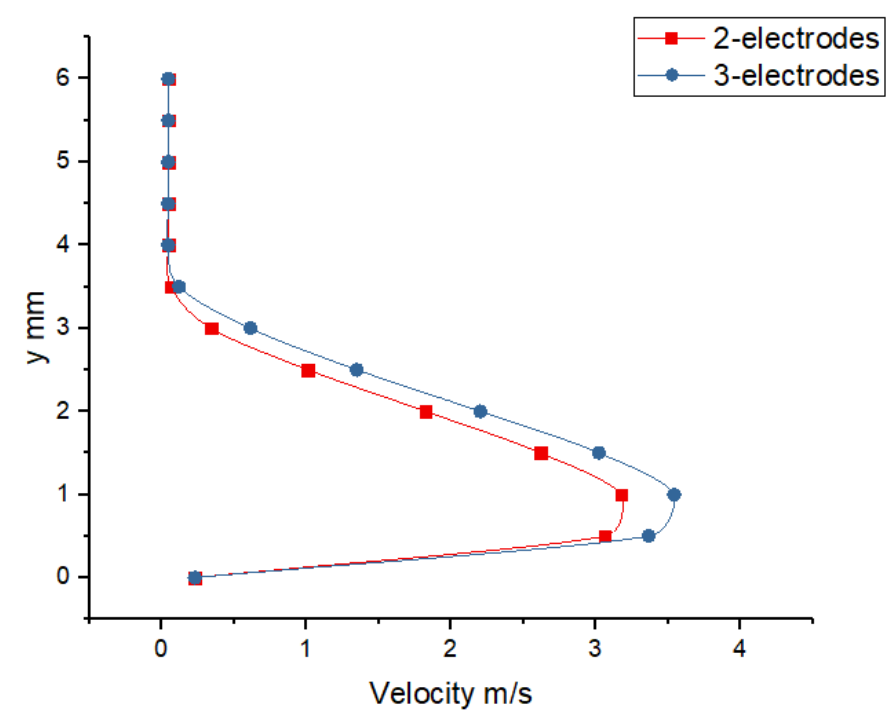

Figure 65 - $\mathrm{x}$-velocity profile in $\mathrm{m} / \mathrm{s}$ along the $\mathrm{y}$ direction in $\mathrm{mm}$ for both configurations at $\mathrm{x}=5 \mathrm{~mm}$. 


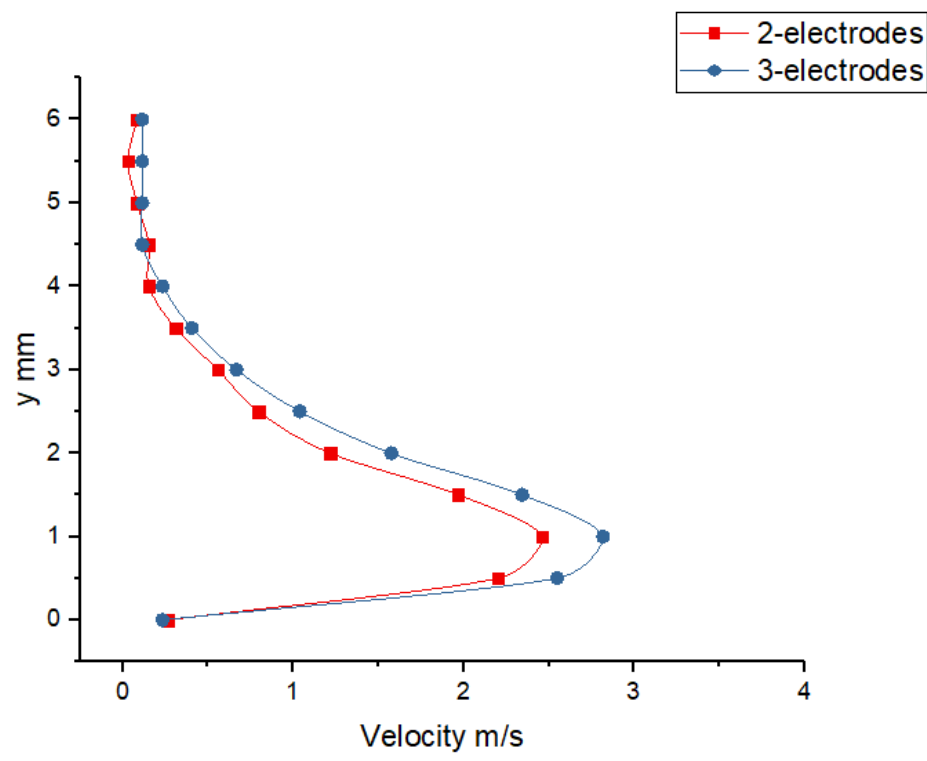

Figure 66 - $\mathrm{x}$-velocity profile in $\mathrm{m} / \mathrm{s}$ along the $\mathrm{y}$ direction in $\mathrm{mm}$ for both configurations at $\mathrm{x}=10 \mathrm{~mm}$.

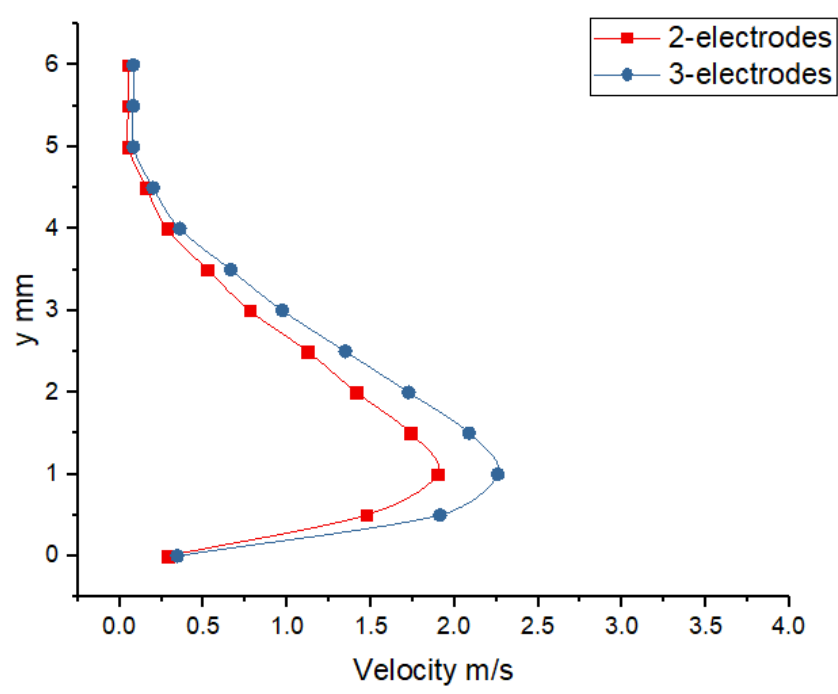

Figure 67 - $\mathrm{x}$-velocity profile in $\mathrm{m} / \mathrm{s}$ along the y direction in $\mathrm{mm}$ for both configurations at $\mathrm{x}=20 \mathrm{~mm}$. 
We can see that the flow profile exhibits a peculiar and interesting curve. The flow velocity is fastest near the wall along the surface, while diminishing in altitude for about 3 to $4 \mathrm{~mm}$. The velocity profiles show a consistent velocity gain when using the 3-electrode configuration. In our calculations, the relative error grew as y increased. This is due to the low, almost zero, velocity values for which any small disturbance can exhibit a considerable relative change.

For the values of $\mathrm{x}$ (distance from the cathode edge), the flow thickness appears to grow at a constant value as is expected due to viscous forces acting on the free jet flow. All three velocity curves decay between $y=3 \mathrm{~mm}$ and $y=5 \mathrm{~mm}$. Moreover, the velocity profiles at the three $\mathrm{x}$ distances is plotted in Figure 68 for visualization of the flow evolution in space.

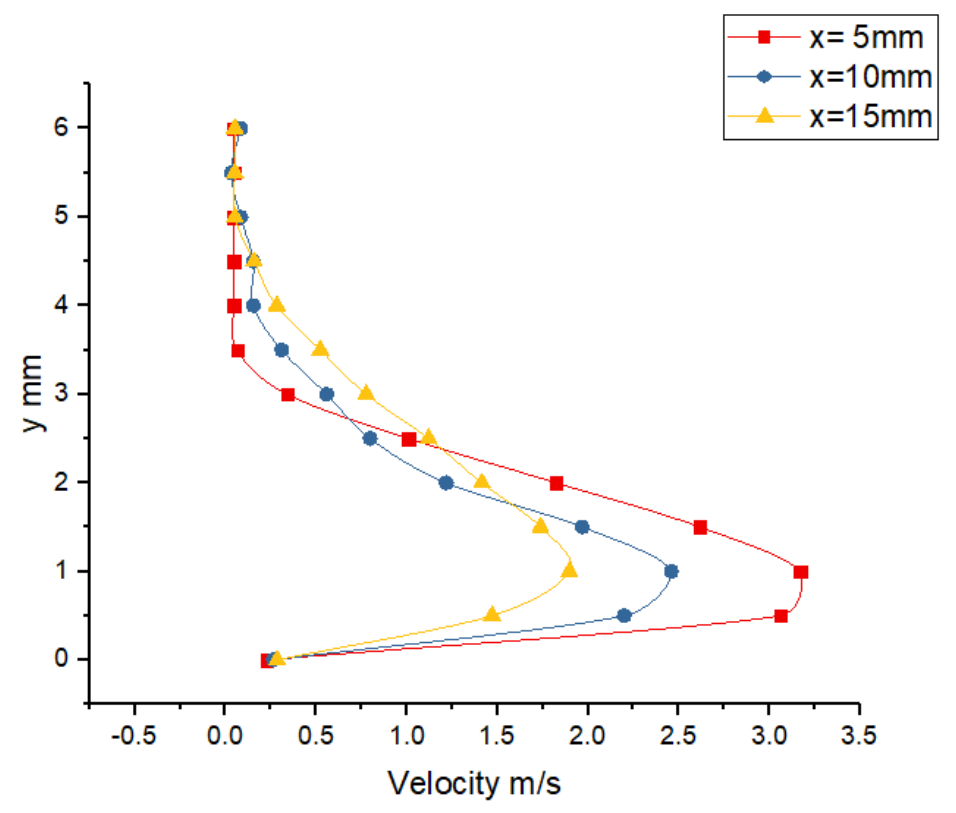

Figure 68 - Velocity profile evolution in x-direction. 


\subsection{Power ANd Efficiency Calculations}

The input power of the plasma actuator per unit length of Electrode could be calculated according to function,

$$
P_{i}=\frac{1}{t \cdot L} \int V(t) I(t) d t
$$

where $\mathrm{V}$ is the Voltage function and I the current function. The Input to the primary coil of the transformer is supplied by the DC voltage controlled by a transistor switch operating at $50 \%$ duty cycle. Then the Power input is simply: $V \cdot I \cdot 0.5=30 \cdot 0.5 \cdot 0.5=7.5 \mathrm{~W}$. Having a length of $10 \mathrm{~cm}$, the Power input per unit length becomes $0.75 \mathrm{~W} / \mathrm{cm}$.

The Work done by the actuator on the fluid can be reasoned by the following manner.

$$
P_{o}=\int \frac{F \cdot d s}{d t}=\int \frac{v d m \cdot d s}{d t \cdot d t}
$$

having

$$
\begin{gathered}
\frac{v d m}{d t}=\frac{1}{2} \rho v d a v=\frac{1}{2} \rho v^{2}(l d y) \\
\frac{d s}{d t}=v
\end{gathered}
$$

where $\mathrm{l}$ is the length of the electrode and $\mathrm{y}$ is the vertical distance.

We get 


$$
P_{o}=\frac{1}{2} \int_{y} \rho l v^{3} d y=\frac{1}{2} \int_{y} \rho l v^{3} d y
$$

And the power per length of electrode is

$$
P_{o}=\sum_{0}^{y} \frac{1}{2} \rho y v^{3}
$$

This is calculated from the velocity graphs, where for every length $y$, the corresponding velocity is used. The power is calculated for both electrode configurations and for all $3 \mathrm{x}$-positions. The Results are shown below in Table 5.

The efficiency $\mu$ is then calculated by: $\mu=\frac{P_{o}}{P_{i}}$

\begin{tabular}{c|ccc} 
& $\begin{array}{c}\text { Po for } 2 \\
\text { electrodes } \mathbf{W} / \mathbf{c m}\end{array}$ & $\begin{array}{c}\text { Po for 3 } \\
\text { electrodes } \mathbf{W} / \mathbf{c m}\end{array}$ & Power gain \\
\hline X=5mm & 0.0325 & 0.0412 & $26.61 \%$ \\
$\mathbf{X = 1 0 m m}$ & 0.0204 & 0.0274 & $34.32 \%$ \\
$\mathbf{X = 1 5 m m}$ & 0.00793 & 0.0117 & $47.54 \%$
\end{tabular}

Table 5 - Output Power values for the different configurations

A graphical representation of the power values of the induced jet by the 2-electrode and 3-electrode configuration is shown in Figure 69. 


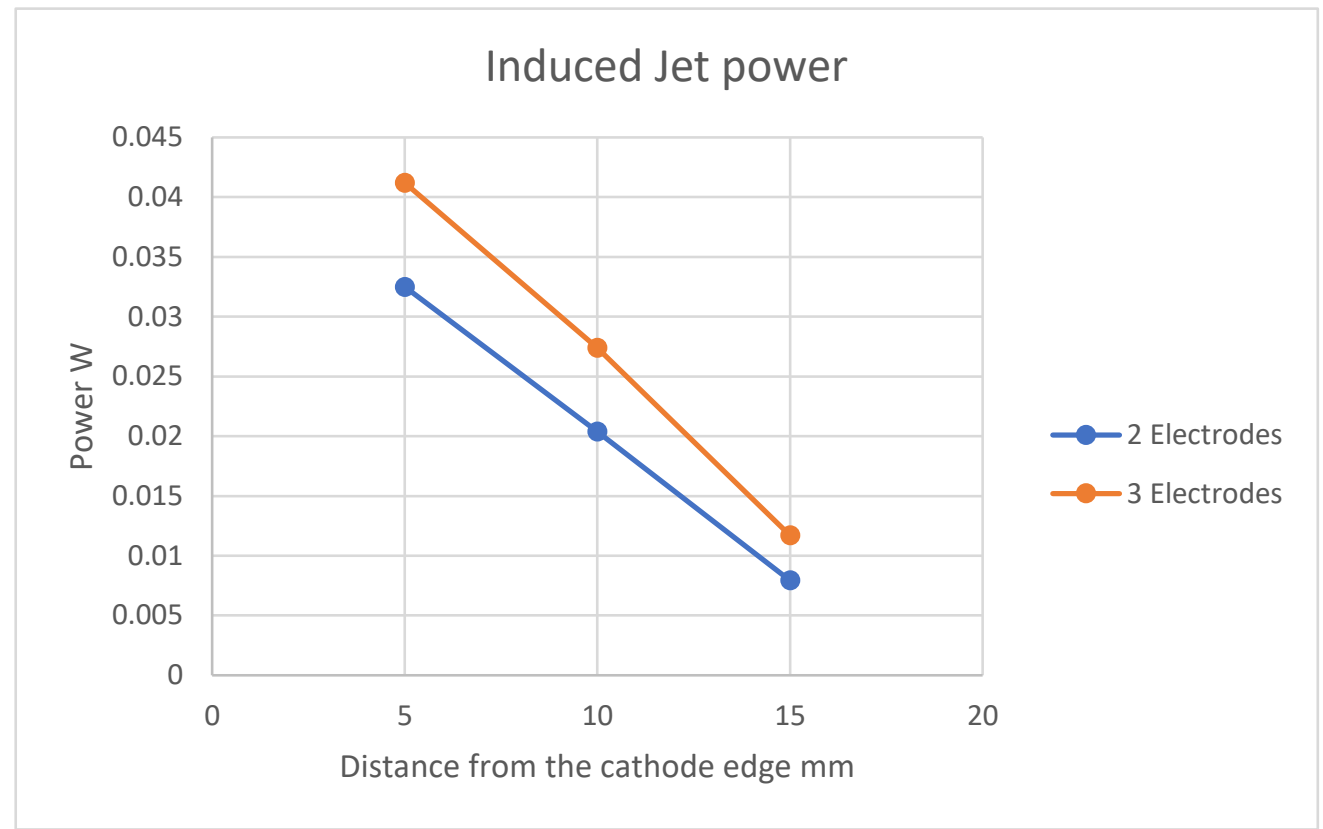

Figure 69: A graphical comparison between the power of the induced jet with both configurations.

As for the efficiency, the calculated results for both configurations are listed in the Table 6.

\begin{tabular}{l|cc} 
& $\boldsymbol{\mu}$ for $\mathbf{2}$ electrodes & $\boldsymbol{\mu}$ for $\mathbf{3}$ electrodes \\
\hline $\mathbf{X}=\mathbf{5 m m}$ & $0.0433 \%$ & $0.0549 \%$ \\
$\mathbf{X}=\mathbf{1 0 m m}$ & $0.0272 \%$ & $0.0365 \%$ \\
$\mathbf{X}=\mathbf{1 5 m m}$ & $0.0106 \%$ & $0.0156 \%$
\end{tabular}

Table 6 - Output Efficiency values for the different configurations 
Although the relative efficiency gain is higher downstream, the absolute gain in lower. This, again, is due to the lower values that are more sensitive to small variations.

\subsection{FURTHER EXPERIMENTS AND OBSERVATIONS}

In order to confirm the validity of our hypothesis, a series of additional experiments were made. First the encapsulated electrode was removed from the actuator setup. Having only the exposed cathode and the exposed anode in the actuator, no effect has been observed. This eliminates the possibility that the further jet acceleration is due to a coronal discharge between the exposed electrodes. The presence of the encapsulated anode is necessary for the functioning of the tri-electrode system.

Furthermore, the same experiment had been rerun, this time with the presence of the encapsulated electrode, however the latter was not connected to the ground or any other terminal. This "floating" electrode shows a very interesting effect on our actuator. The result is shown in Figure 70. A schematic is shown in Figure 71 for easier comprehension. 


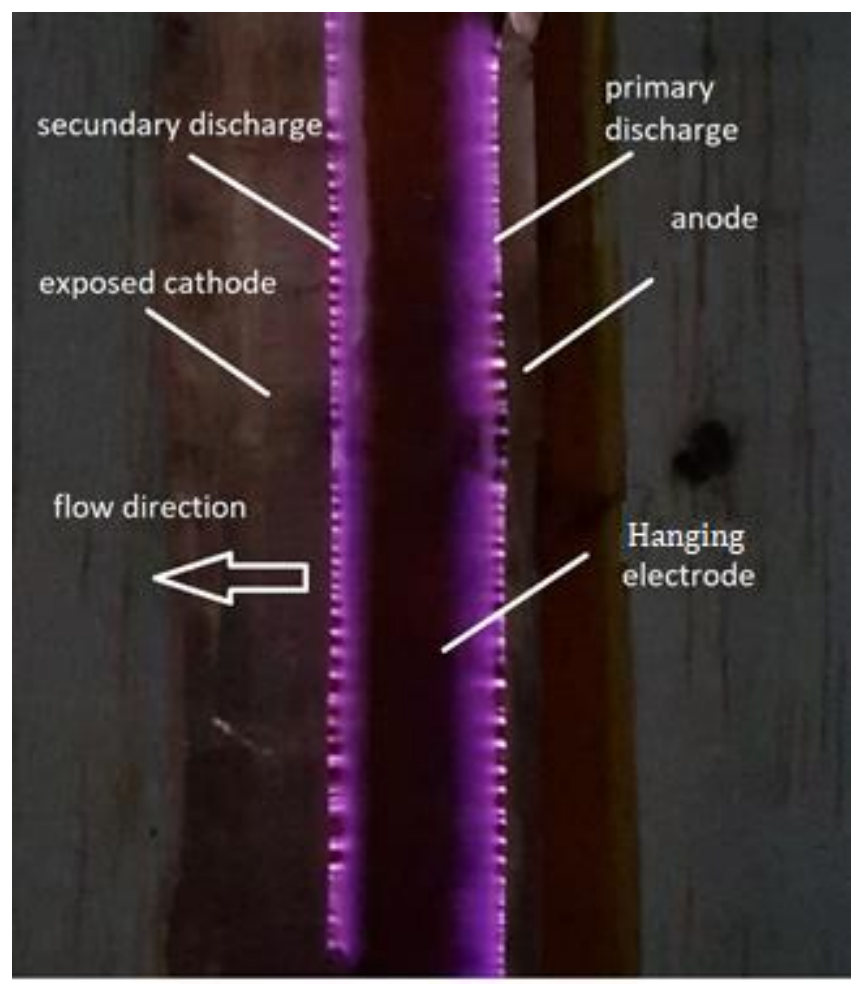

Figure 70 - Double discharge due to "floating" electrode.

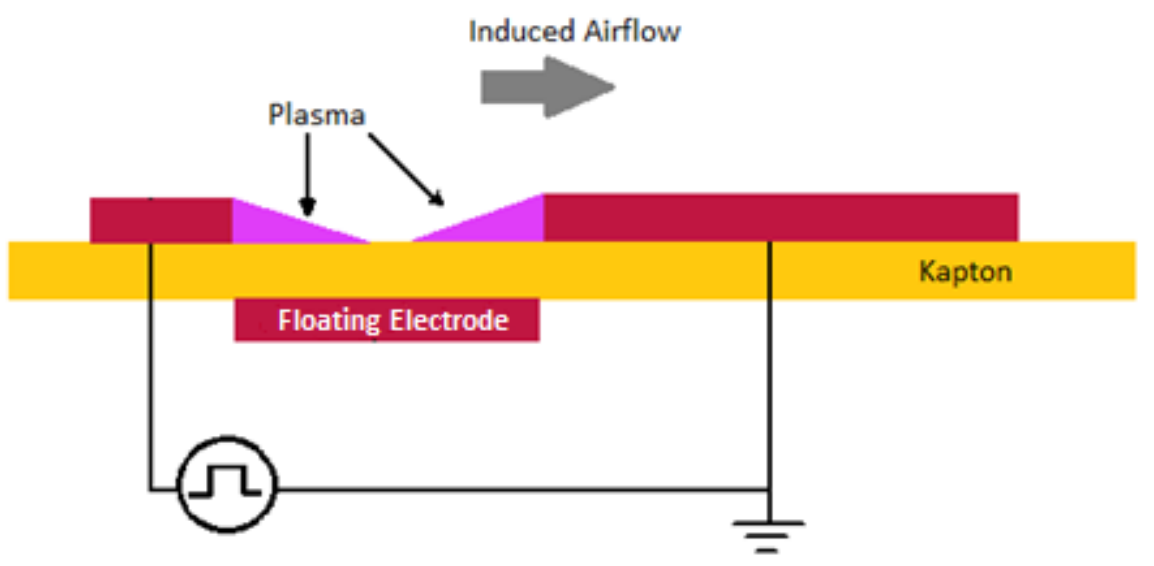

Figure 71 - A schematic of the floating electrode configuration. 
One can clearly see that the mere presence of the floating electrode induced what can be postulated as evidence for charge migration to the exposed anode. This effect was observed only around $12 \mathrm{kHz}$, rapidly decaying at $11 \mathrm{kHz}$ and $13 \mathrm{kHz}$. Also, the second discharge was more prominent with higher voltage values. Surface velocity measurements were made at $\mathrm{x}=10 \mathrm{~mm}$, right at the edge of the exposed cathode for different frequencies. Figure 72 shows the surface velocity and input power in relation to the frequency.

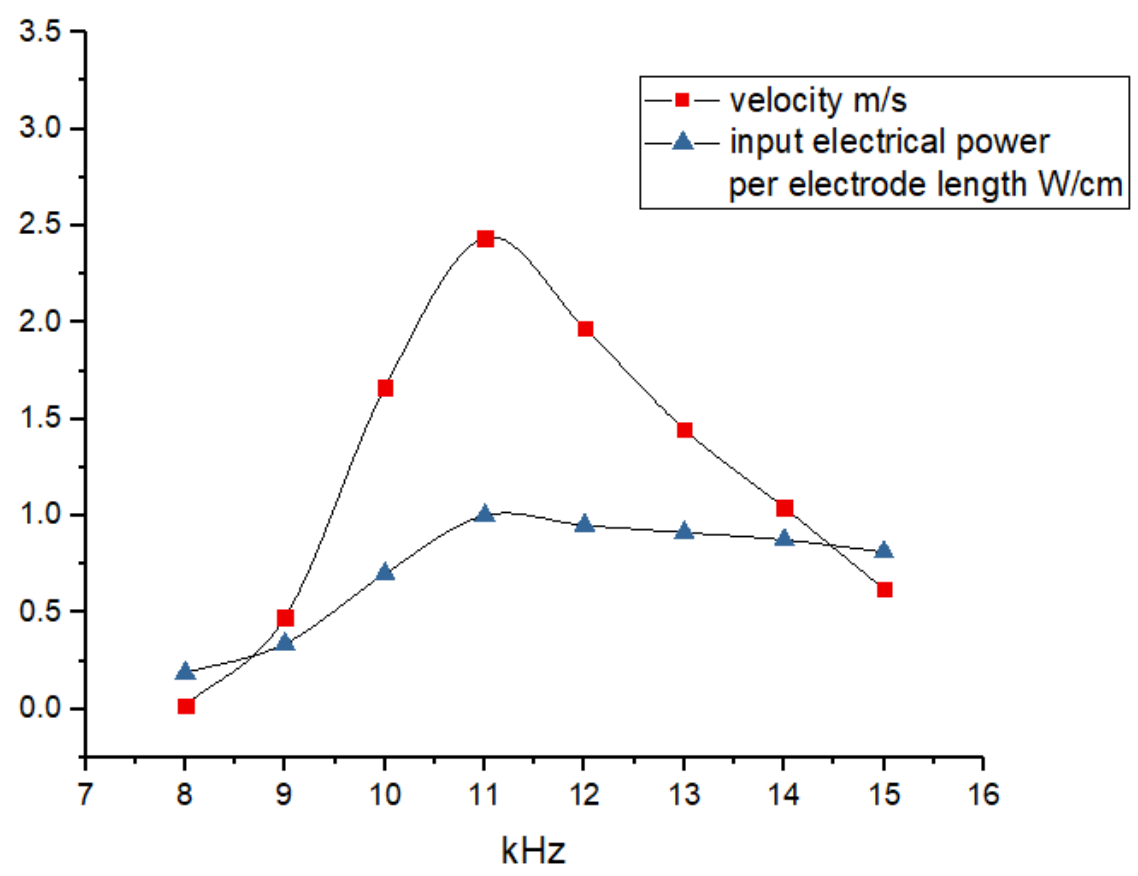

Figure 72 - Surface velocity at different frequencies of the floating electrode configuration. 
We can see a peak velocity at $11 \mathrm{kHz}$. This is not surprising as it is the frequency at which the discharge is most dense on both sides of the actuator. It also shows the highest power consumption. We proceeded to obtain the vertical velocity profile at $\mathrm{x}=10 \mathrm{~mm}$ and at $11 \mathrm{kHz}$. The result is in Figure 73.

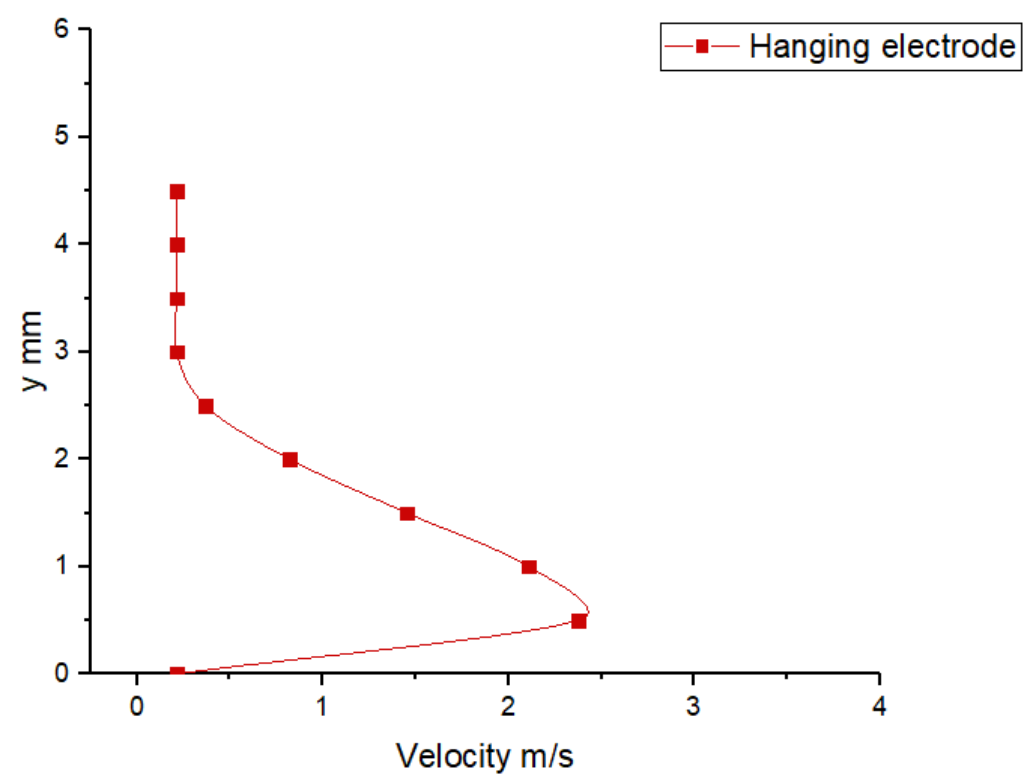

Figure 73 - Velocity profile for floating electrode at $\mathrm{x}=10 \mathrm{~mm}$ and frequency of $11 \mathrm{kHz}$. 


\section{7 concussoor}

This thesis studied some of the effects that a newly proposed configuration of the Dielectric barrier discharge plasma actuator has on airflow velocity. This configuration addresses one of the problems of the DBD actuator that is the backward stroke force present in the second half cycle.

We have started from describing the mechanism of DBD discharge. We referred to the memory charge accumulation model. Two different theories for force actuation in DBD configuration were described, both showing a backward force. The hypothesis that a charge grabbing third electrode would help in redirecting the backward force during the second half cycle by redirecting the memory charges further downstream was elaborated. The charges accumulate on the dielectric surface in the first half cycle. Instead of these charges going back to the exposed electrode and thus introducing a backward force, they are seen to be pushed forward, further down the flow direction, to the third electrode.

To measure the effectivity of such a configuration, some instruments necessary for the experimental procedure were constructed. We first designed and constructed a high voltage circuit capable of delivering thousands of volts to the plasma actuator, necessary for ionizing and plasma creation. Afterwards, the we listed the pressure sensor ratings adequate for our purpose and demonstrated the construction of an electromechanical positioner for the pitot probe through which the measurements are taken. This sensor is then calibrated.

The measurements were taken at 3 different distances from the exposed electrodes. The $\mathrm{x}$-velocity profile along the vertical line was calculated from the pressure measurements for both the traditional 2-electrode configuration and our proposed 3-electrode configuration. 
The surface velocity was also calculated for different signal frequencies. It was found that the actuator delivered highest jet velocities at $8 \mathrm{kHz}$.

The effect of the presence of this third electrode was successfully observed as a larger pressure gradient and thus a greater flow velocity. As this was achieved without an additional energy source input, it was shown that the configuration under study delivered an efficiency of $0.0549 \%$ which was a $26.6 \%$ increase from that of the traditional 2-electrode DBD.

During the investigation process, a new DBD phenomenon was encountered where an exposed anode and cathode were separated by an encapsulated "floating" electrode. This setup induced a double plasma discharge at both electrode edges and was only visible at small range of peak frequencies $(10-13 \mathrm{kHz})$. The flow velocity in such a configuration was characterized along the vertical direction and appeared to have a slightly lower velocity but a thinner profile.

There are several aspects of the system that can be studied further for a better performance. One of them is the width of the third electrode and its effect on the jet acceleration. Another is the relative positioning of the third electrode with respect to the cathode and anode. Another study can possibly investigate the effect of a negative DC voltage at the third electrode, thus favoring the migration of the accumulated charges downstream. It is important to visualize the flow under the effect of the third electrode. It is expected to be less turbulent than with the 2 electrode actuator as there is less backward force induced in the second voltage half cycle. 


\section{Appendix A Statistical Data Analysis}

Given a sample of $\mathrm{n}$ observations, the sample average is calculated as:

$$
\bar{x}=\frac{\sum x_{i}}{n}
$$

where $x i$ represents the $i^{\text {th }}$ individual observation. The sample average is a statistic that is an estimate of $\eta$, the true mean, or central tendency, of the underlying random variable. The sample variance is

$$
s^{2}=\frac{\sum\left(x_{i}-\bar{x}\right)}{(n-1)}
$$

The sample variance is a statistic that is an estimate of the variance, $\sigma^{2}$, in the underlying random variable. Another useful statistic is the sample standard deviation, s, which is the square root of the sample variance, $\sigma$.

$$
s=\sqrt{\frac{\sum\left(x_{i}-\bar{x}\right)}{(n-1)}}
$$

The quantity n-1 is the number of degrees of freedom associated with the sample standard deviation. It is often the case that we are more interested in the estimate of the mean than in the individual observations. What we really want to know then is what is the variance 
in the average value. That is, how does the variance in $\mathrm{x}$ translate into uncertainty in our ability to estimate the mean? The standard error of the mean is

$$
s_{\bar{x}}=\frac{s}{\sqrt{n}}
$$

which also has n-1 degrees of freedom. Clearly, when the number of observations, $n$, is large, the uncertainty in the estimate of the mean is small. This relationship demonstrates that there is more uncertainty in an individual observation than in the estimated mean. Even if the underlying phenomenon is quite variable and there are significant measurement errors, it is still possible to reduce uncertainty in the estimate of the mean by making many measurements.

Most statistical techniques require an assumption that the measurement errors have a normal probability distribution. The normal distribution is also frequently called the Gaussian distribution. A plot of a probability distribution function (PDF) for a normally distributed random variable $\mathrm{x}$ with mean of zero and standard deviation of unity is shown in Figure 74:

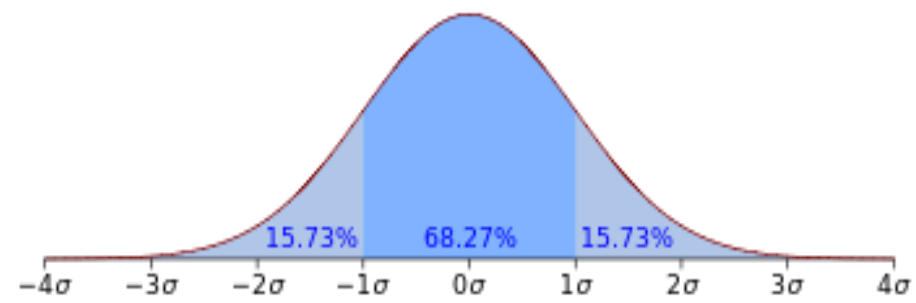

Figure 74 - probability density function of a normal distribution $\mathrm{N}(0, \sigma 2)$. 
For a given value of $\mathrm{x}$, the value on the $\mathrm{y}$ axis is $\mathrm{f}(\mathrm{x})$, the probability density. The normal PDF is symmetric, centered at the mean of $x$, and it extends from negative infinity to positive infinity. By definition, the area under any probability distribution function equals unity. For a normal probability distribution, $68 \%$ of the area under the curve lies within $\eta \pm \sigma$, meaning that $68 \%$ of the total probability is within one standard deviation of the mean. Practically speaking, one would expect that roughly $2 / 3$ of one's observations would fall within this range. Roughly, 95\% lie within $\eta \pm 2 \sigma$.

For any estimated statistic, such as a sample average, for which we have an estimated value and an estimate of the standard error in that statistic, we can report confidence intervals. If the errors in the measurement variable, $x$, have a normal probability distribution and if the observations are independent, then the probability distribution for the error in the sample average, normalized by the standard error in the sample average, is the t-distribution. The t-distribution is a symmetric probability distribution centered at zero, like the normal probability distribution. The difference is that the t-distribution has a variance that depends on the degrees of freedom of the standard error in the statistic of interest. Recall that x $\mathrm{s}$ has n-1 degrees of freedom. If very few measurements have been taken, the number of degrees of freedom is very small and the t-distribution has a very large variance. The t-distribution is used to determine a t-statistic which is then used to calculate a confidence interval for the true value of the mean, $\eta$.

We get a random variable by standardizing the standard error:

$$
Z=\frac{\bar{x}-\mu}{s / \sqrt{n}}
$$


dependent on the parameter $\mu$, the true standard deviation, to be estimated, but with a standard normal distribution independent of the parameter $\mu$. Hence it is possible to find numbers $-z$ and $z$, independent of $\mu$, between which $Z$ lies with probability $1-\alpha$, a measure of how confident we want to be.

The t-statistic of interest is that which bounds a chosen level of probability, 1- $\alpha$, for the $\mathrm{t}$-distribution with n-1 degrees of freedom. For example, at a $90 \%$ probability level $1-\alpha=$ 0.90 and $\alpha=0.10$. Tables of values of the t-statistic for various levels of probability and values of degrees of freedom are easily found. The 1- $\alpha$ confidence interval for $\eta$ is

$$
\bar{x} \mp t_{\alpha / 2} \cdot \frac{s}{\sqrt{n}}
$$

The reason the appropriate t-statistic is that which corresponds to the $\alpha / 2$ probability level is because that value represents one side of a symmetric two-sided interval. We say that there is a 1- $\alpha$ probability that the confidence interval contains the true value of $\eta$. Conventionally used probability levels are the 90\% (somewhat confident), 95\% (fairly confident), and 99\% (quite confident) probability levels. 


\section{APPENDix $\boldsymbol{B}$ EXPERIMENTAL DATA AND CALCULATIONS}

\begin{tabular}{ccc}
\hline $\begin{array}{c}\text { Upward Vertical } \\
\text { Displacement in mm }\end{array}$ & $\begin{array}{c}\text { Measured Voltage for 2 } \\
\text { Electrodes }\end{array}$ & $\begin{array}{c}\text { Measured Voltage } \\
\text { for 3 Electrodes }\end{array}$ \\
\hline $\mathbf{0}$ & 2.31953 & 2.34363 \\
\hline $\mathbf{0 . 5}$ & 2.31266 & 2.32497 \\
\hline $\mathbf{1}$ & 2.30587 & 2.31478 \\
\hline $\mathbf{1 . 5}$ & 2.30092 & 2.30926 \\
\hline $\mathbf{2}$ & 2.29473 & 2.3036 \\
\hline $\mathbf{2 . 5}$ & 2.28388 & 2.29204 \\
\hline $\mathbf{3}$ & 2.27137 & 2.28071 \\
\hline $\mathbf{3 . 5}$ & 2.25043 & 2.25176 \\
\hline $\mathbf{4}$ & 2.249 & 2.2491 \\
\hline $\mathbf{4 . 5}$ & 2.2489 & 2.2482 \\
\hline $\mathbf{5}$ & 2.247 & 2.2473 \\
\hline $\mathbf{5 . 5}$ & 2.2465 & 2.2466 \\
\hline $\mathbf{6}$ & 2.2466 & 2.2464 \\
\hline
\end{tabular}

Applying the calibration offset. $V_{\text {off- }} V_{\text {off-calibration }}$

Upward Vertical

Displacement in Mm
Measured Voltage for 2

Electrodes
Measured Voltage

for 3 Electrodes 


\begin{tabular}{lll}
\hline $\mathbf{0}$ & 2.33053 & 2.35463 \\
\hline $\mathbf{0 . 5}$ & 2.32366 & 2.33597 \\
\hline $\mathbf{1}$ & 2.31687 & 2.32578 \\
\hline $\mathbf{1 . 5}$ & 2.31192 & 2.32026 \\
\hline $\mathbf{2}$ & 2.30573 & 2.3146 \\
\hline $\mathbf{2 . 5}$ & 2.29488 & 2.30304 \\
\hline $\mathbf{3}$ & 2.28237 & 2.29171 \\
\hline $\mathbf{3 . 5}$ & 2.26143 & 2.26276 \\
\hline $\mathbf{4}$ & 2.26 & 2.2601 \\
\hline $\mathbf{4 . 5}$ & 2.2599 & 2.2592 \\
\hline $\mathbf{5}$ & 2.258 & 2.2583 \\
\hline $\mathbf{5 . 5}$ & 2.2575 & 2.2576 \\
\hline $\mathbf{6}$ & 2.2576 & 2.2574 \\
\hline
\end{tabular}

Calculating the pressure from the calibration curve: $\mathrm{y}=48.894 \mathrm{x}-110.34$

\begin{tabular}{ccc}
\hline $\begin{array}{c}\text { Upward Vertical } \\
\text { Displacement in Mm }\end{array}$ & $\begin{array}{c}\text { Calculated dynamic } \\
\text { Pressure for 2 Electrodes }\end{array}$ & $\begin{array}{c}\text { Calculated Dynamic } \\
\text { Pressure for } \mathbf{3} \\
\text { Electrodes }\end{array}$ \\
\hline $\mathbf{0}$ & 3.60881 & 4.78721 \\
\hline $\mathbf{0 . 5}$ & 3.27279 & 3.87496 \\
\hline $\mathbf{1}$ & 2.94096 & 3.37658 \\
\hline $\mathbf{1 . 5}$ & 2.69905 & 3.10667 \\
\hline $\mathbf{2}$ & 2.39628 & 2.83027 \\
\hline
\end{tabular}




\begin{tabular}{lll}
\hline $\mathbf{2 . 5}$ & 1.8658 & 2.26484 \\
\hline $\mathbf{3}$ & 1.25415 & 1.71093 \\
\hline $\mathbf{3 . 5}$ & 0.23028 & 0.29546 \\
\hline $\mathbf{4}$ & 0.16044 & 0.16533 \\
\hline $\mathbf{4 . 5}$ & 0.15555 & 0.12132 \\
\hline $\mathbf{5}$ & 0.06265 & 0.07732 \\
\hline $\mathbf{5 . 5}$ & 0.03821 & 0.04309 \\
\hline $\mathbf{6}$ & 0.04309 & 0.03332
\end{tabular}

Velocity is then calculated from the following relation:

$$
p=\frac{1}{2} \rho u^{2}
$$

\begin{tabular}{ccc}
\hline $\begin{array}{c}\text { Upward Vertical } \\
\text { Displacement in Mm }\end{array}$ & $\begin{array}{c}\text { Calculated dynamic } \\
\text { Pressure for 2 Electrodes }\end{array}$ & $\begin{array}{c}\text { Calculated Dynamic } \\
\text { Pressure for 3 } \\
\text { Electrodes }\end{array}$ \\
\hline $\mathbf{0}$ & 2.57326 & 2.96376 \\
$\mathbf{0 . 5}$ & 2.45054 & 2.66646 \\
$\mathbf{1}$ & 2.32299 & 2.48909 \\
\hline $\mathbf{1 . 5}$ & 2.22539 & 2.38753 \\
\hline $\mathbf{2}$ & 2.09686 & 2.27885 \\
\hline $\mathbf{2 . 5}$ & 1.85026 & 2.03855 \\
\hline $\mathbf{3}$ & 1.51697 & 1.77181 \\
\hline $\mathbf{3 . 5}$ & 0.65002 & 0.7363 \\
\hline $\mathbf{4}$ & 0.54257 & 0.55078 \\
\hline $\mathbf{4 . 5}$ & 0.53424 & 0.47182 \\
\hline
\end{tabular}




\begin{tabular}{ccc}
\hline $\mathbf{5}$ & 0.33905 & 0.37666 \\
\hline $\mathbf{5 . 5}$ & 0.26477 & 0.2812 \\
\hline $\mathbf{6}$ & 0.2812 & 0.24724 \\
\hline
\end{tabular}

Pressure sensor Calibration Data

\begin{tabular}{ccccccc}
\hline $\begin{array}{c}\text { wind } \\
\text { Tunnel } \\
\text { rpm }\end{array}$ & $\begin{array}{c}\text { manomete } \\
\text { r Pressure } \\
\text { Pa }\end{array}$ & $\begin{array}{c}\text { sensor } \\
\text { Voltage } \\
\text { V }\end{array}$ & $\begin{array}{c}\text { Standard } \\
\text { Deviatio } \\
\text { n }\end{array}$ & $\begin{array}{c}\text { Wind speed } \\
\text { m/s }\end{array}$ & \% error & 士error \\
\hline $\mathbf{0}$ & 0.3 & 2.264 & 0.002 & 0.707106781 & 0.0883392 & 0.001 \\
\hline $\mathbf{1 0 0}$ & 1.2 & 2.2902 & 0.0027 & 1.414213562 & 0.1178936 & 0.00135 \\
\hline $\mathbf{1 5 0}$ & 3.1 & 2.3276 & 0.0027 & 2.273030283 & 0.1159993 & 0.00135 \\
\hline $\mathbf{2 0 0}$ & 5.8 & 2.3728 & 0.0027 & 3.109126351 & 0.1137896 & 0.00135 \\
\hline $\mathbf{2 5 0}$ & 9.8 & 2.4582 & 0.003 & 4.041451884 & 0.1220405 & 0.0015 \\
\hline $\mathbf{3 0 0}$ & 14.6 & 2.5492 & 0.003 & 4.932882862 & 0.117684 & 0.0015 \\
\hline $\mathbf{3 5 0}$ & 21 & 2.6783 & 0.003 & 5.916079783 & 0.1120114 & 0.0015 \\
\hline $\mathbf{4 0 0}$ & 28.3 & 2.8361 & 0.003 & 6.867799259 & 0.1057791 & 0.0015 \\
\hline $\mathbf{4 5 0}$ & 36.3 & 3.0061 & 0.0037 & 7.778174593 & 0.1230831 & 0.00185 \\
\hline $\mathbf{5 0 0}$ & 45.5 & 3.1876 & 0.005 & 8.708233652 & 0.1568578 & 0.0025 \\
\hline $\mathbf{5 5 0}$ & 56.5 & 3.405 & 0.005 & 9.703951085 & 0.1468429 & 0.0025 \\
\hline $\mathbf{6 0 0}$ & 69.6 & 3.6571 & 0.006 & 10.77032961 & 0.1640644 & 0.003 \\
\hline $\mathbf{6 5 0}$ & 83.5 & 3.9767 & 0.007 & 11.79689225 & 0.1760253 & 0.0035 \\
\hline
\end{tabular}




\section{appendix C Windspeed Calculation - Matlab Code}

function [windSpeed] $=$ findWindSpeed(voltageMeasurement)

$\%$ Add density model using humidity, ambTemperature, ambPressure

density = 1.225;

load('differentialSensorCurveFitData.mat');

dynPressFitResult

dynPressGoodnessOfFit

dynamicPressureInterpolated $=$ dynPressFitResult(voltageMeasurement);

sgn = dynamicPressureInterpolated/abs(dynamicPressureInterpolated);

windSpeed $=\operatorname{sgn}^{*}\left(2^{*} \operatorname{abs}(\text { dynamicPressureInterpolated }) / \text { density }\right)^{\wedge} 0.5$;

display(['For a measurement of ', num2str(voltageMeasurement), ...

'V the dynamic pressure is ', num2str(dynamicPressureInterpolated),...

'Pa and the wind speed is ', num2str(windSpeed), 'm/s.']) end 


\section{Appendix $\boldsymbol{D}$ Pressure transducer Acquisition- Matlab Code}

\% Pressure Transducer Acquisition Code

\% Uses cDAQ9174 and NI9105 module board for data acquisition

devices = daq.getDevices;

devices(1);

$\mathrm{s}=$ daq.createSession('ni');

channels $=[0,1,2,3,5,8,9,10,11,13]$

for $\mathrm{i}=1$ :length(channels)

s.addAnalogInputChannel('cDAQ9184-18968CFMod1', channels(i), 'Voltage');

s.Channels(i).TerminalConfig = 'SingleEnded';

s.Channels(i).Range $=[-5,5]$;

end

$\% \mathrm{~s}$;

s. Rate = 10000;

s.DurationInSeconds = 10;

[data,time $]=$ s.startForeground; 


\section{Appendix $\boldsymbol{E}$ Electromechanical Positioner-ARduino Code}

// Stepper motor control using pullup buttons

\#include <Stepper.h>

const int stepsPerRevolution $=20$;

//Standard value

const int maxStepsX $=400$;

$/ /$ const int maxStepsY $=250$;

//Max 400 steps for new dvd stepper motor

const int numberOfPositons $=40$;

//Max 250 steps for dvd/cd stepper motors

const int stepX = maxStepsX / numberOfPositons; //Step size

$/ /$ const int stepY $=$ maxStepsX $/$ numberOfPositons; //Step size

const int standardSpeed $=1500$;

//Ideal speed is greater than 1000

int stepsCountX;

//Counter for stepper motors position

// int stepsCountY;

//Counter for stepper motors position

//Create two stepper motor objects

Stepper myStepperX(stepsPerRevolution, 6, 7, 8, 9);

// Stepper myStepperY(stepsPerRevolution, 2, 3, 4, 5);

//Define control button pins

const byte button1Pin = 11; // Pushbutton 1 pin for stepping

const byte button2Pin $=12$; $/ /$ Pushbutton 2 pin for stepping back

const byte button3Pin $=10 ; / /$ Pushbutton 3 pin for home position

void setup() \{

//Default (starting position) at home position

stepsCount $\mathrm{X}=0$;

// stepsCount $Y=0$;

//Set speed of the stepper motors: 
myStepperX.setSpeed(standardSpeed);

// myStepperY.setSpeed(standardSpeed);

//Pullup the pins

pinMode(button1Pin, INPUT_PULLUP);

pinMode(button2Pin, INPUT_PULLUP);

pinMode(button3Pin, INPUT_PULLUP);

Serial.begin(9600);

\}

void loop() \{

// put your main code here, to run repeatedly:

int buttonStepForwardState, buttonStepBackwardState, buttonStepHomeState;

buttonStepForwardState = digitalRead(button1Pin);

buttonStepBackwardState $=$ digitalRead(button2Pin);

buttonStepHomeState = digitalRead(button3Pin);

if (buttonStepForwardState $==$ LOW) \{

if ((stepsCountX + stepX) <= maxStepsX) \{

Serial.println("Button 1");

myStepperX.step(stepX);

stepsCountX = stepsCountX + stepX;

Serial.println(stepsCountX);

\}

\}

if (buttonStepBackwardState $==$ LOW) \{

if ((stepsCountX - stepX) >= 0) \{

Serial.println("Button 2");

myStepperX.step(-stepX);

stepsCountX = stepsCountX - stepX;

Serial.println(stepsCountX);

\}

\} 
if (buttonStepHomeState $==$ LOW) \{

Serial.println("Button 3");

Serial.println(stepsCountX);

myStepperX.step(-stepsCountX);

stepsCountX = 0;

Serial.println(stepsCountX);

\}

delay(200); //This delay must be adjusted in order to make the system as renponsive as you desire

//You might want to change this "if clauses" for "interrupts", but it will work anyway

\} 


\section{REFERENCES}

[1] Liepmann, H. W. and Nosenchuck, D. M. (1982). Active control of laminarturbulent transition. Journal of FluidMechanics, 118:201-204.

[2] Lin, J. (2002). Review of research on low-profile vortex generators to control boundary-layer separation. Progress in Aerospace Sciences, 38(4-5):389-420.

[3] Greenblatt,D. andWygnanski, I. J. (2000). The control of flow separation by periodic excitation. Progress in Aerospace Sciences, 36(7):487 - 545.

[4] Wang, J., Li, Y., and Choi, K. (2008). Gurney flap-lift enhancement, mechanisms and applications. Progress in Aerospace Sciences, 44(1):22-47.

[5] Oerlemans, S., Fisher, M., Maeder, T., and K ö gler, K. (2009). Reduction of wind turbine noise using optimized airfoils and trailing-eratdge serions. AIAA Journal, 47(6):1470-1481.

[6] Rothstein, J. (2010). Slip on superhydrophobic surfaces. Annual Review of Fluid Mechanics, 42:89-109.

[7] Gad-el Hak, M. (2000). Flow Control: Passive, Active, and Reactive Flow Management. Cambridge University Press.

[8] Fujii, K. (2014). High-performance computing-based exploration of flow control withmicro devices. Philosophical Transactions of the Royal Society of London A:Mathematical, Physical and Engineering Sciences, 372(2022):20130326.

[9] Droubi, A. El; Izola, D. T. Effect of dielectric barrier discharge on the airflow around a cylinder. Journal of Aeronautical Technologies and Management. 2012

[10] S. EL-KHABIRY AND G. M. COLVER. Drag reduction by dc corona discharge along an electrically conductive flat plate for small Reynolds number flow. Physics of Fluids 9, 587 (1997); https://doi.org/10.1063/1.869219

[11] J.R. ROTH, D.M. SHERMAN, S.P. WILKINSON Electrohydrodynamic flow control with a glow-discharge surface plasma AIAA J., 38 (7) (2000), pp. 1166-1172

[12] HOSKINSON, A.R; HERSHKOWITZ, N. Flow Measurements and Plasma Simulations of Double and Single Barrier DBD Plasma Actuators in Quiescent Air. In 46th AIAA Aerospace Sciences Meeting and Exhibit, page 1370, Reno, NV, 2008.

[13] SANTHANAKRISHNAN; JACOB, J.D. Flow Control Using Plasma Actuators and linear/Annular Plasma Synthetic Jet Actuators. In 3rd AIAA Flow Control Conference, page 3033, San Francisco, CA, 2006.

[14] SAMIMY, M. et al. Active control of high speed jets using localized arc filament plasma actuators. 2nd AIAA Flow Control Conf. Portland, OR: AIAA. 2004. 
[15]C.L. Enloe, T.E. Mclaughlin, R.D. Vandyken, K.D. Kachner, E.J. Jumper, T.C. Corke, M. Post, O.Haddad Mechanisms and responses of a single dielectric barrier plasma actuator: geometric effects AIAA J., 42 (3) (2004), pp. 595-604

[16] PORTER, C. O. et al. Temporal force measurements on an aerodynamic plasma actuator. 44th AIAA Aerospace Sciences Meeting and Exhibit. Reno, NV: AIAA. 2006.

[17] VANDYKEN, R. D.; MCLAUGHLIN, T. E.; ENLOE, C. L. Parametric investigations of a single dielectric barrier plasma actuator. 42nd AIAA Aerospace Sciences Meeting and Exhibit. Reno, NV: AIAA. 2004.

[18] OPAITS, D. F; ROUPASSOV, D.V; STARIKOVSKAIA, S.M; STARIKOVSKII, A.Y; ZAVIALOV, I.N; SADDOUGHI, S. Plasma Control of Boundary Layer Using Low- Temperature Nonequilibrium Plasma of Gas Discharge. In 43rd AIAA Aerospace Sciences Meeting and Exhibit, 2005.

[19] ENLOE, C. L. et al. Plasma structure in the aerodynamic plasma actuator. 42nd AIAA Aerospace Sciences Meeting and Exhibit. Reno, NV: AIAA. 2004.

[20] ANDERSON, R.; ROY, S. Preliminary experiments of barrier discharge plasma actuators using dry and humid air. 44th AIAA Aerospace Sciences Meeting and Exhibit. Reno, NV: AIAA. 2006.

[21] BENARD, N; BALCON, N; MOREAU, E. Electric Wind Produced by a Surface Dielectric Barrier Discharge Operating Over a Wide Range of Relative Humidity. In 47th AIAA Aerospace Sciences Meeting, page 488, Orlando, FL, 2009.

[22] FRIDMAN, A; CHIROKOV, A; GUTSOL, A. Non-thermal atmospheric pressure discharges. Journal of Physics D: Applied Physics, 38(2):R1\{R24, January 2005.

[23] ERFANI, R; ERFANI, T; HALE, C; KONTIS, K; UTYUZHNIKOV, S.V. Optimization of Induced Velocity for Plasma Actuator with Multiple Encapsulated Electrodes using Response Surface Methodology. 49th AIAA Aerospace Sciences Meeting including the New Horizons Forum and Aerospace Exposition. 4 - 7 January 2011, Orlando, Florida.

[24] MARK RIHERD AND SUBRATA ROY. Serpentine geometry plasma actuators for flow control J. Appl. Phys. 114, 083303 (2013); doi: 10.1063/1.4818622

[25] FONT, G. I. Boundary layer control with atmospheric plasma discharges. 40th AIAA/ASME/SAE/ASEE Joint Propulsion Conf. and Exhibit. Fort Lauderdale, FL: AIAA. 2004.

[26] FONT, G. I.; MORGAN, W. L. Plasma discharges in atmospheric pressure oxygen for boundary layer separation control. 35th Fluid Dynamics Conf. and Exhibit. Toronto, Ontario: AIAA. 2005.

[27] TATHIRI, G; ESMAEILZADEH, E; MIRSAJEDI, S. M. MAHDAVI MOGHADDAM, H. Experimental Investigation of "Why an AC Dielectric Barrier Discharge Plasma 
Actuator is Preferred to DC Corona Wind Actuator in Boundary Layer Flow Control? Journal of Applied Fluid Mechanics, Vol. 7, No. 3, pp. 525-534, 2014.

[28] CORKE, T. C.; HE, C.; PATEL, M. P. Plasma flaps and slats: An application of weakly ionized plasma actuators. 2nd AIAA Flow Control Conf. Portland, OR: AIAA. 2004. p. 2127.

[29]CORKE, T. C. et al. Application of weakly-ionized plasmas as wing flow-control devices. 40th AIAA Aerospace Sciences Meeting and Exhibit. Reno, NV: AIAA. 2002.

[30]CORKE, T. C.; MERTZ, B.; PATEL, M. P. Plasma flow control optimized airfoil. 44th AIAA Aerospace Sciences Meeting and Exhibit. Reno, NV: AIAA. 2006.

[31]CORKE, L.; POST, M. Overview of plasma flow control: concepts, optimization, and applications. 43rd AIAA Aerospace Sciences Meeting and Exhibit. Reno, NV: AIAA. 2005.

[32] A. SANTHANAKRISHNAN, J.D. JACOB Flow control with plasma synthetic jet actuators J. Phys.-Lond.-D: Appl. Phys., 40 (3) (2007), p. 637

[33] MOREAU E. et al. Airflow control by non-thermal plasma actuators J. Phys. D: Appl. Phys., 40 (2007), pp. 605-636

[34] M. FORTE, J. JOLIBOIS, J. PONS, E. MOREAU, G. TOUCHARD, M. CAZALENS. Optimization of a dielectric barrier discharge actuator by stationary and non-stationary measurements of the induced flow velocity: application to airflow control. J. Exp. Fluids, 43 (6) (2007), pp. 917-928

[35] J.R. ROTH, Aerodynamic flow acceleration using paraelectric and peristaltic electrohydrodynamic effects of a One Atmosphere Uniform Glow Discharge Plasma. Physics of Plasmas 10, 2117 (2003); https://doi.org/10.1063/1.1564823

[36] M.L. Post, T.C. Corke. Separation control on high angle of attack airfoil using plasma actuators. AIAA J., 42 (11) (2004), pp. 2177-2184

[37] Ist Lisbon database, www.lxcat.net, retrieved on December 8, 2017.

[38] HAGELAAR, G.J.M; PITCHFORD, L.C. Solving the Boltzmann equation to obtain electron transport coefficients and rate coefficients for fluid models. Plasma Sci Sources and Tech 14, 722 (2005).

[39] RIVIR, R. et al. Turbine Flow Control, Plasma Flows. 41st AIAA Aerospace Sciences Meeting and Exhibit. Reno, Nevada, USA: AIAA. 2003.

[40] HULTGREN, L.; ASHPIS, D. Demonstration of separation delay with glow-discharge plasma actuators. 41st AIAA Aerospace Sciences Meeting and Exhibit. Reno, NV: AIAA. 2003.

[41] THOMAS, F. O.; KOZLOV, A.; CORKE, T. C. Plasma actuators for landing gear noise reduction. 11th AIAA/CEAS Aeroacoustics Conf. Monterey, CA: AIAA. 2005. 
[42] GOKSEL, B. et al. Steady and unsteady plasma wall jets for separation and circulation control. 3rd AIAA Flow Control Conf. San Francisco, CA: AIAA. 2006.

[43] BALCER, B. E.; FRANKE, M. E.; RIVIR, R. B. Effects of plasma induced velocity on boundary layer flow. 44th AIAA Aerospace Sciences Meeting and Exhibit. Reno, NV: AIAA. 2006.

[44] ROTH, J. R.; SHERMAN, D. M.; WILKINSON, S. P. AIAA J. 38. [S.I.]: [s.n.]. 2000.

[45] Gad-el Hak,M. (2001). Flow control: The future. Journal of Aircraft, 38(3):402-418.

[46] Moreau, D., Brooks, L., and Doolan, C. (2011). Empirical study of the tonal noise radiated by a sharp-edged flat plate at low-to-moderate reynolds number. pages 379-385.

[48] FRANCIS F. CHEN. Introduction to Plasma Physics and Controlled Fusion. $2^{\text {nd }}$ edition.

[49] GOLDSTON R. J.; RUTHERFORD P. H. Introduction to plasma Physics. $1^{\text {st }}$ edition. 1995.

[50] COBINE, J.D. Gaseous Conductors. New York: Dover, 1958.

[51] FRIDMAN A. Plasma Chemistry (Cambridge: Cambridge University Press 2008)

[52] MOREAU E. et al. Airflow control by non-thermal plasma actuators J. Phys. D: Appl. Phys., 40 (2007), pp. 605-636

[53] R. Erfani, H. Zare-Behtash, K. Kontis Plasma actuator: influence of dielectric surface temperature. J. Exp. Therm. Fluid Sci., 42 (2012), pp. 258-264

[54] HERZBERG, G. Atomic Spectra and Atomic Structure. New York: Dover, 1944.

[55] LIEBERMAN, M. A.; LICHTENBERG, A. J. (2005). Principles of plasma discharges and aterials processing (2nd ed.). Hoboken, N.J.: Wiley-Interscience. 546.

[56] MILLMAN, J; SEELY, S. Electronics. Chapters 9, 10 and 11. New York: McGraw-Hill, 1951.

[57] STARIKOVSKII, A.YU; NIKIPELOV, A.A; NUDNOVA, M.M; ROUPASSOV, D.V. SDBD plasma actuator with nanosecond pulse-periodic discharge. Plasma Sources Science and Technology, 18(3):034015, August 2009.

[58] BAUGHN, J. W. et al. Momentum transfer for an aerodynamic plasma actuator with an imposed boundary layer. 44th AIAA Aerospace Sciences Meeting and Exhibit. Reno, NV: AIAA. 2006.

[59] Orlov, D., T. Corke, and M. Patel. Electric Circuit Model for Aerodynamic Plasma Actuator. AIAA Paper 2006-1206.

[61] http://www.physics.csbsju.edu retrieved on 14 june, 2017

[62] P. Gulati, U. N. Pal, R. Prakash, M. Kumar, V. Srivastava, and V. Vyas "Spectroscopic Diagnostic of Volume Discharge Arrangement of a DBD Source and Comparison with PIC Simulation," IEEE Trans.Plasma Sci.,vol. 40. pp. 2699-2705, 2012. 